Florida International University FIU Digital Commons

3-28-2018

\title{
HIV Knowledge, Attitudes, and Sexual Risk Behaviors among Women from Trinidad
}

Rosemarie Graczkowski

rgrac004@fiu.edu

DOI: $10.25148 /$ etd.FIDC006578

Follow this and additional works at: https://digitalcommons.fiu.edu/etd

Part of the Immune System Diseases Commons, Medical Education Commons, Nursing Commons, and the Virus Diseases Commons

\section{Recommended Citation}

Graczkowski, Rosemarie, "HIV Knowledge, Attitudes, and Sexual Risk Behaviors among Women from Trinidad" (2018). FIU Electronic Theses and Dissertations. 3689.

https://digitalcommons.fiu.edu/etd/3689 


\title{
FLORIDA INTERNATIONAL UNIVERSITY
}

Miami, Florida

\section{HIV KNOWLEDGE, ATTITUDES, AND SEXUAL RISK BEHAVIORS AMONG WOMEN FROM TRINIDAD}

\author{
A dissertation submitted in partial fulfillment of the \\ requirements for the degree of \\ DOCTOR OF PHILOSOPHY \\ in \\ NURSING \\ by \\ Rosemarie Graczkowski \\ 2018
}




\section{To: Dean Ora Strickland}

Nicole Wertheim College of Nursing and Health Sciences

This dissertation written by Rosemarie Graczkowski, and entitled HIV Knowledge, Attitudes, and Sexual Risk Behaviors among Women from Trinidad, having been approved in respect to style and intellectual content, is referred to you for judgment.

We have read this dissertation and recommend that it be approved.

\begin{tabular}{r}
\hline Eric Fenkl \\
\hline $\begin{array}{r}\text { Amy Paul- } \\
\text { Ward }\end{array}$ \\
\hline Audrey Miller \\
\hline Sandra Gracia Jones, Major \\
Professor
\end{tabular}

Date of Defense: March 28, 2018

This dissertation of Rosemarie Graczkowski is approved.

Dean Ora Strickland
Nicole Wertheim College of Nursing
and Health Sciences

Florida International University, 2018 


\section{DEDICATION}

I dedicate this doctoral dissertation to my husband Dr. Marek Graczkowski. Words cannot express the depth of my gratitude for all the love and support you bestowed upon me throughout my $\mathrm{PhD}$ journey. Thank you for you continuous encouragement even when the burdens and stressors seemed too much to bear. Sometimes I wish I could see

myself through your eyes because you make me feel bright, bold, and brilliant. With you I feel like I could conquer anything. I am truly blessed to have you in my world.

I love you Moj Kochany!!! 


\section{ACKNOWLEDGMENT}

I would like to express my deep appreciation and gratitude to my esteemed Professors at Florida International University (FIU): Dr. Sandra Gracia Jones, who served as my doctoral advisor and committee Chair; Dr. Eric Fenkl, Dr. Amy Paul-Ward, and Dr. Audrey Miller, the members of my committee. My gratitude goes to Dr. Anahid Kulwicki who was instrumental at the beginning of my incredible journey in the Nursing PhD program at FIU. I would also like to thank Dr. Dorothy Brooten and Dr. JoAnne Youngblut for sharing with me their infinite wisdom, knowledge, and experience.

Thanks go to The Jonas Center for Nursing Excellence. As a member of the Jonas Nurse Leader Scholar 2016-2018, I am grateful for the funding which supported my doctoral research.

My gratitude goes to Dr. Taryn Fetscher who guided and mentored me through my statistical data analysis: Thank you for your patience and your expertise.

A special thank you goes to my forever-friend, Mrs. Vediah Phekoo-Ramsaran who took time out of her busy schedule to assist me with my data collection in Trinidad. My gratitude goes to all the Trinidadian women who participated in my research study.

I would like to acknowledge my family and friends. I am thankful for words of encouragement and support. Thank you to my parents, Harrilal Adhin \& Bissoondaye Harrilal. Thank you to my sister Shanti "Doll”" Moore who was with me at one of the most challenging times in my life. Thank you to my brother Bhimsingh Harrilal for staying with me in Trinidad while I collected my data. Thank you to my in-laws from Poland who always believed in me and cheered me on during this journey.

Thank you to the love of my life, my soul-mate, Dr. Marek Graczkowski. 


\title{
ABSTRACT OF THE DISSERTATION
}

\section{HIV KNOWLEDGE, ATTITUDES, AND SEXUAL RISK BEHAVIORS AMONG \\ WOMEN FROM TRINIDAD}

\author{
by
}

Rosemarie Graczkowski

Florida International University, 2018

Miami, Florida

\section{Professor Sandra Gracia Jones, Major Professor}

Currently, the Caribbean has the second highest new cases of HIV infection, only after Sub-Saharan Africa. Women are becoming disproportionally more at risk for HIV/AIDS, mainly through heterosexual contact. The purpose of this dissertation study was to evaluate HIV knowledge, attitudes, and sexual risk behaviors among Trinidadian women. A sample of 113 participants was recruited for this study. The Theory of Planned Behavior (TPB) and Purnell Model of Cultural Competence were used to guide this study. Data were gathered using the HIV Knowledge Questionnaire (HIV-KQ-18), Condom Attitude Scale (CAS), Safe Sex Behavior Questionnaire (SSBQ), and a demographic questionnaire. Data were analyzed using statistical analysis software package (SPSS) version 22. Descriptive and Frequencies, Pearson product-moment correlation coefficient $(r)$, one-way between groups ANOVA, and Multiple Regression analyses were implemented to assess HIV knowledge, attitudes about condom use, religious beliefs, level of education, and substance use among Trinidadian women. The results of this study indicated that level of education and race/ethnic backgrounds were associated with HIV knowledge among Trinidadian women. Religious beliefs had a 
negative correlation with attitudes about condom use. Also, there was a positive correlation between attitudes about condom use and safer sexual behaviors. The empirical knowledge obtained from this study can be used to provide a baseline for healthcare providers and policy makers to develop culturally aware, gender-relevant interventions to decrease the rate of HIV infection among Trinidadian women. 
CHAPTERS

TABLE OF CONTENTS

CHAPTER I....

PAGE

INTRODUCTION

Background

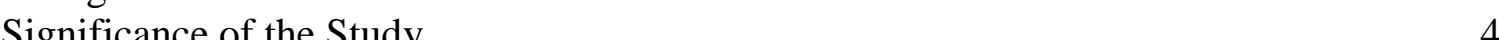

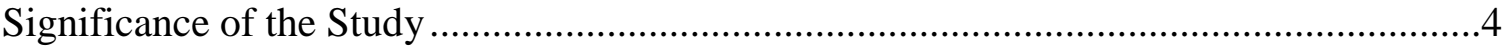

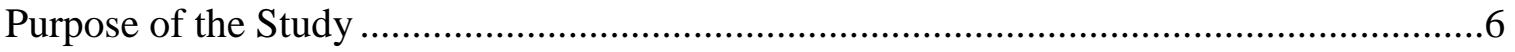

Theoretical Framework: Theory of Planned Behavior ..................................................

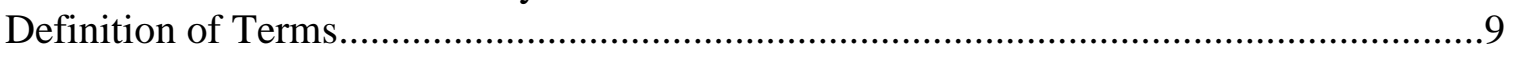

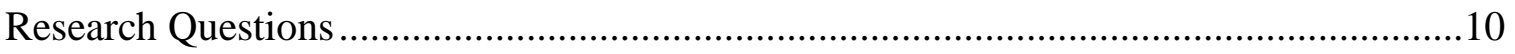

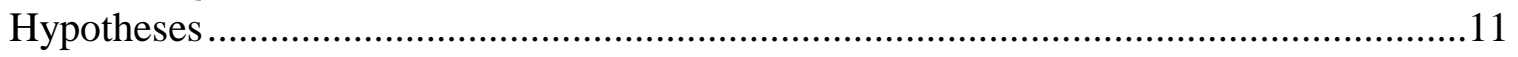

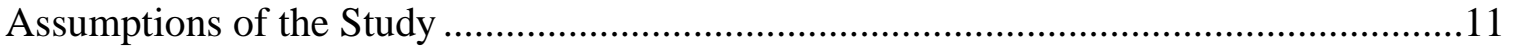

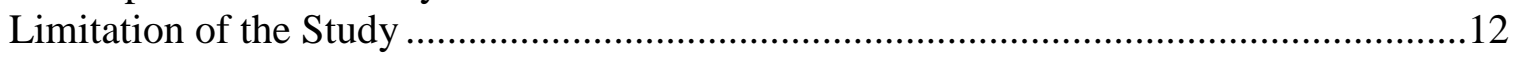

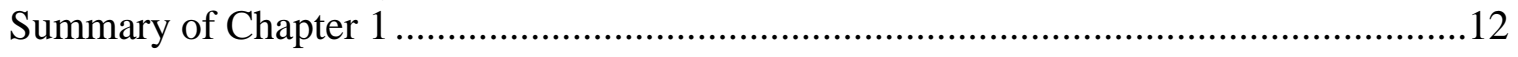

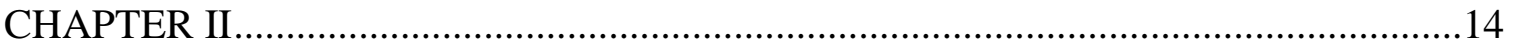

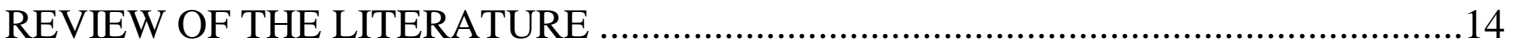

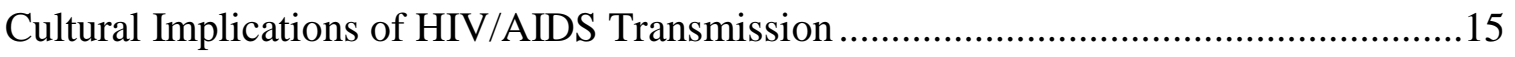

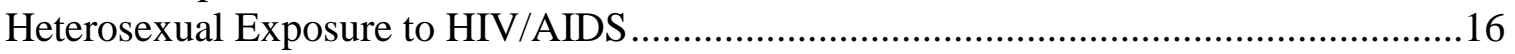

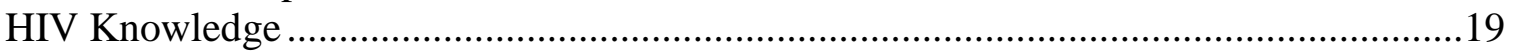

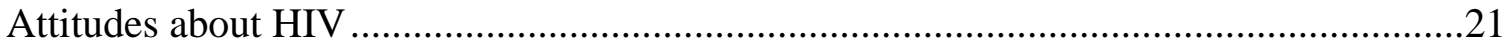

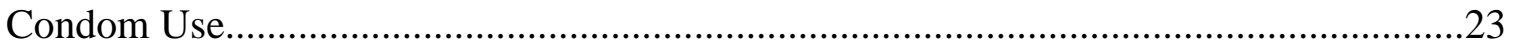

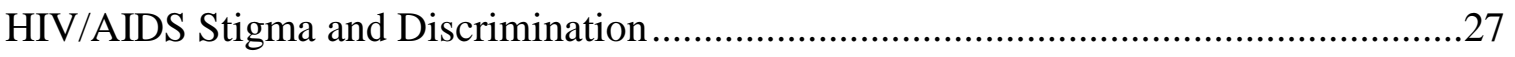

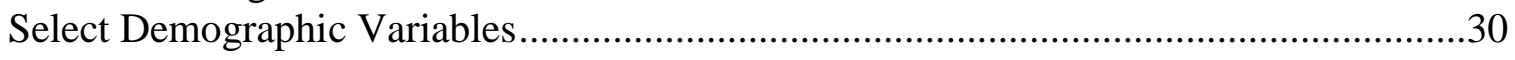

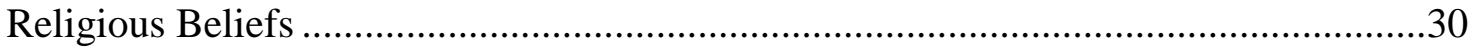

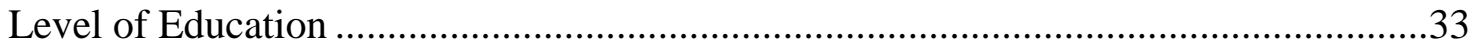

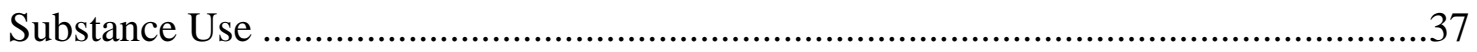

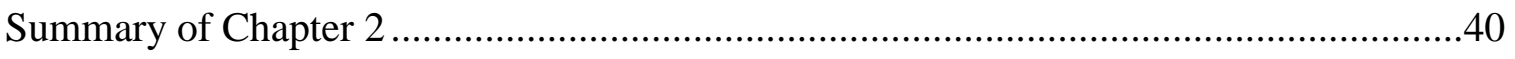

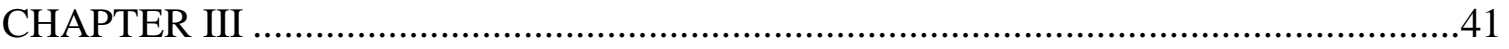

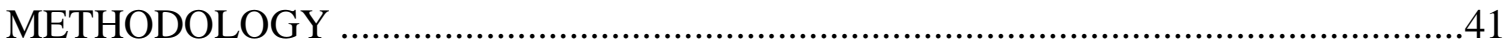

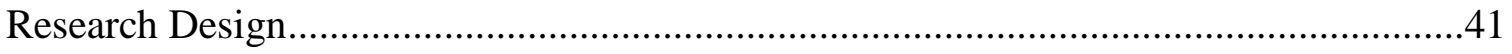

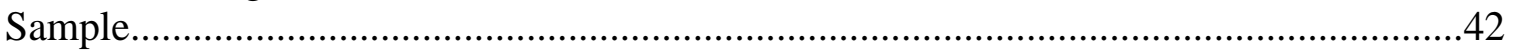

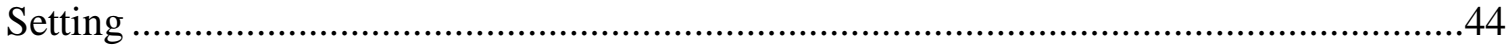

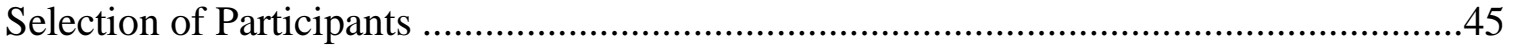

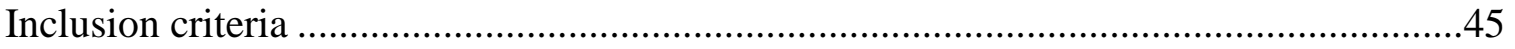

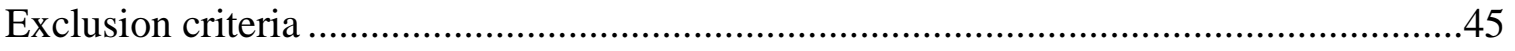

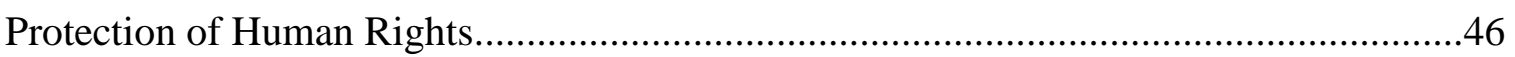

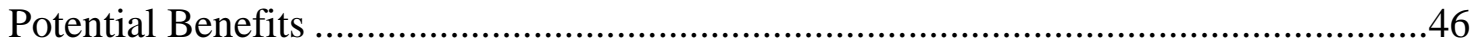

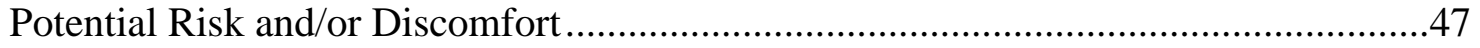

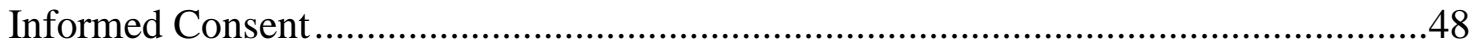

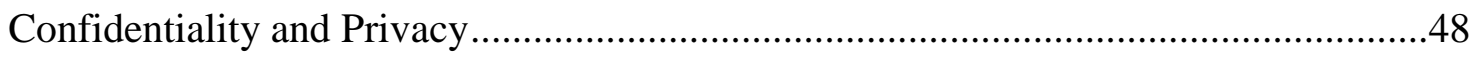

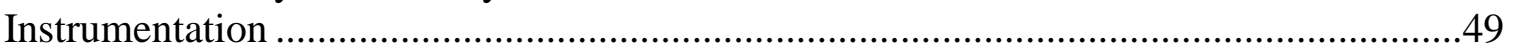

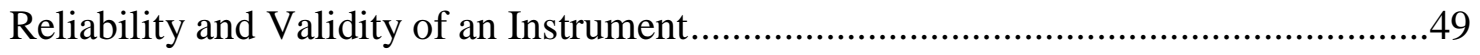

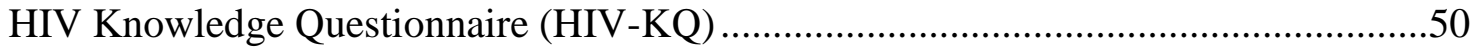

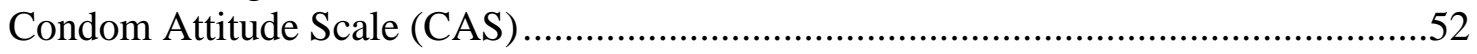


Safe Sex Behavior Questionnaire (SSBQ) ……....................................................53

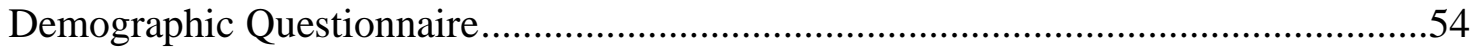

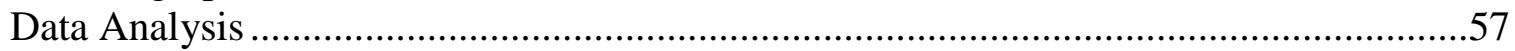

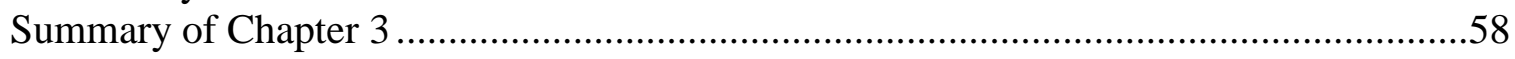

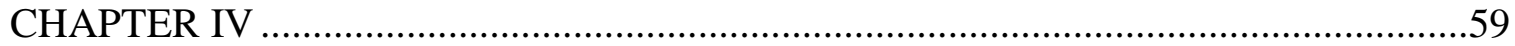

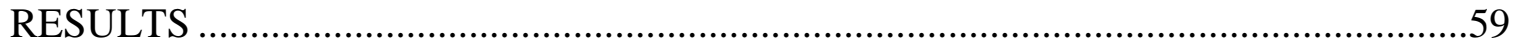

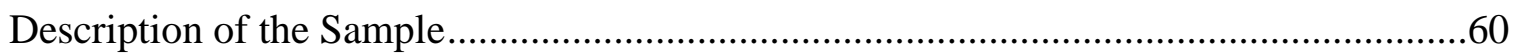

Demographic Characteristics of the Sample ………..............................................61

Exploratory Data Analysis .........................................................................................71

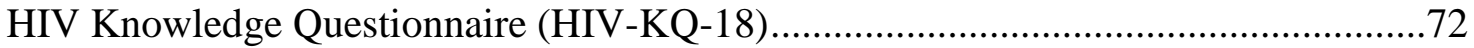

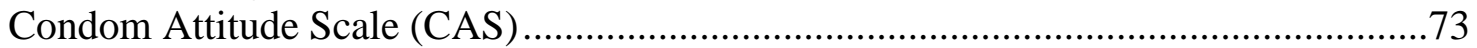

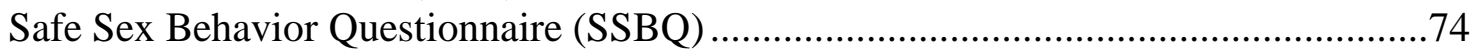

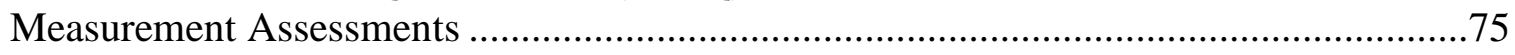

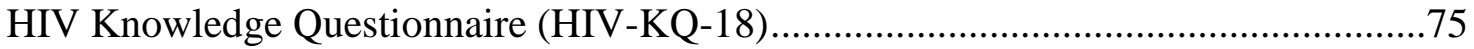

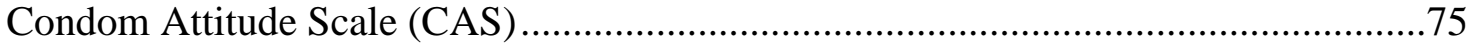

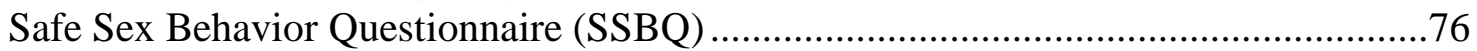

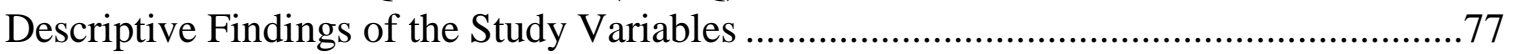

HIV Knowledge Questionnaire (HIV-KQ-18) ........................................................

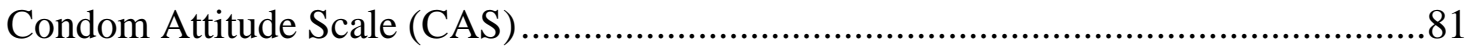

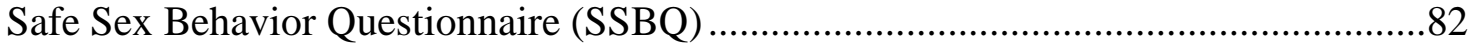

Hypotheses Testing .................................................................................................. 84

Hypothesis 1: There will be a difference in HIV knowledge between young, middle-

aged, and older Trinidadian women .......................................................................

Hypothesis 2: There will be a difference in HIV knowledge between Trinidadian

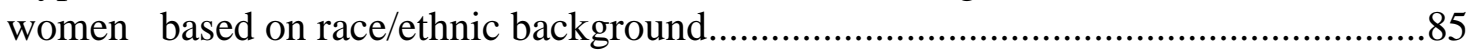
Hypothesis 3: There will be a positive relationship between Trinidadian women's level

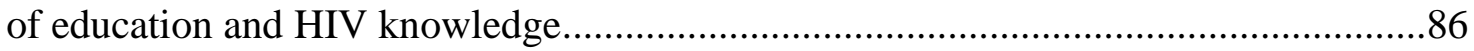

Hypothesis 4: Select demographic factors (religious beliefs, level of education, substance use) will be associated with attitudes about condom use among Trinidadian women

Hypothesis 5: Select demographic factors (religious belief, level of education, substance use), HIV knowledge, and condom attitude will be associated with safe sexual behaviors among Trinidadian women .................................................................89

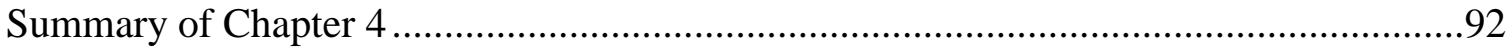

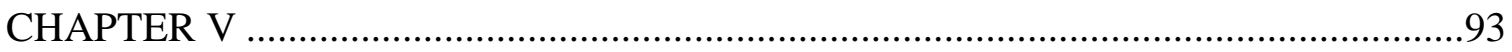

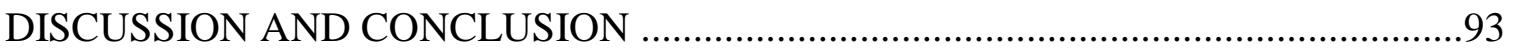

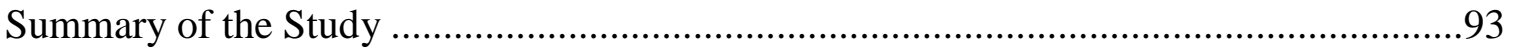

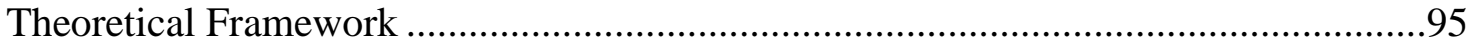

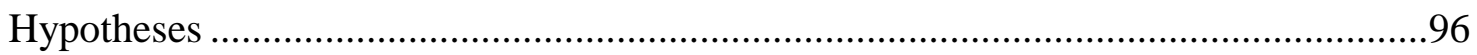

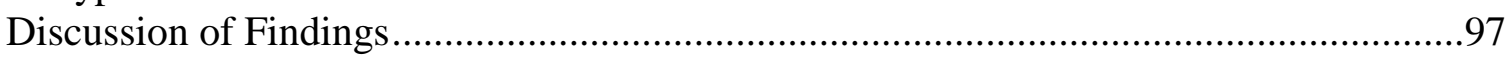

Demographic and Background Characteristics .......................................................97

Relationship between Major Study Variables .............................................................100

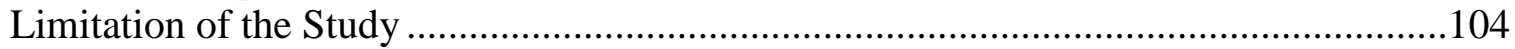

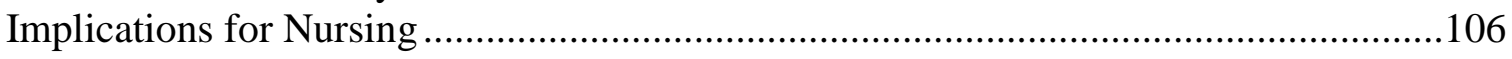




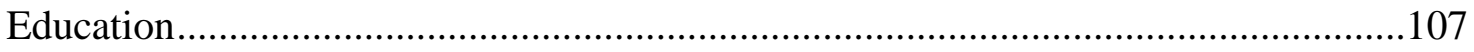

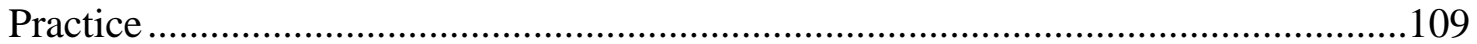

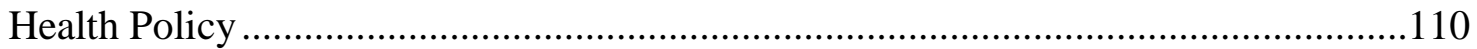

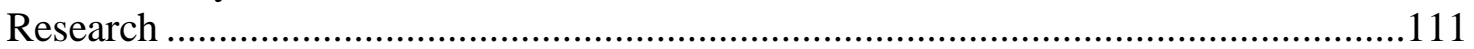

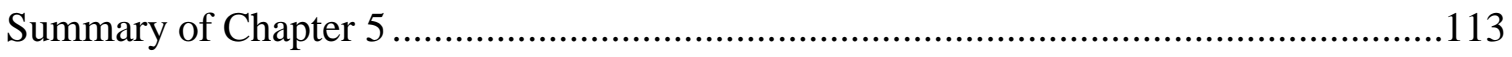

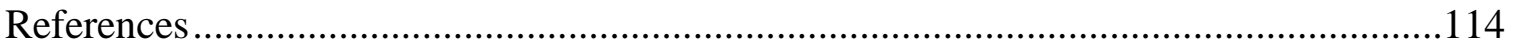

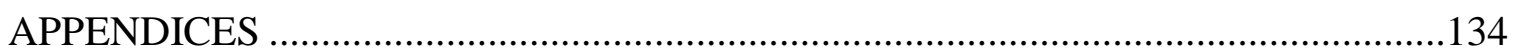

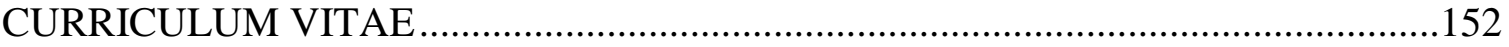




\section{LIST OF TABLES}

TABLES

PAGE

1. Age of Participants 56

2. Relationship Characteristics 58

3. Socioeconomic Status 61

4. Race and Religious Beliefs 63

5. Alcohol and Cigarette Use 65

$\begin{array}{ll}\text { 6. HIV Knowledge } & 74\end{array}$

7. Descriptive Statistics for CAS Score 76

$\begin{array}{ll}\text { 8. Descriptive Statistics for SSBQ Score } & 78\end{array}$

9. Bivariate Correlations between Major Study Variables 85 


\section{LIST OF FIGURES}

FIGURES

PAGE

1. Histogram of the Age of Participants 56

2. Histogram of HIV-KQ-18 Total Score 67

3. Histogram of CAS Total Score $\quad 68$

4. Histogram of SSBQ Total Score $\quad 69$ 


\section{CHAPTER I}

\section{INTRODUCTION}

The Caribbean is the second leading region of new HIV/AIDS infections globally, behind Sub-Saharan Africa, which emphasizes the magnitude of the epidemic (Sutherland, 2014). The Caribbean was first confronted with the HIV/AIDS epidemic in 1981 with the first cases of AIDS recorded in Haiti (Bartholomew, Raju, \& Jankey, 1983). HIV/AIDS prevalence is greater than $1.5 \%$ in the following Caribbean countries: Bahamas, Jamaica, Haiti, and Trinidad and Tobago (Averting HIV and AIDS [AVERT], 2012). Since the first case of HIV was identified in Trinidad in 1983 in a homosexual male (Bartholomew et al., 1983), the prevalence of HIV/AIDS has reached greater than $2 \%$ among adults, ages 15-49 years old, with more than half of new infections among 1524 year olds (Jones, Modeste, Marshak \& Fox, 2013; Deveaux et al., 2011; Wood, 2010; Dixon-Mueller, 2009).

Trinidad and Tobago is a twin island country that is a part of the Caribbean with an estimated population of 1.3 million people. They are the most southerly islands in the Caribbean and are located approximately seven miles off the coast of Venezuela. Trinidad is larger and more populated than Tobago. Trinidad and Tobago have a diverse ethnic population with the two most prominent ethnic groups being of East Indian descent (40.03\%) and of African descent (37.52\%). The remainder of the people are of mixed descent (20.46\%), and others (2\%) including Chinese, Syrian-Lebanese, and Caucasians (Central Statistical Office [CSO], 2016).

Trinidad and Tobago is a multiracial county, with a large number of the population being racially mixed, especially among East Indians and Africans. In certain 
countries in the Caribbean, especially where East Indians inhabit, children born to one East Indian parent and one African parent are often referred to as "Douglas" (Mangla, 2016). The term dougla derives from the Indic language and roughly translated as hybrid or impure breed (Mangla, 2016).

There are several different religions in Trinidad and Tobago and many of its citizens consider themselves religious. The two largest religions are Roman Catholics and Hindus. Muslims, Baptists, Presbyterians, and Methodists are also practiced faiths but on a smaller scale (National HIV and AIDS Strategic Plan 2013-1018 [NSP], 2013). Many religious institutes instruct women to obey their husbands, therefore questioning or confronting male sexual partners about sexual behaviors and requesting the use of condoms during intercourse are considered violations of cultural and religious customs, and may not be supported by the community or religious leaders (Padilla, GuilamoRamos, Bouris, \& Reyes, 2010; Williams, Newman, Sakamoto, \& Massaquoi, 2009). Additionally, religious groups and leaders are more inclined to oppose the use and distribution of condoms, believing it could increase unchaste and promiscuous behaviors (Padilla, et al., 2010; Williams et al., 2009).

Trinidad and Tobago is considered to be a patriarchal society. Consequently, females tend to lean towards conservatism, while men are allowed to be more permissive (NSP, 2013; Voisin \& Dillon-Remy, 2001). These social nuances reinforce abstinence for females, while promiscuity for single males is common, and even reinforced (NSP, 2013; Voisin \& Dillon-Remy, 2001). Resultantly, these women are more submissive and accepting when their sexual partner(s) refuse to use condoms during intercourse, putting 
them at a higher risk of contracting HIV/AIDS and other sexually transmitted infections (STIs).

The estimated prevalence of HIV/AIDS in Trinidad and Tobago is greater than 2\%, accounting for an estimated 15,000 infected individuals (Caribbean Medical News, 2014; AVERT, 2012; Trinidad and Tobago Office of the Prime Minister, 2011).

Although progress has been made in the prevention of the HIV/AIDS epidemic, it still remains the eighth leading cause of mortality in Trinidad and Tobago, with three new cases of HIV infection every day (NSP, 2013).

\section{Background}

The first AIDS case was identified and documented in the United States (US) in 1981 (Gottlieb et al., 1981). At the beginning of the AIDS epidemic, HIV/AIDS in the US was most prevalent among men, reinforcing a belief that HIV/AIDS only affected certain populations which included men who have sex with men (MSM), intravenous (IV) drug users and abusers, people suffering from hemophilia, and Haitians (Centers for Disease Control and Prevention [CDC], 2014a; Schnider \& Stoller, 1995). Due to this belief, the risk of women becoming infected with HIV/AIDS was overlooked (Higgins, Hoffman, \& Dworkin, 2010). Heterosexual transmission was later identified as a mode of contracting HIV infection, with increased cases of women becoming infected (CDC, 2014a; Higgins, et al., 2010). In 2002, the World Health Organization (WHO) reported than on the global scale, approximately $50 \%$ of adults living with HIV/AIDS were women. Moreover, the proportion of women living with HIV/AIDS has steadily increased in the last decade (WHO, 2015). In the Caribbean, an estimated 53\% of 
HIV/AIDS cases were among women (Joint United Nations Programme on AIDS [UNAIDS], 2011).

Among heterosexual relationships, women are three times more likely to contract HIV/AIDS (CDC, 2012; UNAIDS, 2011). According to the CDC (2014b), the highest incidence of HIV infection among women is through heterosexual transmission. Women are vulnerable to HIV infection via heterosexual contact due to the biological makeup of female sex organs (Higgins, et al., 2010). The HIV virus is directly absorbed in the vagina or cervix, through the mucous membrane lining, especially compromised mucous integrity (i.e. tear in the lining) (CDC, 2014b). Consequently, an estimated 80\% of individuals newly infected with HIV through heterosexual transmission, are women (CDC, 2014b). Symptoms of the disease are not apparent when first contracted (AIDS.gov, 2015); symptoms may take 5-10 years to manifest (Florida Department of Health [FDOH], 2012). Consequently, regardless of known HIV/AIDS status, individuals can spread the disease by engaging in unsafe sexual practices (FDOH, 2012). Subsequently, it is imperative that safer sexual practices be consistently implemented. Currently in the Caribbean, HIV infection is primarily transmitted via heterosexual contact with an HIV positive sexual partner (CDC, 2015). Studies have shown that HIV infection can be transmitted through body fluids, including: blood, breast-milk, semen, pre-seminal fluids, rectal fluids, and vaginal fluids (CDC, 2015).

\section{Significance of the Study}

The Human Immunodeficiency Virus (HIV) is considered as a "long-wave" event; wherein, effects of the HIV epidemic still continue to emerge decades after the first wave of infection in the early 1980s (Merson, O’Malley, Serwadda \& Apisuk, 2008). 
The CDC (2017) and WHO (2017), reported an estimated 36.7 million individuals infected with HIV by the end of 2015. The same year, an estimated 2.1 million individuals became newly infected, and 1.1 million died of HIV-related causes.

In developing countries, approximately 15 million people are living with HIV/AIDS (UNAIDS, 2011). Although progress has been made in the overall stabilization of new cases of HIV/AIDS, the epidemic continues to devastate the Caribbean, the United States, and the world (CDC, 2015; National Institute of Allergies and Infectious Diseases [NIAIDS], 2014).

The Caribbean currently has the second highest incidence of new HIV infection in the world (AVERT, 2012; Fitzpatrick, McCray \& Smith, 2004) with women accounting for greater than 50\% of all cases (Padilla et at., 2010; Baird, Yearwood \& Perrino, 2007; Jones, 2005). Sullivan (2008) reported that in Caribbean and Latin American countries, the HIV/AIDS epidemic was the most challenging infectious disease for the public health systems. In areas most infected with HIV/AIDS, women are disproportionally affected (AVERT, 2012; Nanda \& Pramanik, 2010; Clum, Chung \& Ellen, 2009). Caribbean women are particularly vulnerable to HIV infection, accounting for more than half of individuals living with HIV infection in the region (AVERT, 2012; UNAIDS, 2011). The two regions with the highest cases of new HIV infection, Sub-Saharan Africa and the Caribbean, are the only regions in the world where women outrank men in the number of HIV/AIDS cases (UNAIDS, 2011).

HIV/AIDS has the highest mortality rate among 25-44 year-olds in the Caribbean (Padilla et al., 2010). There is currently no cure for HIV/AIDS, therefore it is imperative to implement preventative measures in a culturally sensitive and appropriate manner. In 
2013, there was an estimated 250,000 people living with HIV infection and AIDS in the Caribbean, with 13,000 people newly infected with the disease, and 11,000 persons have died due to AIDS and AIDS-related complications (AVERT, 2012).

An increased number of new HIV cases among Caribbean youths, aged 15-24 years, have been reported, emphasizing the need to identify, address, and promote interventions to decrease HIV rate among this vulnerable population (Jones et al., 2013; Deveaux et al., 2011; Wood, 2010; Dixon-Mueller, 2009). By age 15, a substantial number of boys and girls from the Caribbean have already engaged in sexual intercourse while engaging in risky sexual behaviors, including inconsistent condom use during heterosexual intercourse (Deveaux et al., 2011; Dixon-Mueller, 2009). Engaging in risky sexual behaviors from a young age have been associated with risky sexual behaviors as

adults (Jones et al., 2013; Deveaux et al., 2011; Wood, 2010; Dixon-Mueller, 2009; Bell, Atkinson, Mosier, Riley, \& Brown, 2007).

Migration among Caribbean islands and countries, Latin America, as well as North America (in particular, Florida) is quite common, which in turn contributes to the increasing spread of HIV infection and adds to the epidemic in these regions (AVERT, 2012).

\section{Purpose of the Study}

The purpose of this dissertation study was to evaluate the knowledge, attitudes and sexual risk behaviors of Caribbean women, who are currently living in Trinidad, regarding HIV awareness and their current lifestyle choices and practices. Identifying knowledge, attitudes, and sexual risk behaviors among this vulnerable population will 
provide new information that can be used to recognize and address prevention strategies in a culturally sensitive and gender relevant manner.

\section{Theoretical Framework: Theory of Planned Behavior}

The conceptual framework that guided this dissertation study was the Theory of Planned Behavior (TPB). The theory of reasoned action (TRA) has been used in multiple research study that focuses on sexual risk behaviors and its impact on HIV/AIDS. The TRA was later revised and extended into the theory of planned behavior (TPB). The theory was designed to help predict what factors may lead to involuntary behaviors (Fisher \& Fisher, 2000). The TRA has been widely used to explain and predict sexual risk behaviors, including subjective norms and attitudes, and how this may influence condom use and multiple sexual partners (Fisher \& Fisher, 2000).

The TPB was developed in 1980 by Ajzen to assess the link between attitudes, beliefs, and behavioral intent, which are the motivational factors that influence behaviors (Ajzen, 1991). The TPB has been used to determine the relationship between young adults and their attitudes regarding intentions to use condoms (Hollub, Reece, Herbenick, Hensel, \& Middlestadt, 2011).

The TPB was used in this study to establish and compare the constructs of attitude, subjective norms, perceived behavioral control, and if/how these relate to intentions associated with condom use and sexual risk behaviors among women living in Trinidad and Tobago, as it relates to HIV/AIDS knowledge and prevention.

The conceptual framework of the TPB is an appropriate theory for this phenomenon. Ajzen (1991) noted that behaviors may not be totally voluntary and under a person's control. Prior behavior is a positive indicator in intent to behave in a certain 
way (Ajzen, 1991). The variation in intent includes three global constructs; these are attitude towards the behavior, subjective norms, and perceived behavioral control (Ajzen, 1991).

Attitude is a product of overall belief of whether the behavior is good or bad, and possible outcomes if engaged in the behavior (Ajzen, 1991). Attitude towards the behavior focuses on the extent to which an individual has a favorable or unfavorable assessment of a given behavior, consisting of behavioral beliefs and outcome evaluations (Asare, 2015; Ajzen 1991).

Subjective norms can be described as perceived social influence on the behavior, and what an individual's significant other thinks about the behavior (Ajzen, 2011). This construct suggests that social pressure is an indicator on whether an individual performs or does not perform a given behavior based on normative beliefs, motivation, and perceived behavioral expectations (Asare, 2015; Ajzen 1991).

Perceived behavioral control or a person's volition is the belief that an individual has the ability to perform a certain behavior based on personal perception (Ajzen, 1991). Intention to perform behaviors of different kinds can be predicted based on the attitude towards the behavior, subjective norms, and perceived behavior control (Ajzen, 1991). According to the TPB, intention devoid of unforeseen circumstances that limit individual control will help to predict future behaviors (Ajzen, 2011). The TPB has been used in prior studies and supports the theory's implication of HIV related sexual behaviors.

The TPB has been used to predict condom use behaviors in a variety of settings and demographics, including young Hispanics (Malcolm et al., 2013), Haitian sex workers (Couture, Soto, Akom, Joseph \& Zunzunegui, 2010), Chinese female sex 
workers (Jing et al., 2009), Spanish and Portuguese university students (Munoz-Silva, Sanchez-Garcia, Nunez \& Martins, 2007), and heterosexual men in high-income countries (Gredig, Nideroest \& Parpan-Blaser, 2006).

The TPB has been used extensively with successful application in predicting sexrelated behaviors that can contribute to HIV infection (Rich, Mullen, Sainsbury, \& Kuczmierczyk, 2014; Wise, Goggin, Gerkovich, Methcalf \& Kennedy, 2013; Boer \& Mashamba, 2005).

\section{Definition of Terms}

1. HIV: The human immunodeficiency virus (HIV) is a virus that attacks the immune system, which is the body's natural defense system, and can lead to AIDS (WHO, 2017).

2. AIDS: Acquired immunodeficiency syndrome (AIDS) is the most advanced stage of HIV infection leading to immune deficiency and susceptibility of opportunist infections (WHO, 2017). Not everyone who has HIV will advance to AIDS.

3. Heterosexual: Sexual desires, attractions, and/or engagements with members of the opposite sex (Kitzinger, 2005), and involving sexual intercourse between a male and a female (Merriam-Webster Dictionary, 2017).

4. Condoms: Condoms are a barrier contraceptive used to prevent pregnancies and sexually transmitted infections including HIV/AIDS (CDC, 2013).

5. High-risk sexual behaviors: Individuals engaging in behaviors that increase the risk of contracting HIV infection through sexual contact, including engaging in heterosexual intercourse without condom use, having multiple sexual partners, and alcohol or substances abuse. Multiple sexual partners, together with inconsistent 
condom use are directly associated with increased risk of contracting HIV/AIDS (East, Jackson, O’Brian \& Peters, 2011; Teva, Bermudez, \& Buela-Casal, 2010).

6. East Indian or Indo-Indians: East Indians of Trinidad are descendants of indentured laborers who were brought to Trinidad from India in the nineteenth century, and called East-Indian to differentiate them from the native Indians (Encyclopedia, 2016).

7. Africans or Afro-Trinidadians: brought to Trinidad by the Atlantic slave trade, they were the major work force for the sugar and cotton plantations (Besson, 2011).

8. Trinidadian(s): People from Trinidad

9. Operational Definition of Culture: Culture is the overarching characteristics that shape and delineate a person's attitudes, beliefs, behaviors, and life-norms based on engrained individual, family, and environmental factors which can influence health decisions and health promotion behaviors.

\section{Research Questions}

The research questions are:

Question 1 Is there a difference in HIV knowledge based on Trinidadian women's age?

Question 2 Is there a difference in HIV knowledge based on Trinidadian women's race and ethnicity?

Question 3 Is level of education associated with HIV knowledge among Trinidadian women?

Question $4 \quad$ What are the demographic factors (religious belief, level of education, substance use) contributing to attitudes about condom use among Trinidadian women? 
Question 5 What are the individual and combined contributions of demographic factors (religious beliefs, level of education, substance use), HIV knowledge, and condom attitudes on safer sexual behaviors among Trinidadian women?

\section{Hypotheses}

The hypotheses are:

Hypothesis 1

Hypotheses 2

Hypothesis 3

Hypothesis 4

Hypothesis 5
There will be a difference in HIV knowledge between young, middle-aged, and older Trinidadian women

There will be a difference in HIV knowledge between Trinidadian women based on race/ethnic background

There will be a positive relationship between Trinidadian women's level of education and HIV knowledge

Select demographic factors (religious beliefs, level of education, substance use) will be associated with attitudes about condom use among Trinidadian women

Select demographic factors (religious beliefs, level of education, substance use), HIV knowledge, and condom attitude will be associated with safer sexual behaviors among Trinidadian women

\section{Assumptions of the Study}

1. The main assumption is that participants will be truthful in answering the survey questions.

2. Participants will feel confident that their answers will be confidential and anonymous, thereby encouraging truthful answers and responses. 
Participants will be asked to refrain from including any personal identifiers of their identity (i.e. name, phone number, email, address, contact information).

3. An assumption is made that the instrumentations and questionnaires used to gather data from participants are both reliable and valid.

\section{Limitation of the Study}

Limitations of the study are:

1. Participants were recruited only in Trinidad (not Tobago) which may not completely represent the country as a whole

2. A convenience sample was recruited which might not be a complete and/or correct representation of the general population

3. Data gathered were subjective and self-reports from participants. This may leave room for measurement error (whether intentional for perceived social desirability or recalling accurate retrospective behaviors).

4. The focus of this study was on adult women in Trinidad. Therefore, the study was non-inclusive of men and adolescents.

5. Data were collected using a cross-sectional design. This design may represent only a fraction of the target population at a specific, fixed period of time

\section{Summary of Chapter 1}

Currently, the Caribbean has the second highest rate of new HIV infection worldwide, only after Sub-Saharan Africa (CDC, 2016; Sutherland, 2014; UNAIDS, 2012), which emphasizes the magnitude of the HIV epidemic. In the Caribbean, 
heterosexual transmission is the driving force in new HIV infections, especially among women (Higgins et al., 2010). Select countries in the Caribbean report a prevalence rate of $2 \%$ or greater, including Trinidad and Tobago's estimate of 15,000 infected individuals (Trinidad and Tobago Office of the Prime Minister, 2011). Condom use is one of the most effective methods of preventing STI, including HIV infections (CDC, 2016; International Association of Providers of AIDS Care [IAPAC], 2014; UNAIDS, 2012). When used correctly and consistently during every sexual activity, studies have shown that condoms are a proven means of HIV prevention among women (WHO, 2017). Condoms can protect the mouth, vagina, and/or anus from semen that is HIVpositive (IAPAC, 2014). Therefore, it is imperative that condoms be implemented consistently among Trinidadian women during sexual activity. This dissertation study explored the relationship between select demographic variables (religious beliefs, level of education, substance use), HIV knowledge, condom attitude, and its impact on risky sexual behaviors among Trinidadian women. 


\section{CHAPTER II}

\section{REVIEW OF THE LITERATURE}

The purpose of this literature review was to assess, identify, and describe the knowledge and attitudes on HIV prevention and lifestyle choices made by Caribbean women, with the focus on Trinidadian women. The review examines major sexual risk behaviors and practices among Caribbean women, which may contribute to HIV infection (i.e. HIV knowledge and attitudes, religious beliefs, education level, substance use, and inconsistent condom use).

The review was conducted using the following databases: CINHAL plus full-text, OVID, PsychINFO, MEDLINE - PROQUET, and APA PsychNET. Keywords and phrases that were used in the search were: HIV/AIDS prevention, Caribbean women and HIV, risky sexual behaviors, condom use, HIV and religion, gender inequality and HIV. Inclusion criteria for the literature search were: peer-reviewed, published in English language, full-text and journal articles. Google scholar and other Internet web-based resources were searched including, newspaper, governmental reports, online books, and journal articles. Studies were not limited to specific populations or geographical location.

Articles for the review were chosen based on their relation to the purpose of the literature review. Articles chosen included Caribbean women's knowledge and attitudes of HIV, religion and religious beliefs, socioeconomic status, substance use and abuse, and sexual risk behaviors. Studies were limited to heterosexual relationships and mainly focused on women. No restrictions were placed on studies design. Research studies included both qualitative and quantitative designs that included focused groups, 
questionnaires, and face-to-face individual interviews. Some researchers implemented both experimental groups and control groups in their studies.

\section{Cultural Implications of HIV/AIDS Transmission}

In 1995, Larry Purnell developed the Purnell Model of Cultural Competence to meet the needs of a multicultural society in providing competent care that includes cultural sensitivity, with the goal of improving patient outcomes (Purnell, 2000). Additionally, with the increase in the diversity of healthcare workforce, healthcare providers and patients can benefit from the integration of cultural awareness and competence in all health disciplines in all practice settings (Purnell, 2013). Purnell defines culture as "the totality of socially transmitted behavioral patterns, arts, beliefs, values, customs, lifeways, and all products of human work and thought characteristics of a population of people that guide their worldview and decision making" (Purnell, 2013, p. 6). Purnell's model of cultural competency is an ethnographic model cultivated towards health promotion, as well as disease prevention and treatment by understanding the cultural viewpoint of individuals, which can be used in training, research, and application for nurses to provide culturally sensitive care (Purnell, 2013).

Similarly to the Theory of Planned Behavior (TPB), the Purnell Model of Cultural Competence posits that attitudes and beliefs are learnt and indoctrinated, usually from a very young age; therefore, they are unconsciously accepted as truths, often without question (Purnell, 2013). McNeil (2003) postulates that health is an important component of an individual's culture; therefore, being diagnosed with HIV/AIDS have a cultural impact that could result in emotional distress, societal discrimination, and economic hardship. Consequently, cultural competency must be implemented in seeking 
to explore, examine, and evaluate the knowledge, attitudes, and sexual risk behaviors of Caribbean women, who are currently living in Trinidad.

\section{Heterosexual Exposure to HIV/AIDS}

When the first cases of HIV/AIDS were identified, the disease was mainly among MSM and drug users (CDC, 2014a; Schneider \& Stoller, 1995). However, as the disease progressed over time, heterosexual transmission of HIV/AIDS was identified as a major contributor to the epidemic, with increased number of women becoming infected (Higgins, et al., 2010; Harris et al., 1983). Globally, more than 50\% of women have HIV/AIDS (WHO, 2015), with an estimated 53\% of Caribbean women who have the disease (UNAIDS, 2011). The CDC (2014a) estimated that approximately $86 \%$ of new HIV infections among women were attributable to heterosexual contact.

Sexual risk behaviors (i.e. inconsistent or lack of condom use) among heterosexuals have a direct link with HIV/AIDS. The majority of women who are newly infected with the HIV virus are infected via transmission from their primary male sexual partners (O’Leary, 2000). Condom use is often associated with casual relationships, paying relationships, and concurrent sexual partners (Corbett, Dickson-Gomez, Hilario, \& Weeks, 2009; O’Leary, 2000). Consistent condom use among heterosexual partners are often ignored, especially with perceived monogamous relationships (Higgins et al., 2010; Corbett et al., 2009) or women experiencing intimate partner violence (IPV) (Meyer et al., 2011; Jewkes, Dunkle, Nduna, \& Shai, 2010).

Research findings indicated that as relationships grow, there is a decline in the proportion of condom-protected sexual activity, which may be seen within a few weeks after first sexual encounter (Sayegh, Fortenberry, Shew, \& Orr, 2006). This decline in 
condom use is associated with a decrease in perceived STI risk, especially as the relationship progresses into a steady, monogamous partnership (Sayegh et al., 2006).

Hotton et al. (2015) conducted a study to examine risk-reduction strategies, and condom use to reduce HIV/AIDS among young heterosexual adults. A sample of 33 participants $($ women $=20$, men= 13) ages 18-29 were recruited. Participants reported using condoms during casual sexual encounters, or when engaging in sexual intercourse with multiple concurrent partners. However, as participants perceived a more monogamous relationship with a steady committed partner, condom use was abandoned. Participants, mainly females, stated that if they were in a boyfriend/girlfriend relationship, this implies monogamy. Therefore, the need for condom use with committed partners was not necessary (Hotton et al., 2015).

He, Hensel, Harezlak, and Fortenberry (2016) conducted a study to assess condom use based on the number of sexual encounters among individuals in newly formed relationships. Sample size included 115 participants, ages 18-29. Results indicated that a higher level of relationship and sexual satisfaction were strongly associated with a decline of condom use, especially among women. The findings suggested that the more familiarity, trust, and intimacy perceived in a relationship, the lower the perception of risk. Conversely, the lower the perception of sexual risk, the less likely individuals used condoms during sexual intercourse (He et al., 2016).

Corbett et al. (2009) conducted a study to explore factors that affect initial and continued use of condoms. A sample of 25 heterosexual couples was recruited. Both male and female participants reported not using condoms during sexual activities, especially as the relationship progressed. Rational for lack of or inconsistent condom use 
was to help establish and define their relationships as potentially serious rather than casual sexual engagements. Participants associated a loving, meaningful, and trustworthy relationship with not using condoms during intercourse. Additionally, while most participants reported being aware of the potential risk of not using a condom, they believed the intimacy and trust gained were higher priorities (Corbett et al., 2009).

Stockman and colleagues (2013a) conducted a study to examine the relationship between intimate partner violence (IPV) and HIV risk factors, including inconsistent or lack of condom use. A sample of 668 African American and African Caribbean heterosexual women, ages 18-55 were recruited. Findings from the study suggested that women who experience IPV were less likely to use condoms during vaginal and/or anal sexual intercourse. Additional findings from the study indicated that abused women, in turn were engaging in risky sexual behaviors, including casual and concurrent sexual partners (Stockman et al., 2013a).

Sexual violence against women can increase the risk of contracting HIV infection (Meyer et al., 2011), especially forced or coerced sex from an infected partner without using a condom (Stcokman, Mucea, \& Campbell, 2013b). Coerced or forced sex, as well as sexual IPV, significantly increases the risk of HIV infection among women (Stockman et al., 2013b). Draughon et al. (2015) conducted a study to examine the relationship between IPV and sexual health outcomes. The sample included 901 African Caribbean and African American women, ages 18-55. More than one-third (38\%) of participants reported experiencing forced sexual intercourse, including vaginal, oral, and anal sex. Intimate partner forced sex (IPFS) was strongly associated with abusive partner having multiple concurrent sexual partners. Additionally, more that $40 \%$ of participants reported 
inconsistent condom use from partners, especially during anal intercourse (Draughon et al., 2015).

\section{HIV Knowledge}

According to WHO (2017), the human immunodeficiency virus (HIV) infect cells of the immune system, causing impairment and a decrease in functionality. Over time, the immune system becomes deteriorated and compromised, leading to susceptibility and predisposition for opportunistic infections to incur. HIV/AIDS was first identified in 1981, and almost four decades later, although most people have heard about HIV infection, detailed knowledge of HIV/AIDS still remains low, including misconceptions about transmission of the disease (Pinder-Butler, Frankson, Hanna-Mahase, \& Roberts, 2013).

Among 354 Bahamian students ages11-14, more than 20\% believed that HIV infection can be transmitted via mosquito bites, and $13 \%$ believed that it can be transmitted by sitting on the toilet after an HIV positive person used the facility (PinderButler et al., 2013). Rotimi and Oluwafemi (2008) reported similar findings among 130 medical students ages 19-45 in St. Lucia, with $17.7 \%$ of participants who believed HIV can be transmitted via mosquito bites, and $16.2 \%$ by using toilet facilities. Consequently, despite interventions and efforts to change and reduce risky-sexual behaviors, these myths and misconceptions about HIV transmission often counteract these efforts (Sano et al, 2016).

A descriptive study conducted among 176 Kenyan participants ages 15-19 revealed a concerning lack of knowledge about HIV infection, specifically pertaining to the transmission via body fluids (Lalani, 2006). A study was conducted by Janahi, 
Mustafa, Alsari, Al-Mannai, and Farhat (2016) to assess knowledge, perceptions, and attitudes towards HIV/AIDS in Bahrain. A sample size of 1,038 adult participants was recruited $($ Females $=57 \%$, Male $=43 \%$, mean age $=31$ years-old $)$. The majority of participants $(83.9 \%)$ were aware that HIV/AIDS attacked the immune system, however there were misconceptions regarding mode of transmission. Findings indicated that $77 \%$ of participants believed that the disease can be transmitted via coughing or sneezing from an infected person, $46.4 \%$ from mosquito bites, $41.8 \%$ from sharing toilet facilities and swimming pools, and $27.6 \%$ from using the same utensils for meals. Additionally, among this population, more than 50\% lacked knowledge about antiretroviral treatment (ART), and erroneously believed that antibiotics were the choice of medication to treat HIV/AIDS. Some participants reported belief that there was a cure for HIV/AIDS (Janahi et al., 2016).

HIV/AIDS is currently one of the leading causes of mortality globally (UNAIDS, 2011), accounting for an estimated 1.1 million deaths in 2015 (CDC, 2017; WHO, 2017). In the Caribbean, HIV/AIDS is more prevalent among heterosexual women than men (UNAIDS, 2011), emphasizing the need to determine women's knowledge of the disease, and implement measures to slow or stop the progression.

HIV knowledge is an important construct utilized to assess, predict, develop, and advance HIV prevention behaviors and actions (Burke, Fleming, \& Guest, 2014). Knowledge is a fundamental key component of HIV/AIDS risk-reduction programs and interventions (Carey \& Schroder, 2002). Thereby, emphasizing the importance of assessing current knowledge among specific populations to guide educational curricula, and provide appropriate risk awareness is imperative (Burke et al., 2014). HIV 
knowledge should be established as a pre-requisite, in order to determine appropriate interventions for health-promoting, and risk reducing behaviors (Burke et al., 2014; Glanz, Rimer, \& Viswanath, 2008).

\section{Attitudes about HIV}

HIV risk perceptions can be described as an individual's opinion of his/her chance of contracting the disease (Corneli, Wang, Agot, Ahmed, Lombaard, \& Van Damme, 2014). Research has shown that individuals often tend to underestimate their risk for HIV infection rather than overestimate it, and therefore continue to engage in risky sexual behaviors (Brewer, Weinstein, Cuite, 2004; Chapin, 2000). Individuals may be discouraged from changing their risky behaviors if they perceive minimal risk or no risk (Corneli et al., 2014); thereby setting the tone for future risky sexual behaviors that can lead to HIV infections (Rose, 2008) and STIs.

Attitudes and perceptions about a given phenomenon are related to behavior towards said phenomenon, for example condom attitudes have been linked to actual condom usage (Stephenson et al., 2015; Senn, Scott-Sheldon, \& Carey, 2014). It is important to understand predictors of condom use, in order to implement more effective interventions that may lead to increased condom usage (Senn et al., 2014). An important predictor of condom use in most health behavior model is attitude toward the behavior (Golub, Starks, Payton, \& Parsons, 2012; Reynolds et al., 2010; Sheeran, Abraham, \& Orbell, 1999).

Using the Social Action Theory among 156 participants, Reynolds et al. (2010) reported that environmental influences, less favorable attitudes toward condom use, and higher levels of risk-taking inclination, are contributing predictors of inconsistent or lack 
of condom use during the most recent sexual encounters. Men and women with negative or unfavorable attitude toward condom use are less likely to use condoms during sexual activities (Stulhofer, Graham, Bozicevic, Kufrin, \& Ajdukovic, 2007; Harvey \& Henderson, 2006).

Randolph, Pinkerton, Bogart, Cecil, and Abramson (2007) reported that among 115 heterosexual college students ( 80 females, 35 males, mean age $=22$ years $)$ who were sexually active within the last three months, both female and male participants reported unprotected vaginal sex as more pleasurable than when using a condom. Both female and male participants reported preference and action to forgo condom use during intercourse, in order to experience more sexual pleasure (Randolph et al., 2007). Consequently, these participants put themselves and their partners at risk for contracting HIV infection by not practicing safer sex (i.e. inconsistent or lack of condom use).

Dias, Matos, and Goncalves (2005) conducted a study to examine social norms that contribute to risky sexual behaviors and their relation to HIV/AIDS among a sample of 3,762 Portuguese high school students ( $52 \%$ girls, $48 \%$ boys). Social norms for this study included examination of demographic, personal, family, and school variables and how they relate to HIV attitudes (Dias et al., 2005). Participants reported knowing the importance of condom use as an effective prevention method for STIs, however, admitted that when caught-up in the moment they forget or ignore safer sexual practices by not using condoms. Female participants also reported feelings of powerlessness in negotiating condom use due to masculine ideology and male dominance from their sexual partners. All participants reported knowledge about the dangers of HIV/AIDS. However, despite knowing the dangers, they often underestimated personal risk of 
contracting the disease. Participants reported being in long-term and monogamous relationships, therefore they perceived no risk. Also, participants believed that they can identify individuals who are HIV seropositive, just by looking at them, because individuals with HIV/AIDS have an "anemic aspect". Implications from this study support the collaborative efforts of family, school, and community interventions for safer sexual practices and behaviors (Dias et al., 2005).

\section{Condom Use}

According to UNAIDS (2012), condom use is a vital and critical element in a comprehensive, effective, and sustainable approach in the prevention and treatment of HIV infection. Condom use is one of the most effective methods of preventing STIs, including HIV infections (IAPAC, 2014, CDC, 2016; UNAIDS, 2012). When used properly during every sexual intercourse, studies have shown that condoms are a proven means of HIV prevention among women (WHO, 2017). Condoms can protect the mouth, vagina, and/or anus from semen that is HIV-positive (IAPAC, 2014).

Sexually active women who practice inconsistent condom use during intercourse are at a high risk of contracting HIV infection. There are numerous reasons why this population does not consistently use condom while engaging in sexual activities. Gender and power dynamics often impacts women into taking a passive role in condom negotiation (Lam \& Barnhart, 2006; Amaro, 1995). Initiating the use of condom during sexual intercourse is often challenging for women (Bell et al., 2007; Shlay, McClung, Patnaik, \& Douglas, 2004), whereby, women are afraid of their male sexual partner's reaction when the topic of condom use is initiated, i.e. physical and/or verbal abuse, as well as the threat of abandonment (CDC, 2014a). 
Bertens, Eiling, van den Borne, and Schaalma (2009) conducted a study to assess the effectiveness of interventions on STI/HIV knowledge, self-efficacy/sexual assertiveness, and attitudes toward condom use in new and steady sexual partners (Bertens, et al., 2009). Included in the intervention sessions were sexual negotiation with partners, and discussion of the risks associated with unsafe sexual practices (Bertens, et al., 2009). This study consisted of a sample of 322 Caribbean women living in the Netherlands, between the ages of 15 and 71 years old. Based on the results, participants were more knowledgeable about STI/HIV, more aware of sexual risk factors and behaviors, more inclined to integrate safer sexual practices, and motivated to negotiate and initiate condom use with sexual partners (Bertens, et al., 2009). Similarly, in a study by Holschneider and Alexander (2003), prevention-methods and sexual behaviors of HIV infection were examined among 845 youths between the ages 15-19 living in Haiti. Data were collected from a cross-sectional survey using self-administered questionnaires. Findings indicated inconsistent use of condom during sexual intercourse, reinforcing the need for HIV risk-reducing educational interventions (Holschneider \& Alexander, 2003).

A study was conducted to examine perceptions of HIV risks among 18-39-yearold adults living in Broward County (Hlaing \& Darrow, 2006). Participants were recruited from areas with a high HIV prevalence rate. Participants included immigrated Caribbean adults with the majority (64.1\%) being females (Hlaing \& Darrow, 2006). Three cross-sectional, computer assisted telephone interview surveys were conducted over a 3-year period (Hlaing \& Darrow, 2006). Results indicated an increase in awareness of HIV infection, as well as an increase in condom use (Hlaing \& Darrow, 2006). The findings suggested that adults who become more knowledgeable and more 
aware of HIV infection risk factors are willing to change their behaviors to decrease their risk of exposure.

Gillespie-Johnson (2008) conducted a study to explore HIV/AIDS and safer sexual practices among immigrant heterosexual women. Twenty immigrant Jamaican participants ages 18-30 were recruited from South Florida. Participants reported being afraid to negotiate the use of condoms with male sexual partners, due to possible physical abuse, mental abuse, or abandonment by their sexual partner(s) (Gillespie-Johnson, 2008). Teitelman, Ratcliffe, Morales-Aleman and Sullivan (2008), reported similar findings among 56 sexually active African American and Hispanic urban girls who did not use condoms consistently, thereby placing them at an increased risk of contracting HIV infection and other STIs (Teitelman et al., 2008).

Cook (2011) suggested that there is a symbolic meaning of using condoms, which is often associated with casual sexual encounters and promiscuity among men. When women broach the topic of condom use, it may be misconstrued by their male sexual partners who interpret the request as a negative character assessment (Cook, 2011). Moreover, male sexual partners may become physically, sexually, and/or verbally abusive if women try to negotiate condom use before and during sexual intercourse (Maman, Campbell, Sweat \& Gielen, 2000). Increased risk of violence is reported when the male sexual partner is infected with HIV or when the woman perceives herself as being at risk for contracting HIV from her male partner (William et al., 2009; Maman et al., 2000).

Pulerwitz, Amoro, DeJong, Gortmaker and Rudd (2002) conducted a study in Massachusetts with 388 women, mainly made up of Puerto Ricans and Dominicans, 
between the ages 18 and 45 years-old. Findings indicated that $52 \%$ of participants reported a lack of consistent condom use which can be attributed to low sexual power in the relationship. Moreover, participants were afraid of negotiating condom use because of potential domestic violence and abuse (Pulerwitz et al., 2002).

Relationship status was noted as an important variable, used to determine if women engage in safer sexual practices because, as longevity increases in relationship, women tend to practice fewer behaviors associated with safer sex (Ferguson, Quinn, Eng, \& Sandelowski, 2006). Foreman (2003) reported that as women feel stronger emotional ties to their male sexual partners, condom use becomes less consistent when engaging in sexual intercourse. Some women admitted knowing the importance of consistent condom use, but confessed to not always adhering to this when they are in steady relationships (Foreman, 2003).

In a study conducted by Jarama, Belgrave, Bradford, Young and Hannold (2007) with 51 African American women, $43 \%$ of participants reported not discussing condom use or safer sexual practice with their current sexual partners. Participants reported that if their sexual partners did not want to use condoms that they will be fine with it and still have sexual intercourse because they did not want to pressure their male partners (Jamara et al., 2007).

Multiple sexual partners, paired with inconsistent condom use are directly associated with increased risk of contracting HIV/AIDS (Letamo, Mokgatlhe, 2013; Bombereau \& Allen, 2008; East et al., 2011). About 50\% of young sexually active men, with more than one concurrent sexual partner, reported a lack of condom use while 
engaging in sexual intercourse (Ramezani, Malek-Afzali, 2008; Hajiabdolbaghi et al., 2006).

In a study conducted by van Veen and colleagues (2011), the authors reported a positive association between multiple sexual partners and a low rate of condom use among 1,792 heterosexual Caribbean and African immigrants living in the Netherlands. Findings from the study indicated that $15 \%$ of participants reported having concurrent sexual partners within the last six months and more than half of participants reported not using condoms during sexual intercourse (van Veen et al., 2011). Recent studies have found that individuals who engaged in sexual relations with multiple partners used condom inconsistently or not at all (Gerver et al., 2011; Holschneider \& Alexander, 2003).

\section{HIV/AIDS Stigma and Discrimination}

HIV-related stigma and discrimination are associated with prejudice, negative attitude, denial of services, harassment, and in some instances abuse directed at people who are infected, or believed to be infected with the HIV virus and/or AIDS (Crowell et al., 2017; AVERT, 2017; UNAIDS, 2015). Inevitably, HIV/AIDS stigma and discrimination promote feelings of guilt and shame which can lead to decreased selfesteem and have an impact on mental health (Kontomandis, Michalopoulos, Gkasdaris, \& Fasoulakis, 2017). Consequently, stigma and discrimination often lead to physical, psychological, and economic hardship (Cooperman \& Simoni, 2005). In a study by Rael and Hampanda (2016) conducted among 233 participants, findings indicated a positive correlation between stigma from the community and family, and feelings of depression and low self-worth among women living with HIV/AIDS in the Dominican Republic. In 
like manner, Tanny, Naar-King, and MacDonner (2012) conducted a study in the U.S., and reported a positive relationship between discrimination and depression among 186 youths living with HIV. Furthermore, HIV related stigma and depression were associated with negative impact on health behaviors among this population, especially nonadherence to HIV treatment and increased risky sexual behaviors (Tanny et al., 2012). Individuals who experienced stigma from family, friends, and society are vulnerable to feelings of depression, self-hate, decreased self-worth, and low self-esteem (Lee, Kochman, \& Sikkema, 2002).

Lee et al. (2002) conducted a study to examine internalized stigma among 268 HIV positive men and women living in Milwaukee, Wisconsin, and New York City. Findings indicated that a majority of participants experienced internalized stigma related to their HIV-positive status. Additionally, participants who experienced higher levels of internalized stigma had increased feelings of depression, anxiety, and hopelessness (Lee et al., 2002). In like manner, Vanable, Carey, Blaire and Littlewood (2006) conducted a study to examine the relationships among stigma-related experiences and depression, adherence to HIV medication, and sexual risk behaviors among 221 HIV-positive men and women. Participants were recruited from an infectious disease clinic in New York City. Data for the study were collected from self-administered questionnaires and from patients' medical charts. Based on the findings, HIV-related stigma was associated with depressive symptoms and poor adherence to antiretroviral medication. Moreover, there was a positive association with HIV-related stigma and participants missing follow-up clinical appointments and not seeking regular medical care due to feelings of depression 
and lack of social support. No association was found among HIV-related stigma and risky sexual behaviors among this population (Vanable et al., 2006).

Oskouie, Kashefi, Rafii and Gouya (2017) conducted a study to examine and explore HIV-related stigma and discrimination among women in Iran. The researchers employed a qualitative study design using in-depth and semi-structures interviews with participants. Twenty-five women were recruited for the study. Based on the results of the study, four themes emerged; i.e. fear, shame, rejection by family and/or friends, and feelings of frustration (Oskouie et al., 2017). A majority of the participants reported fear of being killed or losing custody of their children. Additionally, participants reported that HIV/AIDS brought shame and disgrace to their families, including being shunned by friends and relatives, as well as being the targets of gossip. Furthermore, participants were afraid that they will be abandoned by family and society due to social norms and previous abandonment of people living with HIV infection and AIDS in Iran. Participants reported overwhelming feelings of frustration and loneness, with a majority that believed it would be better to have cancer than HIV infection. Consequently, participants also reported that they would rather be in isolation that face the stigma associated with HIV infection (Oskouie et al., 2017).

HIV/AIDS is often associated with certain behaviors that some people disapprove of, including drug use, homosexuality, commercial sex work, and infidelity (AVERT, 2017). Additionally, some people believe that HIV/AIDS are only transmitted through sexual intercourse, which is a taboo topic across many cultures, including the Caribbean (Corwell et al., 2017; AVERT, 2017; Varas-Diaz, Neilands, Rivera, \& Betancourt, 2010). 


\section{Select Demographic Variables}

\section{Religious Beliefs}

Padilla, et al. (2010) asserted that a unified moral belief system and personal spiritual attitude correlated with HIV/AIDS risk behaviors, and help women to define certain behaviors that increase the risk for contracting HIV/AIDS. In Trinidad and Tobago, while religious leaders are esteemed and often collaborate with policy makers, there are still barriers towards promoting safer sexual practices (i.e. condom use outside the sanctity of marriage; beliefs that HIV/AIDS are mainly due to homosexual activities). Consequently, these barriers have hindered collaborations between religious establishments and public health organizations in endorsing HIV initiatives (Genrich \& Brathwaite, 2005; Trinidad and Tobago International Religious Freedom Report, 2003).

Many Caribbean countries are religious, believe in a higher-power, and practice religion by going to houses of worship, praying to a higher being, and living a good Godfearing life. Caribbean people often associate life issues and diseases with their daily actions and behaviors (Padilla, et al., 2010; Williams et al., 2009; Hoffman et al., 2008). In the Caribbean, people still believe that if they are "good and decent" and did nothing "bad", they will not contract diseases like HIV/AIDS (Williams et al., 2009). Similarly, Kopelman (2002) also found that among sub-Saharan population, people also believe that sickness and diseases are punishment from God, with the intent to restore virtue and morality.

Most religious institutes endorse patriarchal hierarchy and sanction women to obey their husbands. Therefore, questioning or confronting male sexual partners about sexual behaviors and/or insisting on condom use during intercourse are considered 
violations of cultural and religious customs, and may not be supported by the community or religious leaders (Padilla, et al., 2010; Williams et al., 2009).

Williams et al. (2009) reported that among immigrant Caribbean and African women living in Toronto, religious leaders still practice patriarchal hierarchy, thereby promoting and supporting male partners' sole authority and power to make decisions on sexual practices. Gillespie-Johnson (2008) reported similar findings among 18-30 yearold Jamaican immigrants in the U.S. Participants reported some knowledge and insight regarding HIV preventative measures. However, religious and cultural norms prevented them from practicing preventative behaviors, i.e. initiating condom use and empowerment in the relationship (Gillespie-Johnson, 2008).

Genrich and Brathwaite (2005) conducted a study among 11 religious representatives in Trinidad and Tobago, including Christian, Hindu, and Muslim denominations. Participants were initially contacted by phone, whereupon willing participants met with researchers for face-to-face interviews. The interview questions included issues related to abstinence, condom use, sexuality, homosexuality, and compassion for people living with HIV/AIDS (PWHA). Representatives from the Roman Catholic Church believed that contributing factors associated with the spread of HIV/AIDS were associated with the degradation of the traditional family unit, as well as abandonment of traditional cultural and religious values. Seventh Day Adventist (SDA) did not support or promote condom use, especially outside of marriage, believing that condom use promotes promiscuity and sexual urges. Similarly, Pentecostal representatives did not condone the use of condoms outside of marriage because 
unmarried individuals should not be engaging in sexual activities. Therefore, it is not right to distribute or promote condom use (Genrich \& Brathwaite, 2005).

Hindu representatives (Genrich \& Brathwaite, 2005), believed that due to religious obligations and doctrine, that Hindus are less likely to contract HIV/AIDS, especially since HIV/AIDS occurred predominantly among homosexuals. In Hinduism, homosexuality is seen as a male contingency rather that among women. While compassion is deeply-rooted in Hindu dogma, individuals living with HIV/AIDS are considered to be "dirty" and "unclean", and are expected to stay away from organized worship and temples (Genrich \& Brathwaite, 2005).

A representative from the Nation of Islam (NOI) (Genrich \& Brathwaite, 2005), theorized that HIV infection was man-made, developed in the U.S., with the objective of controlling population growth. Additionally, reported skepticism of scientific research findings in the literature, especially regarding the effectiveness and efficacy of condoms. The NOI representative purported that only abstinence can protect and prevent HIV infection and other STIs. Therefore, condom use is discouraged and abstinence is promoted. A representative from Jamaat al Muslimeen reported that condoms are forbidden, and that the organization believes that HIV/AIDS was a "sin from God" for unchaste behaviors and practices (Genrich \& Brathwaite, 2005).

Arrey, Bilsen, Lacor, and Deschepper (2016) conducted a study to examine and explore how religion and spirituality are used as a source of resilience, strength, and overall wellbeing among migrant sub-Saharan African women receiving medical treatment in Belgium. A sample of 44 women were recruited for the study, ages 20 to 67 years-old, and diagnosed with HIV infection. Forty-two participants were practicing 
Christians and two were practicing Muslims. A majority of the women reported the integration of prayers, meditation, and religious activities as coping strategies to help deal with their HIV-positive status. Findings from the study indicated that some Christian participants refused HIV treatment, including antiretroviral therapy (ART), because they believed that only God can cure HIV infection. However, this was not the belief of all participants, some participants believed that God was instrumental in the creation of ART; therefore it was not going against God by using ART. These participants implemented ART, medical care, and religious activities in their HIV treatment plan (Arrey et al., 2016).

In like manner, Kremer, Ironson, and Porr (2009) conducted a study to examine spiritual/mind-body beliefs related to adherence to medication and decision-making about HIV treatment. A sample of 79 (male 65\%; female 35\%) HIV-positive participants were recruited from South Florida. The majority (90\%) of participants reported having a religious upbringing. A majority of participants (73\%) were diagnosed with HIV infection over 11 years prior, and were now diagnosed with AIDS based on their CD4 count. Findings from the study indicated that spiritual/mind-body beliefs were positively associated with treatment decision-making and adherence to HIV medications. Findings identified certain beliefs (i.e. God or a Higher Power controlled health or individual's mind controlled health) as barriers to accepting and/or adhering to HIV treatment and ART (Kremer et al., 2009).

\section{Level of Education}

Data from prior studies have shown correlations between level of education and HIV knowledge (Yaya, Bishwajit, Danhoundo, Shah, \& Ekholuenetale, 2016; Pellowski, 
Kalichman, Matthews, \& Adler, 2013). Poverty, discrimination, and inequality are contributing factors associated with an individual's risk behaviors and facilitation of HIV transmission and prevalence (Pellowski et al., 2013). Additionally, income, education, and employment are directly linked, and play an important role in the HIV/AIDS epidemic (Yaya et al., 2016; Song et al., 2011). Song et al. (2011) postulates that health is affected by behaviors and behaviors are strongly associated with an individual's economic status (i.e. income, education).

Quality education provides a powerful force and stronghold that is necessary for the current epidemic of HIV/AIDS (The Global Coalition of Women and AIDS [GCWA], 2017). Mwamwenda (2014) posits that the more education an individual possesses, the less vulnerable the individual, with greater incidence of safer sexual practices, postulating that females with higher levels of education are less likely to contract HIV/AIDS when compared to those with lower level of education (Mwamwenda, 2014). Aslan and Cutler (2013) supported the view that girls should be encouraged to stay in school and gain a higher education, suggesting a direct association between higher level of education and delay of sexual engagement. Delaying the initiation of sexual practices reduces lifetime risk of contracting STIs, including HIV infection (Aslan \& Cutler, 2013).

Rahman, Kabir, and Shahidullah (2009), conducted an investigation on HIV/AIDS knowledge and awareness among 3,362 adolescent females in Bangladesh. Findings from the investigative study suggest that the number of years in school correlated with their knowledge and awareness of HIV/AIDS, in that, the longer students stayed in school, and the higher the education level attained, the less risk of contracting 
HIV infection (Rahman et al., 2009). Similarly, Jukes, Simmons, and Bundy (2008) reported a direct correlation between level of education and HIV/AIDS, whereby education affects the thought processes of individuals, which influence social cognition and behaviors. Furthermore, educated individuals often belong to social groups and networks that influence behaviors, for example social norms are powerful predictors of intention to use condoms during sexual intercourse, depending on the number of network partners that also share these protective behaviors and practices (Jukes et al., 2008; Giles, Liddell, \& Bydawell, 2005).

Oliveira-Campos, Giatti, Malta, and Barreto (2013), reported that among 60,973 Brazilian adolescent participants, having a good family life and being in school are associated with better sexual behaviors and practices, with lower rates of STIs and pregnancies. Conversely, in a retrospective study conducted in the U.S. among 3,886 teenage participants, dropping out of school at an early age was associated with compromised sexual and emotional development, leading to lower rate of condom use (Chen, Wen, Fleming, Demissie, Rhoads, \& Walker, 2007).

Undeniably, there is a strong correlation between level of education, HIV knowledge, and sexual risk behaviors (Global Coalition on Women and AIDS [GCWA], 2017; Jukes et al., 2008; Mwamwende, 2014; Yaya et al., 2016; Pellowski et al., 2013; Song et al., 2011; Rahman et al., 2009). However, there is also a link between level of education and gender inequality that impacts HIV infection and sexual risk behaviors among women (Fladseth, Gafos, Newell, \& McGarth, 2015; Watts \& Seeley, 2014).

There is a strong and undeniable relationship between the current HIV epidemic, gender inequality, and violence against women (Wattes \& Seeley, 2014). Higher levels 
of condom use among men and women have been associated with higher levels of education (Fladseth et al., 2015), whereas inconsistent or lack of condom use have been associated with lower levels of education, substance abuse, and violence against women (i.e. forced sex) (Fladseth et al., 2015; Kalichman, Simbayi, \& Cain, 2010). Additionally, women who experience violence, often engage in risky sexual behaviors, including inconsistent or no condom use, substance and drug abuse, and promiscuous sexual behaviors which ultimately put women at risk for contracting HIV infection and STIs (Campbell, Baty, Ghandour, Stockman, Francisco, \& Wagman, 2008).

Gellespie-Johnson (2008) reported that among 20 Jamaican women who migrated to the U.S., less than $50 \%$ of participants showed interest in gaining more knowledge about HIV prevention strategies, especially related to implementing condom use during intercourse. These participants were afraid of the consequences (i.e. domestic violence and/or abandonment) associated with trying to negotiate condom use with sexual partners. Moreover, one participant shared that her sister was hit in the face and thrown out of the home because she asked her boyfriend to use a condom (Gellespie-Johnson, 2008).

In a study by Wight, Plummer, and Ross (2012), among 158 Tanzanian participants, men generally had more power than women in the relationship. Men had more access to paid employment, and owning land, property, and livestock. Consequently, women with limited economic opportunities adapted into a more subservient and subordinate role, and with ultimately less sexual power within the relationship (Wight et al., 2012). Wight et al, (2012) further explained that due to a lack 
of educational and economic opportunities among this population, there was a lack of sexual health knowledge and inadequate preventative measure from HIV transmission.

Social, economic, and cultural factors contribute to the rising number of HIV infections among heterosexual women, especially among women who are dependent on male sexual partners (Wattes \& Seeley, 2014). Odimegwu and Somefun (2017), emphasized the need to look beyond just individualized psychological processes of HIV transmission, and to recognize sociocultural factors (i.e. social, economic, cultural) that contributes to sexual risk behaviors and practices (Oliveira-Campos et al., 2013; Musiimenta, 2012). Similarly, Wight et al. (2012), suggested that deep-rooted sociocultural factors (i.e. societal norms, gender-power) may be fundamental barriers that deter safer sexual practices and behaviors, accomplished by promoting masculine ideology and discouraging female empowerment.

\section{Substance Use}

There has been an inextricable link between drug/substance use and HIV/AIDS since the beginning of the epidemic (National Institute of Drug Abuse [NIDA], 2017). Alcohol and substance use promulgate risky sexual behaviors among adolescents (NIDA, 2017; Monahan, Oesterle, Rhew, \& Hawkins, 2014; Steinberg, 2004) and adults (Brown, Gauze, \& Nothern, 2016; King, Nguyen, Kosterman, Baily, \& Hawkins, 2012; Ellickson, McCaffery, \& Klein, 2009). Significant relations between excessive alcohol consumption and risky sexual behaviors have been reported, with increased frequency of unprotected sex, sexual intercourse with multiple partners, sex with new partners, and inconsistent or lack of condom use (Lewis, Hutton, Agee, McCaul, \& Chander, 2015; 
Schneider, Cherish, Neuman, \& Parry, 2012), thereby increasing the risk of HIV infection (CDC, 2016; Scott-Sheldon et al., 2009; Cook et al., 2006).

The substances most commonly used in the Caribbean are alcohol, nicotine, marijuana, and crack cocaine (Reid, Malow, \& Rosenberg, 2012; Saint-Jean, Devieux, Mallow, Tammara \& Carney, 2011). Alcohol plays an important social and cultural role among Caribbean youths and adults (NIDA, 2017; King et al., 2012; Ellickson et al., 2009), with the legal drinking age of 18 years (Reid et al., 2012). Substance abuse, including alcohol use, perpetuates hazardous and harmful behaviors, contributing to injury, infectious diseases, and in cases even death (WHO, 2011).

Substance use and alcohol consumption are prevalent in the Caribbean, including Trinidad and Tobago (Reid et al., 2012; Reid, 2005). Data supports the notion that substance and alcohol use/abuse are directly associated with risky sexual behaviors and increased risk for exposure to STIs, including HIV infection (Reid et al., 2012; WHO, 2011). In Trinidad and Tobago, alcohol is more predominantly used than any other drugs during social settings (Baldeo, 2012; Reid et al., 2012) and consumed by both males and females.

Physiologically, females become more intoxicated than males when consuming the same amount of alcohol, putting women drinkers at a disadvantage (Baird et al., 20017), especially with implications for decreased sexual transactions that often occurs while intoxicated (Reid et al., 2012). Females are thereby more inclined to exhibit impaired judgment, increased sexual risk behaviors, and failure to negotiate safer sexual practices (Reid et al., 2012; Saint-Jean et al., 2011; Baird et al., 2007). Reid et al. (2012) reported a positive association between the use of alcohol and HIV infection. Alcohol 
consumption is associated with an increase in sexual desires and heightened sexual arousal, leading to impaired judgment and a decrease in condom use during sexual activities (Reid et al., 2012). Parks, Collins, and Darrick (2012) agreed that alcohol and drug use are associated with inconsistent condom use, thereby influencing safe sexual practices.

Alcohol use is associated with risky sexual behaviors, with an increased risk of contracting STIs, including HIV infection. A study was conducted by Ellickson et al. (2009) to assess school-based substance use prevention and its association with risky sexual behaviors among unmarried young adults who are sexually active. A sample of 1,901 participants was recruited (60\% females, $40 \%$ males). Findings from the study indicated that $71 \%$ of participants reported inconsistent or no condom use during sexual intercourse in the last year and 50\% reported having multiple concurrent sexual partners in the last year. Additionally, 32\% of participants reported engaging in risky sexual behaviors (i.e. unprotected sex), which was directly related to alcohol or other substance use/abuse (Ellickson et al., 2009).

In a study by Morrison-Beedy, Carey, Feng, and Tu (2008), a total of 102 participants were recruited to describe risky sexual behaviors (substance abuse, psychological distress) and identify predictors of vaginal intercourse without using protection. The sample consisted of unmarried, sexually active, heterosexual females, ages 18-21. Binge drinking (4 or more drinks) was reported by $70 \%$ of the population, marijuana use by $30 \%$, and opiates use by $12 \%$. Findings from the study suggested that there is a direct association between psychological stress, sexual risk behaviors, and substance abuse. The higher the psychological stress experienced, the more participants 
reported using substances, while implementing risky and unprotected vaginal intercourse. Among this population, reports of substance abuse, especially marijuana and alcohol, were high. Moreover, many of those participants were not of legal drinking age. Findings supported that there is a correlation between substance use/abuse and sexual risk behaviors (Morrison-Beedy et al., 2008).

\section{Summary of Chapter 2}

Findings from the literature review indicated that there are still myths and misconceptions regarding HIV infection almost four decades after the first reported case of the disease. Attitudes and perceptions of condom use and sexual risk behaviors are predictive measures in assessing actual risky sexual behavior and practices. Negative attitudes often lead to risky behaviors. Religious beliefs and cultural norms often make condom negotiation difficult, even dangerous, for women. Socioeconomic status (i.e. level of education, employment, income) has an impact on woman's ability to negotiate condom use, especially if the woman is dependent on a spouse/partner for support. Substance use, especially alcohol, in the Caribbean is strongly associated with HIV infection, by decreasing inhibition and increasing sexual risk behaviors.

Sexual behavior is a complex and private activity often influenced by personal, social, cultural, moral, and religious norms (Chanakira, O'Cathain, Goyder, \& Freeman, 2014; Fenton, Johnson, McManus, \& Erens, 2001). 


\section{CHAPTER III \\ METHODOLOGY}

\section{Research Design}

The methodological approach that was utilized for this study was a quantitative cross-sectional descriptive and correlational study. The quantitative research method emphasizes objective measurements utilizing statistical or numerical analysis of information gathered via surveys or questionnaire (Babbie, 2010), implementing the process of collecting, analyzing, and interpreting the information to better understand and explain a given phenomenon (Williams, 2007; Leedy \& Ormrod, 2001).

Descriptive statistics are used to describe characteristics and to examine variables for any violation of the assumptions (Pallant, 2016), attempting to determine whether the variables under investigation can predict and provide information on behaviors and attitudes of a given group (Salkind, 2008). Correlational study describes the strength and direction of the relationship between two variables, including similarities or differences between their means (Pallant, 2016). With correlation coefficients, emphases are placed on describing the relationship between variables rather that indicating the causation (Salkind, 2008).

Multiple regressions were also utilized in this dissertation study. Multiple regressions explores the relationship between one continuous dependent variable (i.e. attitudes about condom use and sexual risk behaviors) and several independent variables (HIV knowledge, attitudes, religious beliefs, level of education, substance use) (Pallant 2016; Salkind, 2008). 


\section{Sample}

The study was conducted in the southern part of Trinidad. Trinidad is one part of the twin islands "Trinidad and Tobago" in the Caribbean. There are an estimated 1.3 million individuals living in Trinidad and Tobago (Central Statistical Office, 2016). Adult women (i.e. 18 years and older) were selected as the sample participants for the study. A power analysis, using $\mathrm{G}^{*}$ Power, was conducted to determine the number of participants needed for this specific study. $G^{*}$ Power is a program used to determine appropriate effect size, and is frequently used in social, biomedical, and behavioral sciences (Faul, Erdfelder, Lang, \& Buchner, 2007). Results from the power analysis for multiple regressions determined a sample size of 74 participants was needed for this dissertation study. Additional participants were recruited to ensure adequate power was obtained for descriptive, correlational, and analysis of variance. Furthermore, to accommodate for any missing data, more participants were recruited. One hundred and thirty-two questionnaires were administered to Trinidadian women that met all the inclusion and exclusion criteria for this study. One hundred and twenty-seven questionnaires were completed and returned, while five participants left without completing the questionnaires. Of the 127 questionnaires that were returned, 113 were selected to be part of the study, while 14 were not included due to missing data.

It is neither practical nor feasible to study the whole population; hence an adequate and accurate sample size is imperative in obtaining statistical significance (Faul et al., 2007). Therefore, a smaller number of individuals are selected from the general population to represent the larger populace, with the smaller number of individuals known as the "sample" (Kadam \& Bhalerao, 2010). The sample size of any research 
study is dependent on an acceptable level of significance, power of the study, and effect size (Kadam \& Bhalerao, 2010; Faul et al., 2007). The level of significance or alpha is measured by the p-value which is typically set at 0.05 . Alpha is the probability of finding significance where there is none, getting a false positive, this is known as a Type I error. With an alpha set at 0.05 there is a $5 \%$ chance of committing a Type I error, and erroneously reporting a significant effect (Polit \& Beck, 2012; Kadam \& Bhalerao, 2010).

The power to determine statistical significance in a given test is defined as the probability of failing to detect a difference when there is actually a difference (Kadam \& Bhalerao, 2010), this is known as a Type II error, with the likelihood of rejecting a false null hypothesis, and getting a false negative (Polit \& Beck, 2012). Conversely, Type II error is the probability of reporting no significant finding when there is actually significant finding(s) (Kadam \& Bhalerao, 2010). A power is typically set at 0.80 thereby accepting that one in five times a real difference may be missed (Polit \& Beck, 2012; Kadam \& Bhalerao, 2010). The higher the power, the less likely a real difference will be missed, (Polit \& Beck, 2012; Kadam et al., 2010). For purposes of this study, the power was set at 0.95 , therefore promoting a lesser chance of getting and reporting a false negative. Trochim (2006) agreed that in social research, statistical power should be greater than 0.80 in value.

Effect size is the magnitude of the differences between two groups, with emphasis on the size of the difference (Coe, 2002), without taking into account the variability of the scores (Sullivan \& Feinn, 2012). Cohen (1988) posit that an effect size measures the strength of the relationship between variables in a given population and are classified as 
small (0.2), medium (0.5), and large (0.8). A medium effect size was implemented for this dissertation study.

\section{Setting}

Participants were recruited in Trinidad. A letter of access and support was obtained from the manager of a large supermarket located in the southern region of Trinidad, prior to conducting the study. The manager gave permission to recruit participants from patrons who were frequenting the business establishment. Potential participants were approached as they were entering or exiting the supermarket. Recruitment also took place in some public areas (recreation parks), as well as people participating in group activities (community environmental meetings and educational workshops). The women approached were asked if they would be interested in participating in a research study about HIV/AIDS. A majority of the women approached about the study agreed to participate. However, some women stated they were too busy, while a few were not interested in taking the survey. Only a few women stated that their husbands would not approve of them participating in a study that assessed such private and personal details of their lives, regardless that measure were taken to ensure anonymity and confidentiality of individuals participating in the study. No coercion was used with these women; they were just thanked for their time and wished a good day.

Women who showed interest in participating were given a cover letter to read regarding the research study, upon which they gave verbal consent to be a part of the study (see Appendix D). Some women briefly glanced over the cover letter and then asked the researcher for a verbal description of the study. An overview of the study was 
provided for those women. Verbal informed consent was required from participants before they were given a questionnaire packet to complete.

\section{Selection of Participants}

Convenience sampling techniques were utilized in the recruit of participants for this study. Convenience sampling is a nonprobability or nonrandom selection of a subset of individuals to putatively represent a larger target population based on easy accessibility, willingness to participate, and in the right geographical proximity relevant to the nature of the research (Etikan, Musa, \& Alkassim, 2016; Dornyei, 2007).

Although convenience sampling is considered a somewhat weak sampling technique, it is also affordable, thereby also making it economically sound (Etikan et al., 2016).

\section{Inclusion criteria}

- Female

- 18 years and older

- Able to read, write and understand English

- Self-identified as heterosexual

- Born and raised in Trinidad and Tobago

\section{Exclusion criteria}

- Male

- Ages of less than 18 years

- Cognitive impairment

- Do not self-identify as heterosexual

- Immigrated to Trinidad and Tobago 


\section{Protection of Human Rights}

A request was submitted to the Institutional Review Board (IRB) at Florida International University (FIU) for the purpose of gathering data from human subjects for this dissertation study. Under the Florida International University's (FIU) research site, the IRB is a committee that was established to ensure the protection of human subjects in research and guided by federal regulations, with the purpose of protecting the rights and welfare of human participants in research. IRB approval was obtained from FIU on June, $16^{\text {th }}, 2017$. Shortly after obtaining IRB approval from FIU, recruitment and data collection were initiated among participants in Trinidad.

\section{Potential Benefits}

For this study, there were no direct benefits to individual participants. However, brochures with information about HIV/AIDS prevention strategies, and local HIV testing sites were offered to both participants of the study and individuals who declined to participate in the study.

This study sought to examine the knowledge and attitudes about HIV infection, and sexual risk behaviors among Trinidadian women. Therefore, knowledge gained from the study has the potential to contribute to health education, research, policies, and practices that can be beneficial to nurses, physicians, and other healthcare providers. Data obtained can be used to provide HIV intervention in a culturally sensitive and genderrelevant manner.

Participants were not paid to participate in the study. However, small tokens of appreciation were given to participants. Upon completion and return of the questionnaires, participants were given a lip-gloss and a costume jewelry bracelet. 
Participants were able to choose from an assortment of colors for the lip-gloss and different designs, patterns, and colors of the bracelet. The small tokens per participant were worth $\$ 5.00$ (U. S. dollars).

\section{Potential Risk and/or Discomfort}

This study was determined to pose no greater than minimal risk or discomfort to participants. Each participant was verbally informed about the nature of the study, and emphasis was placed on confidentiality and anonymity of the data collected. Participants were asked to refrain from including any personal identifiers (i.e. name, home address, email address, phone number); moreover, each envelope containing questionnaires was unmarked. Upon completion of the questionnaires, participants were asked to seal the envelopes and drop them in an unmarked box. Each participant was informed that participation was strictly voluntary and she could withdraw from the study at any time. Each participant gave verbal consent before being given a packet to complete. Participants were asked to read each question carefully and answer each question honestly and completely.

Some questions included in the questionnaire could be embarrassing or upsetting to participants; therefore, participants were informed that they could withdraw from participating at any time, even if they had already started filling out the survey. None of the participants expressed discomfort or concern about completing the questionnaire, however, five participant left before completing the questionnaires, stating they had to leave for personal reasons. Additionally, participants were offered brochures with information about HIV/AIDS, as well as locations of local HIV testing sites. Data collection took place over a two-month period in 2017. 


\section{Informed Consent}

Recruitment of participants was conducted at a local business establishment in Trinidad, local recreation park, at community environmental workshops, and educational meetings. Participants were approached and asked if they would be interested in participating in a study about HIV/AIDS. Potential participants were given a cover letter to read, which detailed the nature of the study. Participants who agreed to take the survey, had to verbally say "yes", and were then given the questionnaires to complete. A booth was set up for the study outside the business establishment, and at the other places where participants were recruited. Participants who said "no" to the study were not given the questionnaires to complete, however were offered brochures with information about HIV prevention strategies, as well as locations of HIV testing sites. Participants were informed that they could stop taking the survey at any time before or after starting without any consequences.

\section{Confidentiality and Privacy}

The booth that was set up at the supermarket was strategically placed to the side of the main entrance to ensure visibility. To ensure privacy, each participant was provided with a chair and an individual clipboard to complete the survey. The surveys were self-administered with the researcher being present to answer any possible questions. Upon completion, each participant placed the survey in the provided envelope, and dropped the sealed envelope in the enclosed and secure box. Additionally, participants were asked to not disclose extremely sensitive, private information (i.e. HIV status). Each participant was verbally informed about the nature of the study, and emphasis was placed on confidentiality and anonymity of the data collected. 
After each day of data collection, the sealed envelopes were removed from the enclosed box and placed in a file cabinet in the locked bedroom of the researcher in the researcher's home in Trinidad and Tobago. Additionally, only the researcher had access to her private bedroom. After all the necessary data were collected, the researcher then personally transferred the data from Trinidad and Tobago in her carry-on luggage to ensure security, and minimize the risks of data loss. Upon arriving back to Florida, the researcher placed all the data collected from Trinidad in a locked cabinet in her home office. The researcher did not utilize any electronic form of data collection and storage while in Trinidad and Tobago.

\section{Instrumentation}

\section{Reliability and Validity of an Instrument}

Assessment instruments must be both reliable and valid to ensure the credibility of research findings. Therefore, it is imperative that instruments being used for gathering data be tested for reliability and validity to uphold the integrity of study outcomes (Sullivan, 2011; Cook \& Beckman, 2006).

Reliability is used to describe the overall consistency of a measure instrument (Salkind, 2008). A measure has a high reliability if it produces similar results under consistent condition over time (Salkind, 2008) using the same setting and the same type of subjects (Sullivan, 2011).

The most commonly used indicator of internal consistency is the Cronbach's alpha (Salkind, 2008). The Cronbach's alpha is found in the Reliability Statistics table. Values of $\geq .7$ are considered acceptable, with values $\geq .8$ being preferable. 
Validity is the extent to which a test measures what it is supposed to measure. It is essential for a test to be valid in order for the results to be accurately interpreted and applied (Salkind 2008) . For outcome measures, including questionnaires and surveys, validity refers to the "accuracy" of the measurement (Sullivan, 2011). The validation of a scale involves the collection of empirical data concerning its use (Salkind 2008). There are three different types of validity, these are content validity, criterion validity, and construct validity. Content validity is used to determine if a sample of items truly reflects all items in a certain topic; criterion validity is used to determine if test scores are systematically related to other criteria that the test taker is competent in a certain area; and construct validity is used to determine if a test measures some underlying psychological construct (Salkind 2008).

\section{HIV Knowledge Questionnaire (HIV-KQ)}

Knowledge is a key element in successfully implementing risk reduction programs. Knowledge assessment is used by researchers and scientists to guide educational interventions and to provide recommendations to enhance sexual risk awareness (Carey, \& Schroder, 2002; Carey \& Lewis, 1999). Therefore, it is imperative that interventionists, practitioners, and research scientists have a reliable, valid and feasible instrument to assess HIV knowledge (Carey \& Schroder, 2002).

The HIV Knowledge Questionnaire (HIV-KQ) was originally developed and used as an evaluation tool among adults in a diverse community (Carey, Morrison-Beedy, \& Johnson, 1997). The HIV-KQ is a self-administer instrument that was developed using item analysis, factor analysis, and scale construction which resulted in an initial 45-item questionnaire that assessed HIV-related knowledge (Volpe, Nelson, Kraus, \& Morrison- 
Beedy, 2007; Carey et al., 1997). The HIV-KQ was reported to be both reliable and valid. Reliability and validity testing were conducted and determined to have internal consistency; with Cronbach's alpha of 0.91, that was stable over time (Volpe et al., 2007; Morrison-Beedy, 2003; Carey et al., 1997).

Although the HIV-KQ was found to be reliable and valid, the questions spanned a broad range of HIV-related information and were extensive, causing concerns about possible participant burden. Subsequently, the original 45-item HIV-KQ was revised and adapted into a brief 18 -item version (Carey \& Schroder, 2002). The modified 18-item HIV-KQ (HIV-KQ-18) was created by selecting a smaller set of items from the original questionnaire, thereby continuing to represent the equivalent domain of interest (Carey \& Schroder, 2002). The 18-item version of the questionnaire was evaluated and determined to possess strong and stable item association and internal consistency, with Cronbach's alpha of 0.75-0.89. The psychometric analysis of the HIV-KQ-18 indicated strong levels of internal consistencies and test-retest reliabilities. All items are scored on a three-point scale (i.e. true, false, or I don't know [DK]).

The HIV-KQ was created and evaluated to assess HIV-related knowledge in heterosexual adults of both gender (Carey \& Lewis, 1999). It has also been used in studies to assess HIV-related knowledge in adolescent girls (Volpe et al., 2007; Morrison-Beedy, Carey, \& Aronowitz, 2003), college students (Adefuye, Abiona, Balogun, \& Lukobo-Durrell, 2009), and heterosexual and homosexual college students (Eisenberg, 2001). 


\section{Condom Attitude Scale (CAS)}

The CAS (Sacco, Levine, Reed, \& Thompson, 1991) is an instrument that is used to measures attitudes about condom use in HIV-relevant behaviors. The CAS measures feelings, biases, ideas, and convictions about an individual's ability to control impulse and perceived risks of contracting HIV/AIDS during sexual intercourse (Banaj \& Heiphetz, 2010).

The original CAS has eight factors (subscales) with a total of 57-items with a testretest correlation of 0.86 , and an 8 -factor solution was found accounting for $85 \%$ of the variance. Two studies were conducted to investigate the reliability and validity of the subscales and the total scale. The Cronbach's alphas for both studies were between 0.75 and 0.92, yielding acceptable internal consistency. The eight factors that made up the CAS were interpersonal impact (11 items), effects on sexual experience (10 items), selfcontrol (9 items), global attitude (9 items), perceived risk (6 items), inhibition (4 items), promiscuity (3 items), and relationship safety (5 items). Attitudes about condom use were assessed using three factors with a total of 15-items: perceived risk (6 items), inhibition (4 items), and relationship safety (5 items). The responses to each item had a 5-point Likert scale i.e. (0) strongly disagree, (1) somewhat disagree, (2) neither agree nor disagree, (3) somewhat agree, and (4) strongly agree. The test-retest correlation for the CAS subscale (Sacco et al., 1991) ranged from 0.49 to 0.85 . The higher the score on the CAS, the more positive the participant's attitude is toward condom use during sexual intercourse.

The CAS was developed through research conducted among heterosexual college students (Helweg-Larsen \& Collins, 1994). Several instruments were reviewed as 
potential tools to measure condom attitudes (Asante \& Doku, 2010; Lam \& Barnhart, 2006; Helweg-Larsen \& Collins, 1994), however the CAS was deemed the best fit for this study based on demographic considerations (Avants, Warburton, Hawkins, \& Margolin, 2000), after a comprehensive review of the CAS subscales.

\section{Safe Sex Behavior Questionnaire (SSBQ)}

The Safe Sex Behavior Questionnaire (SSBQ) was used to measure safe sex behaviors among Trinidadian women. The SSBQ was constructed for the use with college students to investigate dimensions of safer sex. Initially the questionnaire consisted of 35 items and then reduced to 27 items. The 27-item Likert scale was designed to measure frequency of safe sex practices and behaviors, and its impact on reducing the risk of HIV/AIDS transmission and exposure (DiIorio, Parsons, Lehr, Adame, \& Carlone, 1992).

The SSBQ was assessed through a series of tests; the findings indicated that it had content validity, reliability, and construct validity. Three items were dropped to form a 24-item questionnaire. The 24-item scale possesses strong internal consistency with Cronbach's alpha of 0.815 (DiIorio et al., 1992). Each item is rated on a 4-point scale ranging from 1 (never) to 4 (always) and interval levels of measurement. The 24 -item SSBQ questionnaire consists of 15 positively worded items (e.g. "I avoid direct contact with my sexual partner's semen") and 9 negatively worded items (e.g. "It is difficult for me to discuss sexual issues with my sexual partner(s)"). Subsequently, reverse coding was utilized for the negative worded items, whereupon responses were added to obtain a total score. The added scores for the 24 -item scale ranged from 24 to 96 . The higher the scores on the scale, the greater frequency of safer sex are practiced. The SSBQ is divided 
into five subscales, i.e., risky behaviors, assertiveness, condom use, avoidance of bodily fluids, and avoidance of anal sex (DiIorio et al., 1992).

The SSBQ was used to measure correlations between self-efficacy and the implementation of condom use among 1,349 college students of both genders. The reported findings posit that the more confident an individual felt about discussing condom use the easier it was to negotiate the use of condoms during sexual intercourse. Thereby, indicating a link between self-efficacy and safer-sex communication (DiIorio, Dudley, Lehr, \& Soet, 2000). This finding supported and validated those of BasenEngquist (1992) whose findings indicated that greater self-efficacy begets greater intention to discuss and implement safer sex practices with sexual partners.

\section{Demographic Questionnaire}

A demographic questionnaire was developed to collect descriptive data and sociodemographic characteristics. A 26-item demographic questionnaire was developed by the researcher. The questionnaire encompassed both categorical (nominal, ordinal, dichotomous) and continuous (interval, ratio) data, as well as select open-ended questions. This study integrated select demographic factors into the research questions and hypotheses as predictor variables.

The first item on the demographic questionnaire was an open-ended question "What is your current age?" and measured in years. The next five items asked about relationships, with the second item "What is your current relationship status?" which implemented a nominal approach, with $(1=$ single, $2=$ married, $3=$ separated, $4=$ divorced, $5=$ widowed $)$. The third item measured monogamy in a dichotomous level $(1$ $=y e s, 2=n o, 3=N / A$ not in a relationship). Item number four was an open-ended 
question "How long are you in your relationship (if applicable)?" measured in years. Item number five was an open-ended question "How old were you when you had your first sexual experience?" measured in years. Item number six was an open-ended question "What is the total number of sexual partners you had in your lifetime?" measured in years. Items number seven and eight were dichotomous questions "Have you been tested for HIV?" and "Have you been tested for any sexually transmitted diseases?" with $(1=y e s, 2=n o)$. Item number nine was designed to reaffirmed sexual orientation "What is your sexual orientation?" since being heterosexual was an inclusion criteria for participating in this study. This item proved to be appropriate and necessary because one of the participants checked the "bisexual" option and was excluded from the study.

Item number ten was measured as an ordinal variable that measured the level of education participants completed "What is your highest level of education?" with $(1=$ less than high school, $2=$ completed high school, $3=$ technical (trade) school, $4=$ associate degree, $5=$ bachelor degree, $6=$ graduate degree [Masters or Doctoral]). Item number eleven was a dichotomous question "Are you currently employed?" with (1 $=y e s, 2=n o)$. Item number twelve was to assess annual income, and was measured categorically in Trinidad and Tobago currency, with the question "What is your yearly income? [Answer in Trinidad dollars]", the options provided were $(1=$ less than $\$ 25,000 ; 2=\$ 25,001$ to $\$ 50,000 ; 3=\$ 50,001$ to $\$ 75,000 ; 4=\$ 75,001$ to $\$ 100,000 ; 5$ $=\$ 100,001$ to $\$ 125,000 ; 6=\$ 125,001$ to $\$ 150,000 ; 7=$ greater than $\$ 150,000,8=$ prefer not to answer). For item number twelve, the option "prefer not to answer" was 
given as an alternative in the event that participants did not feel comfortable disclosing their income.

Item number thirteen used nominal categories to determine race "What is your race?" with $(1=$ East Indian, $2=$ African, $3=$ Caucasian, $4=$ Chinese, $5=$ Hispanic, 6 $=$ mixed race, 7 = other: please specify). Item number fourteen "What is your religion?" was measured as a nominal variable $(1=$ Roman Catholic, $2=H i n d u, 3=$ Muslim, $4=$ Baptist, 5 = Methodist, $6=$ Presbyterian, 7 = Jehovah's Witness, $8=$ other Christian: please specify, 9 = other non-Christian: please specify), with alternative options in the event that participants religious affiliation was not listed. Item number fifteen "Would you consider yourself religious?" was measured using a nominal variable $(1=$ very religious, 2 = somewhat religious, $3=$ not religious $)$. Item number sixteen measured attendance at place of worship "How often do you attend religious services?” using nominal measurement $(1=$ two or more times per week, $2=$ once per week, $3=$ two times per month, $4=$ once per month, $5=$ only on special occasions, $6=$ not at all). Item number seventeen "If you do something bad, do you think God will punish you?" implemented a dichotomous measurement, with $(1=y e s, 2=n o)$. Item number eighteen "How strongly do your religious beliefs influence your daily life?" was measured using a nominal variable $(1=$ very $m u c h, 2=$ somewhat, $3=$ not at all $)$.

Items number nineteen to twenty-one asked about drug use. Item number nineteen "Do you use any type of drugs?" with options ( $1=$ yes, $2=$ no, $3=$ sometimes $)$. Item number twenty was an open-ended question to determine what type of drugs participants used, "If you do use drugs: what type do you use? Please specify". Item number twenty-one was to determine the frequency of participants drug use "If you do 
use drugs: how often do you use? Please specify" which was measured as an open-ended question.

Item number twenty-two "Do you drink alcoholic beverages?" implemented a dichotomous measurement $(1=$ yes, $2=n o)$. Item number twenty-three implemented a select all that applies approach to determine the types of alcoholic beverages participants consumed, with the question "If you drink alcohol: what type is it? (select all that applies", with the options $(1=$ beer, 2 = wine, $3=$ rum, $4=$ vodka, $5=$ scotch whiskey, 6 = cocktails, 7 = other [please specify]). Item number twenty-four "If you drink alcohol: how much and how often do you drink? (Choose one answer)" used a nominal measurement with the options $(1=$ more than 3 alcoholic drinks per day, $2=1-2$ alcoholic drinks per day, $3=$ more than 3 alcoholic drinks per week, $4=1-2$ alcoholic drinks per week, 5 = only on special occasions [family meetings, weddings, farewells]). Item number twenty-five "Do you smoke cigarettes?" implemented a dichotomous measurement, with the options $(1=$ yes, $2=n o)$. Item number twenty-six "Does smoking cigarettes make you want to drink more alcohol?" with the options $(1=$ yes, $2=$ no, 3 = not applicable [does not smoke cigarettes]), was the final item on the demographic questionnaire.

\section{Data Analysis}

Upon completion of data collection from Trinidadian women, the information gathered was analyzed using statistical analysis software package (SPSS) version 22. SPSS is a computer software program, developed in 1968, and it is used by professionals in business, academia, and research. The software provides a range of statistical techniques that allow the researcher to manage data, perform a variety of different 
analysis, and disseminate results (IBM, 2012). SPSS software has been widely used in research studies. Ouzouni and Nakakis (2012) utilized the SPSS software (Version 17) to analyze the data collected in a study to examine and explore behaviors, knowledge, and attitudes about HIV/AIDS among 279 nursing students in Greece. The researchers employed descriptive and inferential statistical analysis for the study (Ouziuni \& Nakakis, 2012). Rairikar and Bhandari (2016) used SPSS (Version 20) to perform t-test analysis on data gathered to examine knowledge and attitude of paramedical staff and hospital support staff towards HIV infection.

\section{Summary of Chapter 3}

This dissertation study focused on acquiring data regarding HIV knowledge, attitudes, and sexual risk behaviors among Trinidadian women. The study took place in Trinidad, with a target population of adult (minimum 18 years) women. Recruitment took place over a two-month period in 2017. Data were gathered using the HIV-KQ-18, CAS, SSBQ, and a demographic questionnaire. Precautions were taken to ensure the privacy of the participants.

Data were analyzed using statistical analysis software package (SPSS) version 22. Descriptive and Frequencies, Pearson product-moment correlation coefficient $(r)$, oneway between groups ANOVA, and Multiple Regression analyses were implemented to assess HIV knowledge, attitudes about condom use, religious beliefs, level of education, and substance use among Trinidadian women. 


\section{CHAPTER IV}

\section{RESULTS}

The purpose of this study was to examine and evaluate the knowledge, attitudes, and sexual risk behaviors of Caribbean women, who are currently living in Trinidad, regarding HIV awareness and their current lifestyle choices and behaviors. Identifying knowledge, attitudes, and sexual risk behaviors among this population will provide new information that can be used to recognize and implement prevention strategies in a culturally sensitive and gender-relevant manner.

This study was guided by the Theory of Planned Behavior to explain and predict sexual risk behaviors, including subjective norms and attitudes, and how this may influence condom use (Fisher \& Fisher, 2000) among Trinidadian women. A descriptive, correlational design was utilized to for the study. Descriptive and correlational statistics were used to assess and understand the impact of factors (i.e. HIV knowledge, attitudes about condom use, religious beliefs, level of education, substance use) associated with sexual behaviors among Trinidadian women. One-way between-groups ANOVA were used to explore the impact of age and race/ethnicity on HIV knowledge. Multiple regressions were used to explore the relationship between one continuous dependent variable (i.e. sexual risk behavior) and several independent variables (i.e. HIV knowledge, attitudes about condom use, religious beliefs, level of education, substance use).

Data were collected from Trinidadian women, ages 18 years and older, living in the Southern region of Trinidad. Data were collected over a two-month period, using a non-probability convenience sample technique. Recruitment also took place in a large 
supermarket, public areas (recreation parks), as well as individuals participating in group activities (environmental community meetings and workshops). After receiving verbal consent participants were given a self-administered questionnaire that consisted of three standardized instruments (i.e. HIV-KQ, CAS, SSBQ, and a demographic questionnaire). The questionnaire consisted of 83 items (HIV-KQ - 18 items, CAS - 15 items, SSBQ 24 items, and demographic questionnaire -23 items). The 23 - item demographic questionnaire was developed by the researcher and used to obtain descriptive information and characteristics from participants. Data were analyzed using Statistical Package for Social Sciences (SPSS) Version 22.

\section{Description of the Sample}

Through the use of convenience sampling techniques, a total of 132 questionnaires were administered to Trinidadian women, ages 18 years and older. Five of the participants had to leave before fully completing the questionnaire and left without returning the incomplete questionnaires. Therefore, a total of 127 questionnaires were completed and returned. Of the 127 questionnaires that were returned, 113 questionnaires were completed without any missing data, 13 questionnaires had between $5 \%$ and $20 \%$ missing data, and in one questionnaire the participant responded that she engaged in bisexual relationships. Only the fully completed questionnaires $(n=113)$ were used in this study, giving the survey a response rate of $85.6 \%$. Based on the $\mathrm{G}^{*}$ Power analysis conducted to determine sample size, a total of 113 participants was an adequate and appropriate sample size for the purpose of this study. Additionally, the 113 questionnaires used in this study met all of the inclusion and exclusion criteria discussed in Chapter III. 


\section{Demographic Characteristics of the Sample}

The sample size comprised of 113 participants in this study. All participants ( $n$ $=113 ; 100 \%)$ reported their age. The average age of participants was $35.52(S D=10.69)$, and ranged from 18 to 58 years old. The largest number of participants $(n=9,8 \%)$ was 40 years old and

( $n=7,6.2 \%)$ was 24 years old, with $(n=57,50.4 \%)$ being 37 years and older.

See Table 1 and Figure 1 for the descriptive statistics of age.

Table 1. Age of Participants $(N=113)$

\begin{tabular}{|c|c|c|c|c|}
\hline \multirow[t]{2}{*}{ Range } & \multicolumn{2}{|c|}{$\mathrm{M}$} & $\mathrm{SD}$ & Median \\
\hline & $18-58$ years & 35.52 & 10.69 & 37.00 \\
\hline
\end{tabular}


Figure 1. Histogram of the Age of Participants $(N=113)$

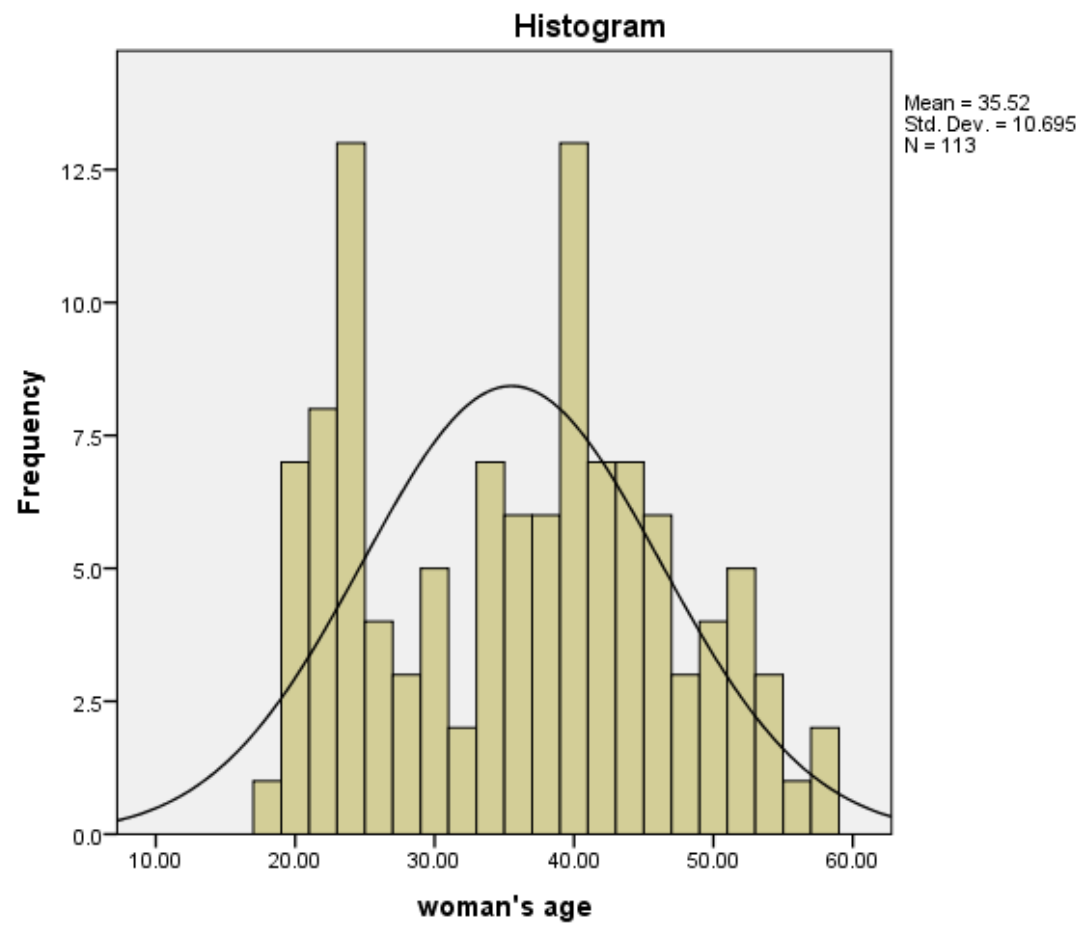

Relationship status was measured as single, in a relationship but not legally married (common-law), married, separated, divorced, and widowed. James (2012) reported in the Trinidad and Tobago Guardian that in Trinidad and Tobago, common law relationships are when two people from the opposite sex live together without legally getting married; however they have the same rights as married couples after five years of cohabitation or by sharing children together. Majority of participants were married $(n=$ $62,54.9 \%)$, with $(n=32,28.3 \%)$ in common law relationships, and $(n=16,14.2 \%)$ were single. Ninety one participants (80.5\%) reported being monogamous in their relationship, while $9(8 \%)$ reported not being faithful to their spouses/partners, and $13(11.5 \%)$ were currently not in a relationship. The average length of time participants were in their 
current relationship was $11.90(S D=10.54)$ years, and ranged from less than one year to as long as 42 years.

The mean for how long participants were in their current relationships was 11.90 $(S D=10.54)$ with a range of 42 years. Minimum length of relationship was one year; with the maximum length of relationship being 42 years. Thirteen (11.5\%) participants were not in a relationship. Thirty three $(29.2 \%)$ participants were in their current relationship between 1 and 5 years; $15(12.4 \%)$ between 6 and 10 years, $16(14.2 \%)$ between 11 and 15 years; $9(9.3 \%)$ between 16 and 20 years; and 28 (24.8\%) were in their current relationship for more than 20 years.

The mean average for how old participants were when they had their first sexual experience was $18.47(S D=2.98)$ years, and ranged from as young as 13 to as old as 30 years, with the largest number of participants $(n=24,21.2 \%)$ at 18 years old. The average total number of sexual partners was $3.69(S D=3.32)$ ranging from a minimum of one partner to a maximum of 18 sexual partners. A majority of participants $(n=35$, $31 \%)$ had only one lifetime sexual partner, with $(n=20,17.7 \%)$ had two lifetime sexual partners, $(n=13,11.5 \%)$ had three lifetime sexual partners, $(n=15,13.3 \%)$ had four lifetime sexual partners, $(n=26,23 \%)$ had between 5 and 10 lifetime sexual partners, and $(n=4,3.5 \%)$ had between 11 and 18 lifetime sexual partners.

Fifty nine $(52.2 \%)$ participants reported being tested for HIV infection, while 44 $(47.8 \%)$ reported never getting tested. Fifty seven (50.4\%) participants reported being tested for sexually transmitted infections, while 56 (49.6\%) reported never getting tested. See Table 2 for descriptive statistics of relationship characteristics. 
Table 2. Relationship Characteristics $(N=113)$

\section{Characteristics}

Relationship Status

Single

Common law (in a relationship: not legally married)

Married

Separated

Divorced

Widowed

Monogamy

Monogamous

91

9

13

NA (not in a relationship currently)

Not monogamous $n$

$\%$

16

32

62

1

1

1

14.2

28.3

54.9

9

.9

.9

80.5

3

8.0

11.5

Length of current relationship (years)

$$
\begin{aligned}
& 1-5 \\
& 6-10 \\
& 11-15 \\
& 16-20
\end{aligned}
$$

14

16

9

28

29.2

12.4

14.2

More than 20

9.3

24.8

Age of first sexual experience (years)

Thirteen (13)

3

2.7

Fourteen (14)

2

1.8

Fifteen (15)

4

3.5

Sixteen (16)

19

16.8

Seventeen (17)

17

15.0

Eighteen (18) 


\begin{tabular}{lll}
\hline Nineteen (19) & 12 & 10.6 \\
Twenty (20) & 12 & 10.6 \\
Twenty-one (21) & 6 & 5.3 \\
Twenty-two (22) & 3 & 2.7 \\
Twenty-three (23) & 6 & 5.3 \\
Twenty-five (25) & 1 & .9 \\
Twenty-seven (27) & 2 & 1.8 \\
Twenty-nine (29) & 1 & .9 \\
Thirty (30) & 1 & .9
\end{tabular}

Total number of lifetime sexual partners

$\begin{array}{lll}\text { One (1) } & 35 & 31.0 \\ \text { Two (2) } & 20 & 17.7 \\ \text { Three (3) } & 13 & 11.5 \\ \text { Four (4) } & 15 & 13.3 \\ \text { Five (5) } & 6 & 5.3 \\ \text { Six (6) } & 7 & 6.2 \\ \text { Seven (7) } & 3 & 2.7 \\ \text { Eight (8) } & 2 & 1.8 \\ \text { Nine (9) } & 4 & 3.5 \\ \text { Ten (10) } & 4 & 3.5 \\ \text { Eleven (11) } & 4 & .9 \\ \text { Twelve (12) } & 1 & .9 \\ \text { Eighteen (18) } & 1 & 1.8\end{array}$

Tested for HIV infection

$\begin{array}{lll}\text { Yes } & 59 & 52.2 \\ \text { No } & 54 & 47.8\end{array}$

Tested for Sexually Transmitted Infection

\begin{tabular}{lll} 
Yes & 57 & 50.4 \\
\hline
\end{tabular}


Socioeconomic status was measured by level of education, employment status, and income. Level of education was broken down into different categories, i.e. less than high school, completed high school, technical (trade school), associate degree, bachelor degree, or graduate degree. Majority of the participants $(n=49 ; 43.4 \%)$ reported having completed high school, with the second largest percentage $(n=35,31 \%)$ earning a bachelor degree. Majority of the participants were currently employed $(n=91 ; 80.5 \%)$, while the number of participants that were unemployed was much lower $(n=22 ; 19.5 \%)$.

Yearly income was measured in Trinidad and Tobago currency, which is also called dollars. The current exchange of U.S. $\$ 1.00$ is equal to Trinidad and Tobago $\$ 6.76$. The majority of participants $(n=30 ; 26.5 \%)$ earned less than $\$ 25,000$. Nineteen (16.8\%) earned between $\$ 25,001$ and $\$ 50,000 ; 17$ (15\%) earned between $\$ 50,001$ and $\$ 75,000 ; 2(1.8 \%)$ earned between $\$ 75,001$ and $\$ 100,000 ; 6(5.3 \%)$ earned between $\$ 100,001$ and $\$ 125,000 ; 10(8.8 \%)$ earned between $\$ 125,001$ and $\$ 150,000$; and $4(3.5 \%)$ earned greater than $\$ 150,000$ on a yearly basis. Twenty five $(22.1 \%)$ participants were either unemployed or preferred not to disclose their yearly income. There was an option to select "prefer not to answer" in the event participants did not want to disclose their yearly income. See Table 3 for descriptive statistics of socioeconomic status. 
Table 3. Socioeconomic status $(N=113)$

\section{Characteristics}

Highest Level of Education

Less than high school

Completed high school

Technical (Trade) school

Associate Degree

Bachelor Degree

Graduate Degree $n$

$\%$

6

5.3

49

43.4

10

8.8

7

6.2

35

31.0

6

5.3

Employment Status

Employed

91

80.5

Not employed

19.5

Yearly Income (Trinidad and Tobago Dollars)

$<\$ 25,000$

$\$ 25,001-\$ 50,000$

19

16.8

$\$ 50,001-\$ 75,000$

17

15.0

$\$ 75,001-\$ 100,000$

2

1.8

$\$ 100,001-\$ 125,000$

6

5.3

$\$ 125,001-\$ 150,000$

10

8.8

$>\$ 150,000$

4

25

No income or prefer not to answer

22.1

Among the participants, the majority $(n=70 ; 61.9 \%)$ were of East Indian descent; $(n=12,10.6 \%)$ were from African descent; and $(n=31 ; 27.5 \%)$ were of mixed race. For this study, participants were not asked to disclose or include their mixed racial heritage. 
One participant $(.9 \%)$ reported not being in a religion (no religion). Sixty (64.6\%) were Christians, while 39 (34.5\%) reported being Hindu, and 6 (5.3\%) were Muslims. Christianity was broken down into different denominations, i.e. Roman Catholic, 15 (13.3\%); Baptist, 10 (8.8\%); Presbyterian 14 (12.4\%); Jehovah's Witness, 1 (.9\%); and other Christians, 27 (23.9\%).

Thirty one (27.4\%) reported being very religious, with $72(63.7 \%)$ being somewhat religious, and $10(8.8 \%)$ reported not being religious. Participants were asked about the frequency of attending religious services. Seventeen (15.0\%) attended services two or more times per week, $32(28.3 \%)$ attended once per week, $12(10.6 \%)$ attended at least twice per month, $14(12.4 \%)$ attended once per month, $33(29.2 \%)$ attended only on special occasions, and 5 (4.4\%) did not attend religious services at all. Eighty-eight (77.9\%) participants believed that if they did something bad that God would punish them for it, while 25 (22.1\%) did not believe that God would punish them if they did something bad. When asked about how strongly religious beliefs affect their daily lives, $70(61.9 \%)$ participants reported that they affect them very much, $40(35.4 \%)$ reported somewhat, and $3(2.7 \%)$ reported that religious beliefs do not influence their daily life at all.

See Table 4 for descriptive statistics of race and religious beliefs.

Table 4. Race and Religious Beliefs $(N=113)$

Characteristics

Race

East Indians

Africans

Mixed Race $n$

$\%$

70

12

31
61.9

10.6

27.5 
Religion

Not religious

Roman Catholic

Hindu

Muslims

Baptist

Presbyterians

Jehovah's Witness

Other Christians
.9

13.3

34.5

5.3

8.8

12.4

.9

23.9

27

27.4

72

63.7

Somewhat religious

31

Not religious

10

8.8

Attends Religious Services

Two or more times per week

17

15.0

Once per week

32

28.3

Two per month

12

10.6

Once per month

14

12.4

Special occasions

33

29.2

Not at all

If you do something bad, will God punish you?

Yes

No

25

How strong do religious beliefs influence daily life?

Very much

61.9

Somewhat

40 
When asked about drug use, $100 \%(n=113)$ of participants reported not using any type of illicit drugs. Eighty-four (74.3\%) participants reported drinking alcoholic beverages, while 29 (25.7\%) reported that they do not consume alcoholic beverages. Twelve (10.6\%) participants reported that they drank beer, 9 (8.0\%) drank wine, $6(5.3 \%)$ drank rum, 3 (2.7\%) drank whiskey, 2 (1.8\%) drank cocktails, 1 (.9\%) drank vodka, and majority of the participants, $52(46.0 \%)$ drank two or more types of alcoholic beverages. Twenty eight (24.8\%) did not partake of alcoholic beverages.

When asked about how much and how often participants consumed alcoholic beverages, the majority, $70(61.9 \%)$ reported that they drank on special occasions, 10 (8.8\%) consumed one to two alcoholic drinks per week, 2 (1.8\%) consumed more than three alcoholic drinks per week, $2(1.8 \%)$ consumed one to two drinks per day, and 1 (.9\%) reported consuming more than three drinks per day. When asked about cigarette use, $1(.9 \%)$ participant reported being a smoker, while the majority, $112(99.1 \%)$ reported that they did not smoke. See Table 5 for descriptive statistics of alcohol and cigarette use.

Table 5. Alcohol and Cigarette Use $(N=113)$

\section{Characteristics}

Consume Alcoholic Beverages

Yes

No $n$

$\%$
74.3

25.7 
Types of Alcohol

$\begin{array}{lll}\text { Beer } & 12 & 10.6 \\ \text { Wine } & 9 & 8.0 \\ \text { Rum } & 6 & 5.3 \\ \text { Vodka } & 1 & .9 \\ \text { Whiskey } & 3 & 2.7 \\ \text { Cocktails } & 2 & 1.8 \\ 2 \text { or more types of alcohol } & 52 & 46.0\end{array}$

Alcohol Frequency and Amount

More than 3 drinks/day $\quad 1 \quad 9$

$1-2$ drinks/day $\quad 2 \quad 1.8$

More than 3 drinks/week $\quad 2 \quad 1.8$

$1-2$ drinks/week $\quad 10 \quad 8.8$

$\begin{array}{lll}\text { On special occasions } & 70 & 61.9\end{array}$

\section{Exploratory Data Analysis}

Frequency distributions and histograms were run with normal distribution curve to determine outliers, skewness, kurtosis, and missing values for all subscales. Skewness and kurtosis are applications used to test for normality, in that distributions should be normal or near normal. Skewness measures the symmetry, or lack-thereof, of a distribution, while kurtosis describe the characteristics of the appearance of the distribution i.e. how flat or peaked the distribution appears in relation to a normal distribution. The skewness and kurtosis of normal or near normal distribution are zero; therefore, both of the constraints should be close to zero to equate a normal distribution. The distribution range should be between -2.0 and +2.0 (Salkind, 2008; Joanes \& Gill, 1998). 


\section{HIV Knowledge Questionnaire (HIV-KQ-18)}

The HIV-KQ-18 scores were totaled, with a possible range from 0 to 18 , with higher scores indicating greater knowledge about HIV transmission, diagnosis, and prevention (Carey \& Lewis, 1999). No items were deleted from the total summed score. The skewness of the distribution (-0.84) and the kurtosis of the distribution (0.85) fell between the range of -2.0 and +2.0 , indicating the variables in the HIV-KQ-18 for this study had a normal or near normal distribution. See Figure 2 for histogram with superimposed normal distribution curves for HIV knowledge among Trinidadian women.

Figure 2. Histogram of HIV-KQ-18 Total Score $(N=113)$

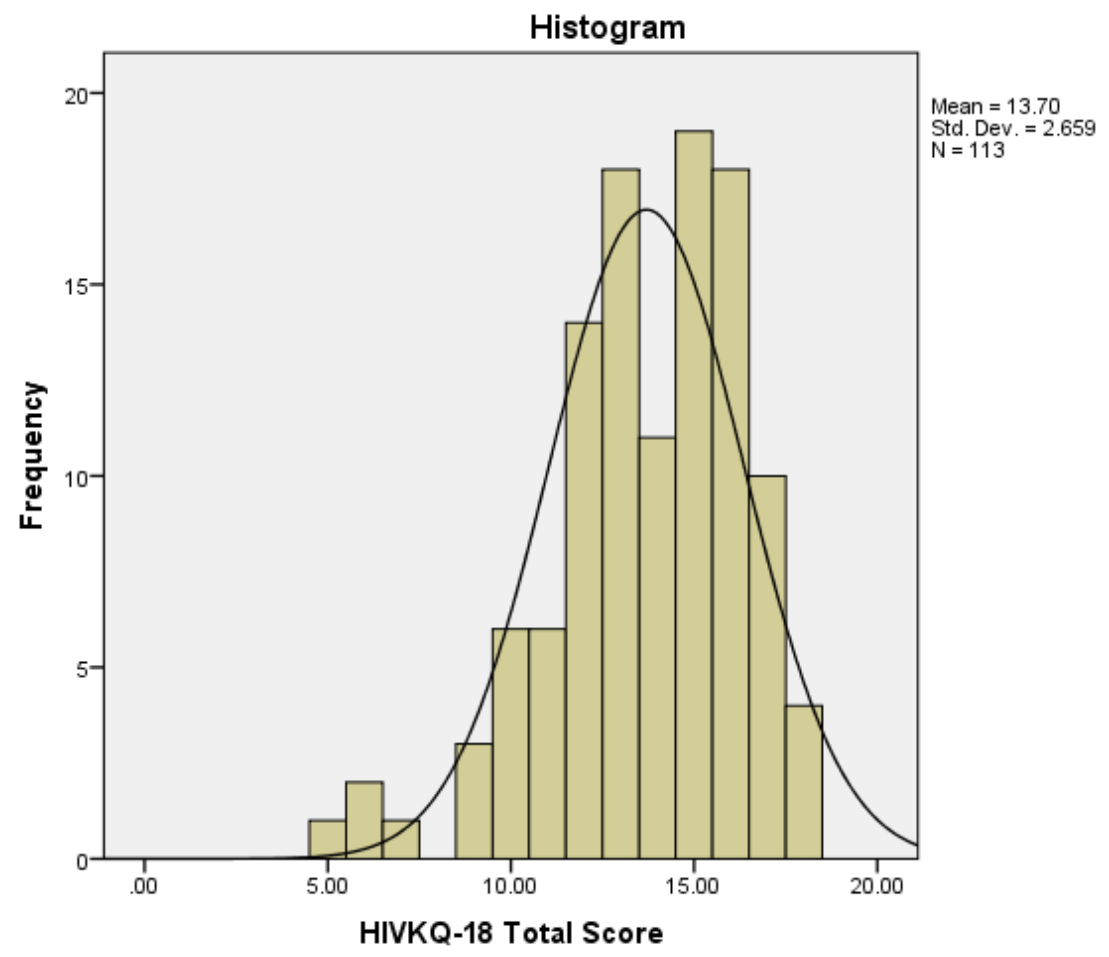




\section{Condom Attitude Scale (CAS)}

The CAS 15-item scores were totaled, with a possible range between 0 and 75 , with higher scores indicating more positive attitudes toward condom use. No items were deleted from the total summed score. Additionally, subscale scores were not necessary for this present study. The skewness of the distribution (0.01) and the kurtosis of the distribution (0.59) fell between the range of -0.2 and +0.2 , indicating the variables in the CAS for this study had a normal or near normal distribution. See Figure 3 for histogram of superimposed normal distribution curves for condom attitudes among Trinidadian women.

Figure 3. Histogram of CAS Total Score $(N=113)$

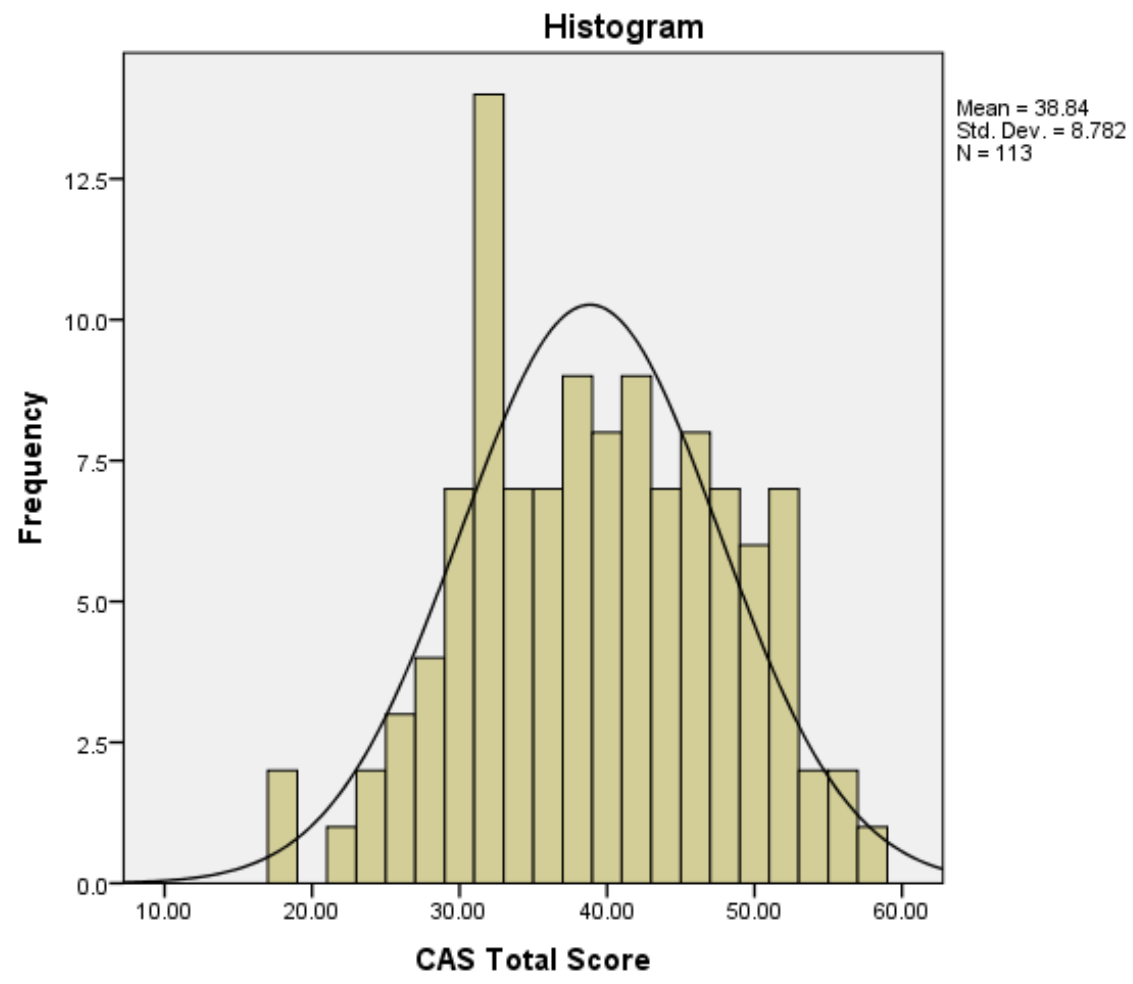




\section{Safe Sex Behavior Questionnaire (SSBQ)}

The SSBQ 24-item scores were totaled, with a possible range between 24 and 96, with higher scores indicating safer sex behaviors among Trinidadian women. No items were deleted from the total summed score. The skewness of the distribution (-0.91) and the kurtosis of the distribution $(-0.76)$ fell between the range of -0.2 and +0.2 , indicating the variables in the SSBQ for this study had a normal or near normal distribution. See Figure 4 for histogram of superimposed normal distribution curves for safe sex behaviors and practices among Trinidadian women.

Figure 4. Histogram of SSBQ Total Score $(N=113)$

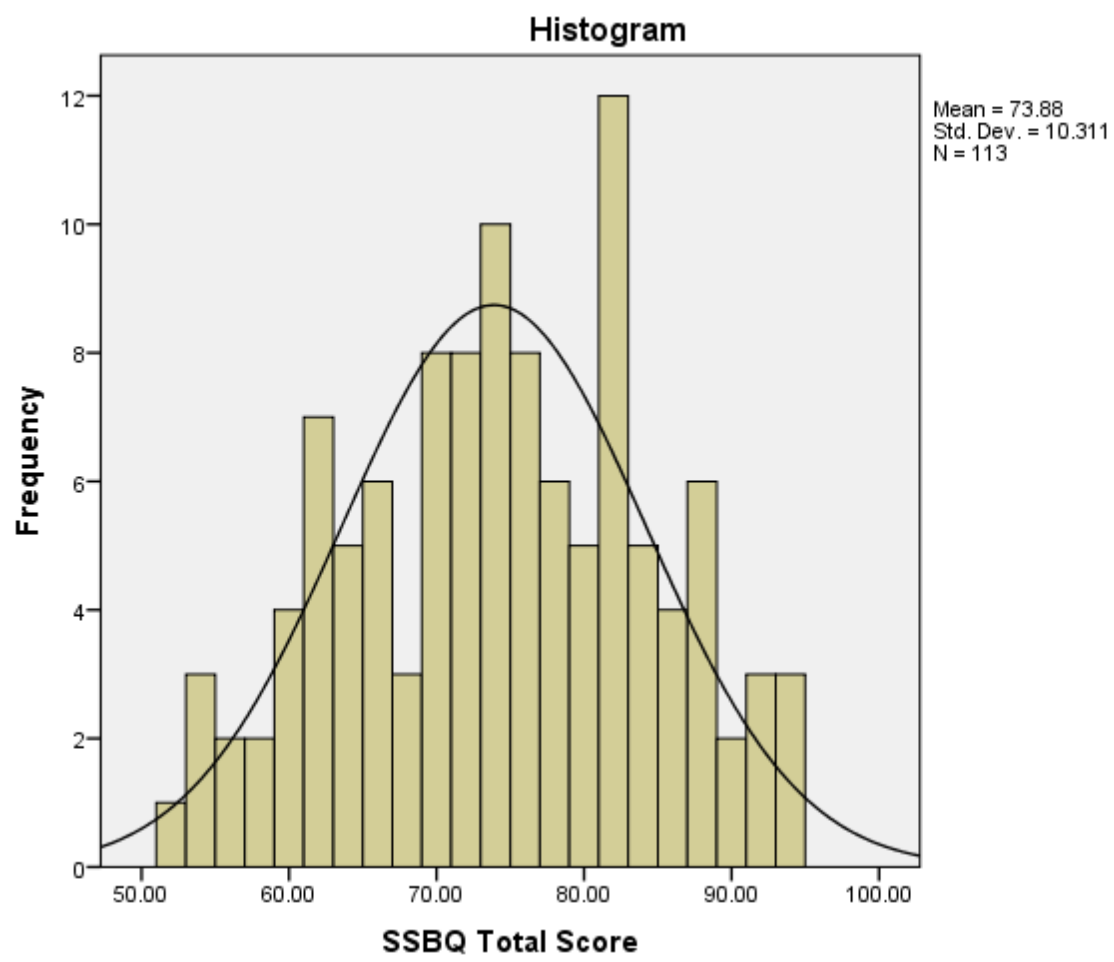




\section{Measurement Assessments}

\section{HIV Knowledge Questionnaire (HIV-KQ-18)}

The HIV-KQ is an 18-item self-administered questionnaire (Carey \& Lewis, 1999) that assesses knowledge of HIV transmission, diagnosis, and prevention. The HIV-KQ-18 was originally developed as an evaluation tool among adults in a diverse community (Carey, Morrison-Beedy, \& Johnson, 1997). Reliability and validity testing were conducted and were determined to have strong internal consistency, with Chronbach's alpha of 0.91, and maintained stability over time (Volpe eta 1., 2007; Morrison-Beedy, 2003; Carey et al., 1997). The psychometric analysis of the HIV-KQ18 indicated strong levels of internal consistencies and test-retest reliabilities. All items are scored on a three-point scale, with the options true, false, or I don't know (DK). Using the provided answer key, responses was scored as correct, incorrect or I don't know. For analysis, the HIV-KQ-18 was scored using 0 for incorrect or I don't know, and 1 for correct, with possible scores ranging from 0 to 18 .

High reliability estimates were not obtained for this present study with Trinidadian women. The Chronbach's alpha for the total scale resulted in a moderate internal consistency of 0.64 . However, this is consistent with estimates found in prior study, in which Lui, Sarangapany, Begley, Coote, and Kishore (2014) reported an internal consistency (Chronbach's alpha) of 0.62 among 527 medical and nursing student's perceived knowledge of HIV infection in Fiji.

\section{Condom Attitude Scale (CAS)}

The 15-item CAS was used to measure attitudes about condom use among Trinidadian women. The items used in this present study consisted of the following 
subscales: 5-item relationship safety, 4-item promiscuity, and 6-item perceived risk. The CAS measure feelings, biases, ideas, and convictions about an individual's ability to control impulse and perceived risks of contracting HIV/AIDS during sexual intercourse (Sacco et al., 1991; Banaj \& Heiphetz, 2010), and was originally developed with predominately White American adults (Sacco, Rickman, Thompson, Levine, \& Reed, 1993). The CAS is a five-point Likert scale ranging from 0 (strongly disagree) to 4 (strongly agree). All items on the CAS are interval levels of measurement. Of the 15 items, eight questions were reverse scored. After reverse coding and scoring, all items were summed up to provide a total general score. Possible total scores range between 0 and 60, wherein higher scores indicate more positive attitudes toward condom use.

Sacco et al., (1993) conducted two separate studies using the CAS and reported internal consistency (Cronbach's alpha) between 0.75 and 0.92 for both studies, yielding acceptable internal consistency. The study was conducted one-year apart, with 248 participants in the first study and 528 participants in the second study. Both studies were conducted to investigate gender differences in AIDS-related condom attitudes, condom use behaviors, and the subsequent relationship between condom attitudes and condom use behaviors (Sacco et al., 1993). A favorable internal consistency (Cronbach's alpha) of 0.80 was obtained for this present study among Trinidadian women. Internal consistencies (Cronbach's alpha) for subscale score were: perceived risk subscale 0.84; inhibition subscale 0.77 ; and relationship safety subscale 0.79 .

\section{Safe Sex Behavior Questionnaire (SSBQ)}

The 24-item SSBQ was used to measure safer sex behaviors among Trinidadian women. The SSBQ was developed and used to investigate dimensions of safer sexual 
behaviors and practices, and its impact on reducing the risk of transmission and exposure to HIV/AIDS among college students (DiIorio et al., 1992). The SSBQ is a four-point Likert scale ranging from 1 (never) to 4 (always). All items on the SSBQ are interval levels of measurement. Nine questions from the 24-items were reverse scored. After reverse coding and scoring, all items were summed up to provide a total general score. Possible total scores range between 24 and 96, with higher scores indicating greater frequency of safer sex behaviors and practices.

A favorable internal consistency (Cronbach's alpha) of 0.79 was obtained for this present study among Trinidadian women. This finding is similar to the one obtained by DiIorio and colleagues (2004) with internal consistency (Cronbach's alpha) of 0.79.

\section{Descriptive Findings of the Study Variables}

\section{HIV Knowledge Questionnaire (HIV-KQ-18)}

The HIV-KQ-18 consists of 18 items that was used to assess knowledge of HIV transmission, diagnosis, and prevention. Each participant responded "true" or "false" to each item, with the option of selecting "I don't know", thereby decreasing the chance of obtaining a correct answer by guessing. The higher the number of correct answers participants scored, the greater their knowledge of HIV. For coding purposes prior to data analysis the option "I don't know" responses were coded with 0 . According to Wagebaar, Sullivan, and Stephenson (2012), questions in the HIV-KQ-18 that are left unanswered or selected as "I don't know" are categorized and coded as incorrect answers. Summing up the scores from the 18 items have a possible range of scores from between 0 (lowest knowledge of HIV) to 18 (highest knowledge of HIV). Therefore, the closer the number is to 18 , the more knowledge demonstrated by answering each statement item 
correctly. Measurement parameters were based on a 2-point scale, with score codes $(0=$ incorrect and I don't know, 1 = correct).

No demarcated scores were established by the developer of the HIV-KQ-18 to indicate higher versus lower level of knowledge. However, the developer suggested that the higher the score, the more knowledge demonstrated by the participant (Carey et al., 1997). Therefore, based on utilization of the HIV-KQ-18 in prior studies, the use of categories or cut scores were based on researchers' interpretations.

The HIV-KQ-18 minimum score was 5.00 and maximum score was 18.00 , with a range of $13.00(M=13.69, S D=2.65)$. Since there are no demarcation scores to categorize lower versus higher level of HIV knowledge, it is necessary to determine the demarcation point between lower and higher levels of HIV knowledge among Trinidadian women. For this study, parameters established as the demarcation point were established as percentile categories. Participants who scored less than $50 \%$ of questions correctly $(n=7,6.2 \%)$ were interpreted as low level of HIV knowledge, participants that scored between $50 \%$ and $75 \%$ of questions correctly $(n=44,38.9 \%)$ were interpreted as minimal to moderate HIV knowledge, and scores greater than $75 \%$ of questions correctly $(n=62,54.9 \%)$ were interpreted as high level of HIV knowledge regarding transmission, diagnosis, and prevention.

In prior studies, researchers established demarcation based on their interpretation, and appropriateness of their studies. Talwar and Rahman (2015) also used categorical scoring in a study they conducted to assess HIV knowledge among 405 university students in Malaysia, using the HIV-KQ-18 survey. However, the parameters implemented in their study used a scoring of $(\geq 7=$ high, $<7=$ low $)$. Lou and colleagues 
(2014) used a different approach with scoring, in that they reported a majority $(n=405$, 76.9\%) of participants had at least 15 questions correct, with reported finding that approximately $80 \%$ of participants had high knowledge on HIV infection.

HIV knowledge items from the HIV-KQ-18 that most of the Trinidadian women who participated in this study got correct were: (a) "Pulling out the penis before a man climaxes/cums keeps women from getting HIV during sex $(n=97,85.8 \%)$; (b) "People who have been infected with HIV quickly show serious signs of being infected" $(n=102$, 90.3\%); (c) "A person will NOT get HIV if she/he is taking antibiotics" ( $n=104$, 92.0\%); (d) 'Having sex with more than one partner can increase a person's chance of being infected with HIV" ( $n=108,95.6 \%)$; and (e) "Using Vaseline or baby oil with condoms lowers the chance of getting HIV" $(n=99,87.6 \%)$.

Conversely, HIV knowledge items from the HIV-KQ-18 that a majority, or a substantial number of Trinidadian women who participated in this study got incorrect were: (a) "People are likely to get HIV by deep kissing, if their partner has HIV" $(n=65$, $57.5 \%$ ); (b) “There is a female condom that can help decrease a woman's chance of getting HIV" $(n=58,51.3 \%)$;

(c) "A person can get HIV from oral sex" $(n=41,36.3 \%)$; (d) "A woman can get HIV if she has anal sex with a man" $(n=40,35.4 \%)$; and (e) "A natural skin condom works better against HIV than does a latex condom" $(n=40,35.4 \%)$.

See Table 6 for total scores of HIV knowledge (HIV-KQ18). Included in the table are the answer $(\mathrm{T}=$ true, $\mathrm{F}=$ false $)$ provided by the developer of the instrument, and placed after each of the questions.

Table 6: HIV Knowledge $(N=113)$ 


\begin{tabular}{|c|c|c|}
\hline HIV Knowledge Questionnaire (Items 1-18) & $\begin{array}{c}\text { Correct } \\
(n, \%)\end{array}$ & $\begin{array}{l}\text { Incorrect, } \mathrm{DK} \\
\quad(n, \%)\end{array}$ \\
\hline 1. Sneezing and coughing do not spread HIV $*(\mathrm{~T})$ & $79,69.0$ & $35,31.0$ \\
\hline $\begin{array}{l}\text { 2. A person can get HIV by sharing a glass of water with someone } \\
\text { who has HIV } *(\mathrm{~F})\end{array}$ & $94,83.2$ & $19,16.8$ \\
\hline $\begin{array}{l}\text { 3. Pulling out the penis before a man climaxes/cums keeps a } \\
\text { woman from getting HIV during sex } *(\mathrm{~F})\end{array}$ & $97,85.8$ & $16,14.2$ \\
\hline 4. A woman can get HIV if she has anal sex with a man *(T) & $73,64.6$ & $40,35.4$ \\
\hline $\begin{array}{l}\text { 5. Showering, or washing one's genitals, after sex keeps a person } \\
\text { from getting } \operatorname{HIV} *(\mathrm{~F})\end{array}$ & $98,86.7$ & $15,13.3$ \\
\hline $\begin{array}{l}\text { 6. All pregnant women infected with HIV will have babies born } \\
\text { with AIDS *(F) }\end{array}$ & $76,67.3$ & $37,32.7$ \\
\hline $\begin{array}{l}\text { 7. People who have been infected with HIV quickly show serious } \\
\text { signs of being infected } *(\mathrm{~F})\end{array}$ & $102,90.3$ & $11,9.7$ \\
\hline 8. There is a vaccine that can stop adults from getting HIV $*(\mathrm{~F})$ & $97,85.8$ & $16,14.2$ \\
\hline $\begin{array}{l}\text { 9. People are likely to get HIV by deep kissing, if their partner has } \\
\text { HIV *(F) }\end{array}$ & $48,42.5$ & $65,57.5$ \\
\hline 10. A woman can get HIV if she has sex during her period $*(\mathrm{~F})$ & $98,86.7$ & $15,13.3$ \\
\hline $\begin{array}{l}\text { 11. There is a female condom that can help decrease a woman's } \\
\text { chance of getting HIV *(T) }\end{array}$ & $55,48.7$ & $58,51.3$ \\
\hline $\begin{array}{l}\text { 12. A natural skin condom works better against HIV than does a } \\
\text { latex condom } *(\mathrm{~F})\end{array}$ & $73,64.6$ & $40,35.4$ \\
\hline 13. A person will NOT get HIV if she/he is taking antibiotics * $(\mathrm{F})$ & $104,92.0$ & $9,8.0$ \\
\hline $\begin{array}{l}\text { 14. Having sex with more than one partner can increase a person's } \\
\text { chance of being infected with } \mathrm{HIV} *(\mathrm{~T})\end{array}$ & $108,95.6$ & $5,4.4$ \\
\hline $\begin{array}{l}\text { 15. Taking a test for HIV one week after having sex will tell a } \\
\text { person if she or he has } \mathrm{HIV} *(\mathrm{~F})\end{array}$ & $82,72.6$ & $31,27.4$ \\
\hline $\begin{array}{l}\text { 16. A person can get HIV by sitting in a hot tub or a swimming } \\
\text { pool with a person who has } \operatorname{HIV} *(\mathrm{~F})\end{array}$ & $94,83.2$ & $19,16.8$ \\
\hline 17. A person can get HIV from oral sex $*(\mathrm{~T})$ & $72,63.7$ & $41,36.3$ \\
\hline $\begin{array}{l}\text { 18. Using Vaseline or baby oil with condoms lowers the chance of } \\
\text { getting HIV } *(\mathrm{~F})\end{array}$ & $99,87.6$ & $14,12.4$ \\
\hline
\end{tabular}

$*(\mathrm{~T})=$ True $;(\mathrm{F})=$ False $($ Correct answer for each question) 


\section{Condom Attitude Scale (CAS)}

The CAS consists of 15-items that was used to measure attitudes about condom use among Trinidadian women. The CAS was rated on a 5-point Likert-scale ranging from 0 (strongly disagree) to 4 (strongly agree). Higher scores indicate a more positive attitude about using condom during sexual intercourse. CAS data were analyzed using the CAS total score.

Negatively worded items were reversed and summed for the total score. Total scores for the scale can range from 0 to 60 . The overall mean score on the CAS for Trinidadian women in this study was $(M=38.84, S D=8.78)$, with minimum score of 18 , maximum score of 58, and a range of 40. Three subscales of the CAS were used for this study, with (a) 5-item relationship safety ranging from 3 to $20(M=12.84, S D=4.27)$, (b) 4-item inhibition ranging from 2 to $16(M=10.71, S D=3.32)$, and (c) 6-item perceived risk ranging from 0 to $24(M=15.27, S D=6.29)$ (See Table 7). Fifty-six (49.6\%) participants had negative attitudes about condom use, while 57 (50.4\%) had positive attitudes about condom use during sexual relations.

Condom attitude items with which Trinidadian women were more likely to agree with included the following: (a) "If I engage in sexual intercourse without using a condom, I could definitely catch a sexually transmitted disease" $(M=2.82, S D=1.43)$; (b) "If I'm not careful, I could catch AIDS" $(M=2.82, S D=1.55)$; (c), "I am concerned about catching AIDS or some other sexually transmitted disease" $(M=2.15, S D=1.54)$.

Conversely, condom attitude items with which Trinidadian women were more likely to disagree with included the following: (a) "I am too old-fashioned to buy or carry a condom" $(M=0.89, S D=1.27)$; (b) "A condom is not necessary when you plan to 
marry the person" $(M=1.23, S D=1.28)$; (c) "A condom is not necessary when you know enough about the person to trust his word about his past" $(M=0.88, S D=1.21)$; (d) "I would be embarrassed to buy condoms" $(M=1.39, S D=1.51)$; and (e) "I wouldn't keep condoms at home because someone (e.g. my parents, siblings, friends) might find out I was having sex" $(M=1.24, S D=1.25)$.

Table 7. Descriptive Statistics for CAS Score $(N=113)$

Instrument

Condom Attitude Scale (Total)

Subscales:

Relationship safety

Inhibition

Perceived risk

Subscic
Number of Items
M SD Range

\author{
of Items
}

$15 \quad 38.84 \quad 8.78 \quad 18-58$

Perceived risk $\begin{array}{llll}5 & 12.84 & 4.27 \quad 3-20\end{array}$

$4 \quad 10.71 \quad 3.32 \quad 2-16$

$\begin{array}{llll}6 & 15.27 & 6.29 & 0-24\end{array}$

\section{Safe Sex Behavior Questionnaire (SSBQ)}

The SSBQ consists of 24-items that were used to measure safe sex behaviors and practices among Trinidadian women. The SSBQ was rated on a 4-point Likert-scale ranging from 1 (never) to 4 (always). Higher scores indicate greater frequency of safer sex behaviors and practices. Negatively worded items were reversed and summed for the total score, with a possible total score of 24 to 96 . The overall mean score on the SSBQ for Trinidadian women in this study was $(M=73.88, S D=10.31)$, with minimum score of 52, maximum score of 94, and a range of 42 (See Table 8). Fifty-nine (52.2\%) participants score ranged between 52 and 74, while 54 (47.8\%) participants scored 
between 75 and 94 . The distribution of scores indicates that Trinidadian women have a moderate to high frequency of safer sexual behaviors and practices.

Safer sexual practice items to which Trinidadian women were most likely to agree with included the following: (a) "If I know an encounter may lead to sexual intercourse, I have a mental plan to practice safer sex" $(M=3.11, S D=1.01)$; (b) "I abstain from sexual intercourse when I do not know my partner's sexual history" $(M=3.43, S D=$ $0.95)$; (c) I avoid sexual intercourse when I have sores in my genital area $(M=3.68, S D=$ $0.81)$; and (d) "I initiate the topic of safer sex with my potential sexual partner" $(M=$ $3.00, S D=1.11)$.

Conversely, safer sexual practice items to which Trinidadian women were most likely to disagree with included the following: (a) "I use cocaine or other drugs prior to or during sexual intercourse" $(M=1.15, S D=0.55)$; (b) "I engage in sexual intercourse on a first date" $(M=1.26, S D=0.79)$; (c) "I engage in anal intercourse" $(M=1.25, S D=$ $0.60)$; (d) "It is difficult for me to discuss sexual issues with my sexual partners" $(M=$ $1.74, S D=1.01$ ); and (e) "I engage in oral sex without using protective barriers such as condom or rubber dam” $(M=2.17, S D=1.16)$.

Table 8. Descriptive Statistics for SSBQ Score $(N=113)$

Instrument Number

M SD Range of Items

Safe Sex Behavior Questionnaire (Total) $24 \quad 73.88 \quad 10.31 \quad 52-94$ 


\section{Hypotheses Testing}

\section{Hypothesis 1: There will be a difference in HIV knowledge between young, middle- aged, and older Trinidadian women}

The first research question of this study (Is there a difference in HIV knowledge based on Trinidadian women's age?) was subjected to hypothesis testing. The first hypothesis stated that there will be a difference in HIV knowledge based on different age groups among (young, middle-aged, older) Trinidadian women. One-way, between groups analysis of variance (one-way ANOVA) was used to test the first hypothesis. A one-way, between groups ANOVA is used when there is one independent variable (with three or more levels) and one dependent continuous variable. The independent variable in this hypothesis was women's age divided into three levels (i.e. 30 -years and below, 31 to 45 years, and 46-years and above). The two-tailed Pearson product-moment correlation coefficient $(r)$ was used to test directions of the relationship and the strength among the variables. The results demonstrated that age and HIV knowledge was not statistically associated, with $r=-.142, p=>.05$.

A one-way between-groups ANOVA was conducted to explore impact of age on HIV knowledge. Participants were divided into three groups based on their age (Group1: 30-years and below; Group 2: 31 to 45 years; Group 3: 46-years and above). No statistically significant difference was noted between the three groups: $F(2,110)=1.39$, $\mathrm{p}=.253$. Post-hoc comparisons using the Tukey HSD test indicated that the mean score for participants 30 -years and below $(M=14.07, S D=2.37)$ was not associated with mean score for 31 to 45 year-old participants $(M=13.74, S D=2.39)$, and not associated with participants 46-years and older $(M=12.90, S D=3.56)$. The findings indicated that age 
was not significantly associated with HIV knowledge among Trinidadian women. Therefore the null hypothesis was not rejected.

\section{Hypothesis 2: There will be a difference in HIV knowledge between Trinidadian women based on race/ethnic background}

The second research question (Is there a difference in HIV knowledge based on Trinidadian women's race and ethnicity?) was subjected to hypothesis testing. The second hypothesis stated that there will be a difference in HIV knowledge based on different races and ethnic background among Trinidadian women. One-way, between groups analysis of variance (one-way ANOVA) was used to test the second hypothesis. The independent variable in this hypothesis was Trinidadian women's race divided into three groups (i.e. East Indians, African, and mixed race), and the dependent variable was HIV knowledge (as measured by the HIV-KQ-18). The two-tailed Pearson productmoment correlation coefficient $(r)$ was used to test directions of the relationship and strength among the variables. The relationship between race/ethnicity and HIV knowledge was a moderate, positive correlation between the two variables, $r=-.331, p<$ .001 .

A one-way between-groups ANOVA was conducted to explore impact of race/ethnic background on HIV knowledge. Participants were divided into three groups based on their race (Group 1: East Indians; Group 2: Africans; Group 3: mixed race). There was a statistical significant difference at the $p<.01$ level in HIV knowledge for the three groups: $F(2,110)=8.11, p=.001$. Post-hoc comparisons using the Tukey HSD test indicated that the mean score for East Indians $(M=12.96, S D=2.67)$ was statistically different from Africans $(M=15.08, S D=2.93)$ and statistically different 
from mixed race $(M=14.83, S D=1.86)$. The findings indicated that African participants were more knowledgeable about HIV infection compared to mixed-race participants. Mixed-race participants were more knowledgeable about HIV infection compared to East Indian participants.

\section{Hypothesis 3: There will be a positive relationship between Trinidadian women's level of education and HIV knowledge}

The third research question (Is level of education associated with HIV knowledge among Trinidadian women?) was subjected to hypothesis testing. The third hypothesis stated that there will be a positive relationship between the level of education and HIV knowledge. A correlational analysis was conducted to test for a relationship between level of education and HIV knowledge. Correlation describes the relationship between two variables (Pallant, 2016). Correlational analysis was used to examine associations between the level of education and HIV knowledge. Pearson correlation coefficient $(r)$ was used to test directions of relationship and strength between the study's variables. The relationship between level of knowledge and HIV knowledge (as measured by HIVKQ-18) was investigated using Pearson product-moment correlation coefficient. Preliminary analyses were performed to ensure no violation of the assumptions of normality, linearity, and homoscedasticity. There was a moderate, positive correlation between the two variables, $r=.329, p<.001$. The findings indicated that the higher the level of education, the more knowledgeable Trinidadian women are about HIV infection, including diagnosis, transmission, and prevention. 


\section{Hypothesis 4: Select demographic factors (religious beliefs, level of education, substance use) will be associated with attitudes about condom use among Trinidadian women}

The fourth research question (What are the select demographic factors [religious beliefs, level of education, substance use] contributing to attitudes about condom use among Trinidadian women?) was subjected to hypothesis testing. Hypothesis four stated that religious beliefs, level of education, and substance use will be associated and have a significant effect on attitudes about condom use among Trinidadian women. Multiple regression analysis was performed to test the third hypothesis. Prior to regression analysis, the assumptions of multiple regressions were tested for statistical errors and were satisfied (i.e. outliers, normality, linearity, and homoscedasticity). Multiple regression analysis is a technique that is used to explore the relationship between one continuous dependent variable and a number of independent or predictor variables (Pallant, 2016). Correlations between study variables were conducted and noted. The two-tailed Pearson correlation coefficient $(r)$ was used to determine the relationship and the strength among the select variables.

Multiple regression analysis was performed to explore the relationship, and assess the impact between select demographic variables (religious beliefs, level of education, substance use) and attitudes about condom use. Condom attitudes were measured using the CAS total score, with a possible score ranging from 0-60, with higher scores indicating more positive attitudes about condom use. The mean score for the CAS-total was $38.84(S D=8.78)$. Religious beliefs, level of education, and substance use were measures categorically (i.e. very religious versus somewhat religious/not at all religious; 
completed high-school versus college degree and higher; and alcohol drinkers versus non-alcohol drinkers).

The relationship between religious beliefs and attitudes about condom use (as measured by CAS) was a negative correlation between the two variables, $r=-.225, p=$ .008 , with higher religious beliefs associated with more negative attitudes about condom use. Correlation between two variables (religious belief and alcohol use) was also noted. The relationship between religious belief and substance use was a negative correlation between the two variables, $r=-.164, p=.04$, with higher religious beliefs associated with lower alcohol consumption.

The relationship between level of education and attitudes about condom use was not significant, $r=-.107, p=.18$. The relationship between substance use and attitudes about condom use was not significant, $r=-.164, p=.13$.

The model contained three independent variables (religious beliefs, level of education, and alcohol use) and was not significant, $R^{2}=.06, F(3,109)=2.33, p=.07$, indicating that religious beliefs, level of education, and substance use combined to explain six percent of the variance in attitudes about condom use. Although the regression model as a whole was not significant, there was a significant relationship between religious beliefs and attitudes about condom use $(\beta=-.205, p=.033)$. Level of education $(\beta=-.069, p=.462)$ and alcohol use $(\beta=-.078, p=.411)$ were not found to be significantly related to attitudes about condom use. The findings indicated that religious belief is a significant predictor of condom attitudes after controlling for level of education and substance use. 


\section{Hypothesis 5: Select demographic factors (religious belief, level of education, substance use), HIV knowledge, and condom attitude will be associated with safe sexual behaviors among Trinidadian women}

The fifth research question (What are the individual and combined contributions of demographic factors [religious beliefs, level of education, substance use], HIV knowledge, and condom attitude on safer sexual behaviors among Trinidadian women?) was subjected to hypothesis testing. Hypothesis five stated that religious beliefs, level of education, substance use, HIV knowledge, and attitudes about condom use will be associated and have a significant effect on the sexual behaviors of Trinidadian women.

Multiple regression analysis was performed to test the fifth hypothesis.

Preliminary analyses were performed to ensure no violation of the assumptions of normality, linearity, and homoscedasticity. Correlations between study variables were conducted and noted. The two-tailed Pearson correlation coefficient ( $r$ ) was used to determine the relationship and the strength among the selected variables.

For the fifth hypothesis, multiple regression analysis was performed to explore the relationships between select demographic variables (religious beliefs, level of education, substance use), HIV knowledge, and condom attitudes and how they impact safer sexual behaviors among Trinidadian women. Safer sexual behaviors were measured using the SSBQ total scores, with a possible range of 24-96, wherein higher scores represented safer sexual practices. The mean score for the SSBQ was $73.88(S D=10.31)$.

The relationship between attitudes about condom use and safer sexual behaviors was a positive correlation between the two variables, with $r=.300, p=.001$, with more positive attitudes about condom use associated with safer sexual behaviors and practices. 
Relationships between variables were also noted. The relationship between alcohol use and religious beliefs was a negative correlation, with $r=-.164, p=.042$, indicating that the stronger the religious beliefs, the lower the consumption of alcohol. The relationship between religious beliefs and attitudes about condom use was a negative correlation, with $r=-.225, p=.008$, indicating that the stronger the religious belief, the more negative the attitude about condom use. The relationship between HIV knowledge and attitudes about condom use was a positive correlation, with $r=.275, p=.002$, indicating that the higher the knowledge about HIV, the more positive the attitude about condom use. The relationship between level of education and HIV knowledge was a positive correlation, with $r=.210, p=.013$, indicating that the higher the level of education, the more knowledge about HIV infection, transmission, and prevention.

The relationship between level of education and safer sexual behavior was not significant, $r=.131, p=.084$. The relationship between substance use and safer sexual behavior was not significant, $r=-.117, p=.108$. The relationship between religious belief and safe sexual behavior was not significant, $r=.131, p=.083$. The relationship between HIV knowledge and safe sexual behaviors was not significant, $r=.143, p=$ .066 .

The model contained five independent variables (religious belief, level of education, substance use, HIV knowledge, and attitudes about condom use), and was significant, $R^{2}=.16, \mathrm{~F}(5,107)=4.09, \mathrm{p}=.002$, indicating that religious belief, level of education, substance use, HIV knowledge, and attitudes about condom use combined to explain $16 \%$ of the variance in safe sexual behaviors. 
There was a significant relationship between attitudes about condom use and safe sexual behaviors $(\beta=.337, p=.001)$. Significant relationship between religious beliefs and safe sexual behaviors $(\beta=.202, p=.031)$. Level of education $(\beta=.107, p=.245)$, alcohol use $(\beta=-.114, p=.212)$, and HIV knowledge $(\beta=.039, p=.680)$ were not found to be significantly related to safer sexual behaviors. The findings indicated that religious belief and condom attitudes are significant predictors for safe sexual behaviors after controlling for HIV knowledge, level of education, and substance use.

See Table 9 for bivariate correlations between the major study variables.

Table 9. Bivariate Correlations between Major Study Variables $(N=113)$

\begin{tabular}{|c|c|c|c|c|c|c|c|c|}
\hline & Age & Race & $\begin{array}{c}\text { Religious } \\
\text { Beliefs }\end{array}$ & $\begin{array}{l}\text { Level of } \\
\text { Education }\end{array}$ & $\begin{array}{l}\text { Substance } \\
\text { Use }\end{array}$ & HIV-KQ & CAS & SSBQ \\
\hline Age & -- & -- & -- & -- & $-.231^{*}$ & -- & -- & -- \\
\hline Race & -- & -- & $-.245 * *$ & -- & -- & $.331 * *$ & -- & -- \\
\hline $\begin{array}{l}\text { Religious } \\
\text { Beliefs }\end{array}$ & -- & $-.245 * *$ & $*--$ & -- & -- & -- & $-.225^{*}$ & -- \\
\hline $\begin{array}{l}\text { Level of } \\
\text { Education }\end{array}$ & -- & -- & -- & -- & -- & $.210 *$ & -- & -- \\
\hline $\begin{array}{l}\text { Substance } \\
\text { Use }\end{array}$ & $-.231 *$ & -- & -- & -- & -- & -- & -- & -- \\
\hline HIV-KQ & -- & $.331 * *$ & :- & -- & -- & -- & $.275^{* *}$ & -- \\
\hline CAS & -- & -- & $-.225^{*}$ & -- & -- & $.275^{*}$ & -- & \\
\hline $.300 * *$ & & & & & & & & \\
\hline
\end{tabular}




\begin{tabular}{lllllllll}
\hline SSBQ & -- & -- & -- & -- & -- & -- & $.300^{* *}$ & -- \\
\hline
\end{tabular}

${ }^{*} \mathrm{p}<.05, * * \mathrm{p}<.001$

\section{Summary of Chapter 4}

A convenience sample of 113 Trinidadian women, ages 18 to 58 years $(M=$ $35.52, S D=10.67)$ was used for this study. All participants met the inclusion criteria (i.e. female; 18 years and older; able to read, write, and understand, English; selfidentified as heterosexual; and born and raised in Trinidad and Tobago). All participants were recruited from the southern region of Trinidad. More than half $(n=62,54.9 \%)$ were married, while ( $n=32,28.3 \%)$ were single. The vast majority $(n=107,94.7 \%)$ had completed high school, with ( $n=58,51.3 \%)$ having a bachelor, master or doctoral degree. The majority of participants $(n=91,80.5 \%)$ were employed.

Three instruments (i.e. HIV-KQ-18, CAS, and SSBQ) and one demographic questionnaire were used to examine HIV knowledge, attitudes about condom use, and safe sexual behaviors among the study's participants. Five hypotheses in this study were tested using descriptive and frequencies, Pearson's correlation coefficient, one-way ANOVA, and multiple regression.

Hypothesis one failed to reject the null hypothesis, in that age did not contribute to HIV knowledge among Trinidadian women. Hypothesis two was supported, in that race/ethnicity made a difference in HIV knowledge when subjected to one-way betweengroups ANOVA. Hypothesis three was supported, showing a moderate, positive correlation between level of education and HIV knowledge, using Pearson's productmoment correlation coefficient. Hypotheses four and five were partially supported using multiple regression statistical analyses. Hypothesis four was partially supported, in that 
religious beliefs were statistically significant in attitudes about condom use, wherein the stronger the religious belief, the more negative the attitudes about using condoms. A relationship was also noted among religious beliefs and substance use (i.e. alcohol use), wherein the higher the religious beliefs the lower the alcohol consumption. Hypothesis five was partially supported, in that attitudes about condom use and religious beliefs were statistically significant on safe sexual behaviors. Relationships between variables were also noted (i.e. HIV knowledge and attitudes about condom use; and level of education and HIV knowledge), wherein the higher the HIV knowledge, the more positive the attitudes about condom use; and the higher the level of education, the higher the HIV knowledge.

\section{CHAPTER V}

\section{DISCUSSION AND CONCLUSION}

The purpose of this study was to evaluate the knowledge, attitudes, and sexual risk behaviors of Caribbean women, who are currently living in Trinidad, regarding HIV awareness and their current lifestyle choices and behaviors. This chapter serves to summarize the study and present the findings as it relate to the variables selected and implemented (i.e. demographic variables [religious beliefs, education level, substance use], HIV knowledge, attitudes about condom use, and sexual risk behaviors). Limitations of the study will be discussed, as well as implications for nursing education, practice, policy, and research.

\section{Summary of the Study}

The Caribbean currently has the second highest incidence of new HIV infections globally (AVERT, 2012; Fitzpatrick et al., 2004) with women accounting for greater than 
50\% of all cases (Padilla et al., 2010; Baird et al., 2007; Jones, 2005). In the Caribbean and Latin America, the HIV/AIDS epidemic has been the most challenging infectious disease for the public health systems (Sullivan, 2008). In areas most affected with HIV/AIDS, women are disproportionally affected (AVERT, 2012; Nanda \& Pramanik, 2010; Clum et al., 2009). Caribbean women are particularly vulnerable to HIV infection, accounting for more than half of individuals living with the disease in the region (AVERT, 2012; UNAIDS, 2011). Additionally, among heterosexual relationships, females are three times more likely to contract the HIV virus, when compared to their male counterpart (CDC, 2012; UNAIDS, 2011).

The first case of HIV infection in Trinidad and Tobago was identified in 1983 (Bartholomew et al., 1983), with the current prevalence of HIV/AIDS now increased to greater that $2 \%$ of the population (Jones et al., 2013; Deveaux et al., 2011; Wood, 2010; Dixon-Mueller, 2009). Consequently, there are an estimated 15,000 individuals infected with HIV/AIDS in Trinidad and Tobago (AVERT, 2012; TTOPM, 2011). Currently, HIV/AIDS is the eight leading cause of mortality in Trinidad and Tobago, with an average of three new cases per day (NSP, 2013).

A review of the literature indicated that HIV knowledge, attitudes about condom use, religious beliefs, level of education, and substance use are associated with sexual risk behaviors and practices. Almost four decades after the first case of HIV/AIDS was identified, there are still myths and misconceptions about the disease. There are still false beliefs that the HIV virus can be transmitted via mosquito bites, sitting on the toilet after an HIV-positive person used the facility (Sano et al., 2016; Pinder-Butler et al., 2013; Rotimi \& Oluwafemi, 2008), sharing the swimming pool with someone infected with the 
disease, coughing and sneezing from an infect person, and using the same utensils for meals (Janahi et al., 2016).

Condom use is one of the most effective methods of preventing STIs and HIV/AIDS (CDC, 2016; IAPAC, 2014; UNAIDS, 2012), however heterosexual Caribbean women still practice inconsistent condom use during sexual intercourse. Findings from the literature review indicated that initiating the use of condom is often challenging for women because of low sexual power in the relationship (Lam \& Barnhart, 2006), fear of abuse or abandonment (Gillespie-Johnson, 2008; Bell et al., 2007; Shlay et al., 2004; Pulerwitz et al., 2002), and belief that sexual partners are faithful and monogamous (Ferguson et al., 2006; Foreman, 2003). In addition, religious beliefs and spirituality (Arrey et al., 2016; Padilla et al., 2010; Kremer et al., 2009; Williams et al., 2009; Genrich \& Brathwaite, 2005; Hoffman et al., 2002), socioeconomic status i.e. level of education and employment (GCWA, 2017; Odimegwu \& Somefun, 2017; Yaya et al., 2016; Mwamwenda, 2014; Wattes \& Seeley, 2014; Pellowski et al., 2013; Wight et al., 2012; Song et al., 2011), and substance use (NIDA, 2017; Brown et al., 2016; CDC, 2016; Lewis et al., 2015; Monahan et al., 2014; King et al., 2012; Parks et al., 2012; Reid et al., 2012; WHO, 2011; Morrison-Beedy et al., 2008) are associated with inconsistent condom use and sexual risk behaviors.

\section{Theoretical Framework}

The theoretical framework that guided this study was the Theory of Planned Behavior (TPB) (Ajzen, 1991). The TPB was developed to assess the link between attitudes, beliefs, and behavioral intent, which are the motivational factors that influence behaviors (Ajzen, 1991). The TPB had been used extensively to predict condom use 
behaviors (Malcom et al., 2012; Hollub et al., 2011; Soto et al., 2010; Jing et al., 2009; Munoz-Silva et al., 2007; Gredig et al., 2006), and sexual risk behaviors (Rich et al., 2014; Wise et al., 2013; Boer \& Mashamba, 2005), that can contribute to HIV infection. The TPB was used in this study to examine and explore the constructs of attitudes, subjective norms, and perceived behavioral control, and if/how these constructs are associated with attitudes about condom use, and sexual risk behaviors. The TPB stipulate that certain factors may lead to involuntary behaviors, which in the case of this study are HIV knowledge, attitudes about condom use, religious beliefs, level of education, and substance use.

\section{Hypotheses}

Using the theoretical framework as a guide, five research hypotheses were generated and tested in this study.

Hypothesis 1 There will be a difference in HIV knowledge between young, middle-aged, and older Trinidadian women

Hypotheses 2 There will be a difference in HIV knowledge between Trinidadian women based on race/ethnic background

Hypothesis 3 There will be a positive relationship between Trinidadian women's level of education and HIV knowledge

Hypothesis 4 Select demographic factors (religious belief, level of education, substance use) will be associated with attitudes about condom use among Trinidadian women 
Hypothesis 5 Select demographic factors (religious belief, level of education, substance use), HIV knowledge, and condom attitude will be associated with safe sexual behaviors among Trinidadian women

To determine relationships and associations between the study's variables (including demographic variables), a methodological approach was utilized for this study, employing a non-experimental, cross-sectional research design. The study was conducted in the southern part of Trinidad, with a convenience sample of adult women, 18 years and older. The sample for this study consisted of 113 adult Trinidadian women with ages ranging from 18 to 58 years $(M=35.52, S D=10.69)$. Data were collected, using self-administer questionnaires from Trinidadian women $(N=113)$, over a period of 2-months in 2017. Data analyses were completed using the Statistical Package for the Social Sciences (SPSS) version 22. The hypotheses were subjected to testing using Descriptive and Frequencies, Pearson product-moment correlation coefficients $(r)$, oneway, between-groups analysis of variance (one-way ANOVA), and Multiple Regression analyses.

\section{Discussion of Findings}

\section{Demographic and Background Characteristics}

Data for this study were gathered using a convenience sampling design in the Southern part of Trinidad, with no data collected in Tobago. Since convenience sampling technique was used in this study, it is necessary to compare the demographic findings from this study with the data from the collection setting i.e., Trinidad and Tobago. The average age of participants in the study was $35.52(S D=10.69)$, while the estimated median age of the population in Trinidad and Tobago was 28.1 years (National Census 
Report Trinidad and Tobago [NCRTnT], 2009). Since the average age of participants in this study was higher than the average age of Trinidad and Tobago, generalization of these findings may not be fully representative of the entire population.

With regards to relationship status, participants in this study consisted of $14.2 \%$ (n $=16)$ being single; $28.3 \%(n=32)$ common-law relationships; $54.9 \%(n=62)$ married; and $2.7 \%(n=3)$ widowed, separated, or divorced. All participants $(n=113)$ reported relationship status. Data reported in the NCRTnT (2009) did not differentiate commonlaw relationship versus single women. In Trinidad and Tobago, common-law relationships are when two people from the opposite sex live together without legally getting married; however, have the same rights as married couples after five years of cohabitation or sharing children together (James, 2012). The study sample is fairly consistent in the number of single participants $(42.5 \%)$ with the national average (48.8\%). However, the study sample consisted of more married women (54.9\%) compared to the national average (39.2\%).

An inclusion criterion for taking part in this study was that participants had to be able to read, write, and understand English. Based on the highest level of education, 6 (5.3\%) participants had less than a high school degree, with the majority of participants completing high school, college, and/or university. Forty-nine (43.4\%) completed high school, $58(51.3 \%)$ completed college of university. Forty-one (36.3\%) participants who completed college or university obtained a bachelor or graduate degree. These distributions are consistent with the national trends of literacy rate in Trinidad and Tobago, with a reported $98.7 \%$ adult literacy rate (CSO, 2016). However, according to the United Nations Educational, Scientific and Cultural Organization [UNESCO] (2018), 
there is an estimated $8 \%$ of the population with a tertiary degree in Trinidad and Tobago. Therefore, the distribution is much higher in this study than the national standard in which $41(36.3 \%)$ participants having a tertiary degree. A probable explanation for the difference between the national and the study participants' level of education is that a substantial number of women were recruited at educational and community environmental workshops. Recruitment at educational workshops took place at regional monthly meetings with faculty, staff, and parents. Additionally, community environmental workshop meetings consisted of monthly meetings with community leaders, including church officials, teachers, and individuals with political affiliations. Employment rate $(80.5 \%)$ in this study was relatively consistent, albeit a little below the national standards $(88 \%)$ (NCRTnT, 2009). Some of the participants recruited from the educational workshops were parents, who were stay-at-home mothers. Also, some of the women who were recruited from the supermarket were likely to be stay-athome mothers as well, wherein the fathers were at their places of employment, while the women did the grocery shopping.

The study sample consisted of 70 (61.9\%) East Indians; 12 (10.6\%) Africans; and $31(27.5 \%)$ participants from mixed race heritage. With regards to race and ethnicity, the two largest groups in Trinidad and Tobago consist of persons of East Indian and African descents. East Indians account for an estimated $40.0 \%$ and Africans $37.5 \%$ of the population (CSO, 2016; NCRTnT, 2009). The third largest group is persons of mixed race $(20.5 \%)$ and others $(2 \%)$ including Chinese, Syrian-Lebanese, and Caucasians (CSO, 2016; NCRTnT, 2009). The distribution of race and ethnic background among participants in this study is not quite consistent with the national standard; therefore, 
generalization of these findings may not be fully representative of the entire population of Trinidadian women.

A majority of the participants $(n=67,59.3 \%)$ were Christians; 39 (34.5\%) were Hindus; $6(5.3 \%)$ were Muslims, and 1 (.9\%) reported no religious affiliation. Hindus in this study were higher than the national standard (25.6\%) which can be explained by the number of East Indians that participated in the study. The majority of participants in this study were Christians, which is consistent with the national standard.

\section{Relationship between Major Study Variables}

Results of the statistical analysis conducted for Hypothesis 1 (there will be a difference in HIV knowledge between young, middle-aged, and older Trinidadian women) in this study, indicated that there were no statistical differences in HIV knowledge based on participant's age. The results from this study, in that there are no associated difference in age groups and HIV knowledge, may be explained by the mature age range of the study's participants. Participants in this study were categorized into three age groups (i.e. 30 -years and below, 31 to 45 years, and 46 years and above). Similarly to this study, Garofalo, Gayles, Bottone, Ryan, Kuhns, and Mustanski (2015) reported that among 344 MSM recruited in the U.S., there were no difference in mean scores by age, in that, participants 16 to 18 years-old answered $70.8 \%$ correctly, compared to participants 19 to 21 years-old that answered $71.0 \%$ correctly (Garofalo et al., 2015).

Overall, Trinidadian women were knowledgeable about HIV infection, with 62 (54.9\%) participants answering 75\% or more questions correctly from the HIV-KQ-18. Similarly to this study's findings, Okeke, Onwasigwe, and Ibegbu's (2012) reported high 
level of HIV knowledge among 299 Nigerian army-based participants. However, contrary to this study's findings, age was statistically significant with regards to misconceptions about HIV transmission modes, especially among participants under the age of 30, compared to participants 30 years and older (Okeke et al., 2012).

The results of the statistical analysis conducted for Hypothesis 2 (there will be a difference in HIV knowledge between Trinidadian women based on race/ethnic background) in this study, indicated that there was a significant relationship between race/ethnic background and HIV knowledge. Results from this study showed that among Trinidadian women, African women were more knowledgeable about HIV infection compared to mixed races, and mixed race women were more knowledgeable about HIV infection than East Indian women. After conducting a literature review, no data were found that compared HIV knowledge between East Indian and African women, or other racial backgrounds among Caribbean women. There were studies conducted to explore differences in HIV knowledge among different racial/ethnic groups, however, mainly among minority populations in western countries. Similarly to this study, Garofalo et al., (2015) reported a difference in HIV knowledge based on racial/ethnic background. However, participants were from different racial/ethnic background compared to this study, as well as from a different geographical area (Chicago, U.S.). Garofalo et al., (2015) reported that among 344 Black, White, and Hispanic participants, Blacks scored the lowest correct answers (67\%), Hispanics scored (73.6\%), and Whites scored the highest $(83.1 \%)$. Results indicated that there is a positive association with race/ethnic background and HIV knowledge. 
Results of the statistical analysis conducted to test Hypothesis 3 (there will be a positive relationship between Trinidadian women's level of education and HIV knowledge) in this study, indicated that there is a significant relationship between level of education and HIV knowledge. Findings from this study were consistent with previous studies (GCWA, 2017; Oliveira-Campos et al., 2013; Rahman et al., 2009). Results support Rahman et al.’s (2009) study among 3,362 females in Bangladesh, which reported that the longer females stay in school, and the higher the level of education attained, the more knowledgeable they are about HIV infection and the less risk of them contracting the disease. Findings from this study indicated that higher levels of education leads to higher knowledge of HIV infection, which had the strong potential to reduce the risk of contracting the HIV virus. Based on the results from this study and prior studies, it is imperative that family and society provide support, and encourage young girls and women to stay in school.

Statistical analysis was conducted to test Hypothesis 4 (select demographic [religious beliefs, level of education, substance use] will be associated with attitudes about condom use among Trinidadian women). It was predicted that the selected demographic characteristics would predict attitudes about condom use among Trinidadian women. The results from the multiple regression analysis indicated that Trinidadian woman's religious beliefs were significant predictors of attitudes about condom use. Characteristics not associated with attitudes about condom use in the multiple regression were level of education and substance use.

In this study, the association between religious beliefs and attitudes about condom use was a moderate, negative relationship $(r=-.164, p=.04)$. These findings indicated 
that the more influence religious beliefs had on Trinidadian women's daily lives, the more negative their attitudes about using condoms during sexual activities. These findings are consistent with prior studies (Isler, Eng, Maman, Adimora, \& Weiner, 2014; William et al., 2009; Gillespie-Johnson, 2008; Grenrich \& Brathwaite, 2005). Isler et al., (2014) reported that although some religious leaders do not dispute that condoms are effective in preventing HIV transmission, they would not condone or support the use of condoms in an effort to circumvent sexual activities among unmarried individuals. Condom use as an HIV prevention strategy often contradicts the religious teaching about sexual abstinence before marriage, as well as challenges the notion of monogamy (Hotton et al., 2015; Isler et al., 2014).

Statistical analysis was conducted to test Hypothesis 5 (select demographic factors [religious beliefs, level of education, substance use], HIV knowledge, and attitudes about condom use will be associated with safe sexual behaviors among Trinidadian women). The results from the multiple regression analysis indicated that Trinidadian women's attitudes about condom use were significant predictors of safe sexual behaviors. Therefore, the more positive the women's attitude about condom use, the more Trinidadian women practiced safe sexual behaviors.

Findings from this study were consistent with prior studies ( Stephnson et al., 2015; Senn et al., 2014; Kapadia et al., 2011; Noar, Zimmerman, Palmgreen, Lustria, \& Horosewski, 2006), in which a positive relationship was found between attitudes about condom use and safer sexual behaviors among Trinidadian women. Consistent with findings from this study, Pulerwitz et al., (2002) reported that among 388 female participants, attitudes towards condom use were positively associated with safer sexual 
behaviors and practices. Conversely, individuals and couples with negative and less desirable attitudes towards condom use were less likely to use condoms during sexual activities (Reynolds et al., 2010; Stulhofer et al., 2007; Harvey \& Henderson, 2006). Based on the findings from this study and previous studies, attitudes about condom use can be used as a predictor of safe sexual behaviors. Therefore, it is imperative that individuals are educated and informed about the importance of condom use in implementing safe sexual behaviors, and its association with HIV prevention.

\section{Limitation of the Study}

In Caribbean countries, sexual expression can be quite complex, and challenging to explore. The results from this study provide some insight into factors, and relationships of variables, that have the potential to predict sexual behaviors and practices among Trinidadian women. Results from this study can be explored, and utilized as a foundation for collaborative efforts and interventions aimed at decreasing HIV transmission, and increasing safer sexual behaviors among Trinidadian women. There are however, some limitations to this study, some of which may restrict the generalizability of the findings.

Limitations of the study include:

1. This study used a non-experimental, cross-sectional research design to gather data from Trinidadian women. Due to the cross-sectional design, data for this study were gathered over a two-month period. Consequently, the data collected and analyzed were from a single point in time from a convenience sample of participants. Data gathered over a longer period of time may or may not differ from the data obtained. 
2. Data gathered were based on self-administered, self-reported questionnaires given to participants to complete. Participants may have completed the questionnaires with responses in a manner that reflected social-desirability bias. Additionally, this method may also leave room for measurement error, in that participants may not recall retrospective behaviors accurately. Furthermore, the researcher was present at all times during data collection, which may have influenced participants to respond to self-administered questionnaire in a socially desirable manner.

3. Multiple instruments were combined to create an 83-item self-administered questionnaire. Some of the questions had multiple answers to choose from, which could have proved to be overwhelming for participants, potentially resulting in participant response fatigue. If response fatigue occurred, participants may have answered some questions without fully reading it completely, in order to accelerate the process.

4. Data were collected from specific population i.e. adult Trinidadian women. Therefore, generalizability of the findings may not apply to all women from Trinidad and Tobago. Women were recruited from the southern region of Trinidad; therefore, these results do not represent women from Tobago. Additionally, only women 18 years and older were recruited, so the findings are not applicable to adolescent females in Trinidad.

5. Participants received a fashion bracelet and lip gloss as incentives for completing the questionnaires. Participants may have chosen to participant in the study only to receive the incentives, and possibly felt obligated to complete the questionnaires fully. 
6. Due to the sensitive nature of some of the questions, certain measures may not have generated accurate data from participants. Some questions in the survey included questions about oral and anal sexual activities, number of lifetime sexual partners, age of first sexual experience, alcohol and drug use, and so forth. With the researcher being present, there is the possibility that participants may not have been completely honest with answering certain questions. Therefore, the responses must be viewed with some level of caution.

7. This was an exploratory study; therefore, emphasis was not placed on an operational definition of culture. However, aspects of culture were measured by examining attitudes, values, beliefs, and social norms among Trinidadian women.

\section{Implications for Nursing}

This study sought to identify and understand some of the factors that influence and/or predict HIV knowledge, attitudes about condom use, and safer sexual behaviors

among Trinidadian women. Currently, the estimated prevalence of HIV/AIDS in Trinidad and Tobago is greater than $2 \%$ of the overall population, with approximately 15,000 infected individuals; additionally, more than 50\% are women (Caribbean Medical News, 2014; AVERT, 2012; Trinidad and Tobago Office of the Prime Minister [TTOPM], 2011). Moreover, there are approximately three new cases of HIV infection on a daily basis, and it is the eight leading cause of mortality in Trinidad and Tobago (NSP, 2013).

Prior research among Caribbean women has identified a number of factors which influence HIV knowledge, condom attitudes, and safer sexual behaviors (i.e. religious beliefs, level of education, and substance use) (Corwell et al., 2017; AVERT, 2017; 
NIDA, 2017; King et al., 2012; Reid et al., 2012; Saint-Jean et al., 2011; Padilla et al., 2010; Varas-Diaz et al., 2010; Ellickson, 2009; Gellespie-Johnson, 2008; Grenrich \& Brathwaite, 2005).

The results from this study contribute to the understanding of safer sexual behaviors among Trinidadian women. The findings have identified important implication for nursing education, practice, research, and health policy that can be culturally tailored for Trinidadian women. Tailored risk reduction intervention can be developed in a culturally appropriate manner, designed to reach Trinidadian women, with the potential to reduce the devastating and consequential effects of risky sexual behaviors. Thereby, reducing the transmission of HIV/AIDS and STIs. Moreover, this study has identified gaps in the literature from prior studies; therefore, it is a relevant and timely study.

\section{Education}

The findings from this study have implications for education. HIV/AIDS have been on the rise in the Caribbean (AVERT 2017; CSO, 2016; AVERT 2012), with Trinidad and Tobago's prevalence rate of greater than $2 \%$ of the population (Caribbean Medical News, 2014; TTOPM, 2011). Additionally, in the Caribbean, an estimated 53\% of individuals infected with HIV/AIDS are women (WHO, 2015; UNAIDS, 2011).

Therefore, it is imperative that Trinidadian women be educated about the pathways and risks of HIV transmission. Educating this population needs to be tailored in a culturally, and gender-appropriate manner. Educating Trinidadian women about the consequences of HIV infection should be a collaborative effort between health-care provides, community and religious leaders, and policy makers. 
Health-care providers in Trinidad and Tobago are held in high esteem, especially physicians and nurses. Therefore, physicians and nurses are in pivotal positions to contribution to HIV awareness. Content to HIV infection, transmission, and prevention measures should be included in all health-care curricula, with additional continuing education and workshops for practicing healthcare providers. Since nurses are often the main caregivers in many healthcare settings, nurses are in a vital role to educate all patients, including Trinidadian women about the consequences of HIV infection, modes of transmission, and prevention methods.

Since Trinidad is considered to be a patriarchal society (NSP, 2013), and heterosexual relationships is one of the major contributors to HIV infection in the Caribbean (CDC, 2014a; UNAIDS; 2011), it is important to empower women to be active in protecting themselves, while not ostracizing cultural norms and nuances. Trinidadian women should be taught strategies of condom self-efficacy, and negotiation techniques with their sexual partners. Additionally, couples' education seminars and workshops about HIV/AIDS should also be available. Implementation of couples' seminars have the potential of bringing awareness about HIV/AID, not only to women, but also to the men, which may lead to easier negotiation of condom use, resulting in safer sexual behaviors and practices.

Overall, Trinidadian women were fairly knowledgeable about HIV infection. However, similar to prior studies, there are still misconceptions about HIV transmission (Sano eta 1., 2016; Pinder-Butler et al., 2013) and prevention methods. This study revealed a lack of knowledge about female condoms among Trinidadian women, in that $51.3 \%$ did not know that there is a female condom that can help decrease a woman's 
chance of becoming infected with HIV. Additionally, $36.3 \%$ did not know they can contract HIV infection from having oral sex, $35.4 \%$ did not know that they can become infected via anal sex, and $12.4 \%$ believed that using Vaseline or baby oil with condom can lower the chances of becoming infected with the disease. Nurses and other healthcare providers can use the data gathered from this study to design educational seminars, workshops, brochures, and flyers that focus on safe sexual behaviors and HIV prevention among Trinidadian women.

\section{Practice}

Nursing practice embraces a holistic approach, which is built on the foundations of formal empirical knowledge and research. The knowledge obtained from this study can be used to identify potential barriers and/or facilitators associated with HIV knowledge, attitudes about condom use, and safer sexual behaviors among Trinidadian women. An integral role of nursing is health promotion as a part of disease prevention. Nurses and other healthcare professionals in Trinidad and Tobago need to be proactive in designing and distributing culturally appropriate information to promote HIV knowledge, consistent condom use, reduce risky sexual behaviors, and ultimately prevent HIV infections. Furthermore, not only should these health promotions be implemented during practice in all health-care settings, but also should be integrated into community outreach and education.

In Trinidad and Tobago, as well as the Caribbean as a whole, sexual matters are not discussed openly. It may be difficult for individuals to candidly discuss sexual matters with health-care professionals, thereby making it difficult for nurses to promote safe sexual behaviors and prevention of HIV infections. Additionally, Trinidadian nurses 
born and raised in the same cultural norms may also find it difficult and uncomfortable to have an open discussion about sexual matters. Therefore, it is imperative that nurses and other health-care providers receive the necessary education and skills to be able to discuss such a sensitive topic with Trinidadian women. Nurses should become wellversed in listening, building rapport, facilitating, and communicating with individuals about sexual health and safe sexual behaviors, while ensuring their privacy.

\section{Health Policy}

In Trinidad and Tobago, the national HIV/AIDS prevalence is greater than $2 \%$ and continues to grow, with approximately three new cases per day (AVERT, 2017; NSP, 2013). It is imperative that Trinidad and Tobago's health-care policy makers develop policies that aims to eliminate and eradicate the health disparities associated with the HIV epidemic. As noted by Voisin and colleagues (2006), in the U.S. there are successful strategies that are being implemented and integrated by policy makers to bring awareness about HIV/AIDS, as well as aid in prevention of the disease. However, it is important to embed cultural norms, and modify theoretical models when transferring U.S. research to local agencies in Trinidad and Tobago (Voisin et al., 2006). Therefore, to establish successful HIV programs and policies, delineation of specific and pragmatic aspect of the program should be identified and implemented in HIV education, policies, and research. Additionally, religious and community leaders should be involved as consultants when tailoring these programs, especially since religious and community leaders are revered and well-respected in Trinidad and Tobago.

Condoms are not consistently used in Trinidad and Tobago. Condoms can be difficult and uncomfortable to purchase in Trinidad because they are usually kept behind 
the counter. Therefore, individuals who want to purchase condoms must ask the salesassociate to retrieve the condoms for purchase. Due to cultural norms in Trinidad, people are often anxious about being scrutinized and/or judged when purchasing condoms, especially if they know the sales-associate or other customers who may be shopping in the establishment. Policies should be constructed and implemented to increase accessibility of condoms, while upholding discretion and privacy of the purchaser.

Pre-exposure prophylaxis (PrEP) is an HIV prevention strategy and a way for people who are HIV-negative to protect themselves, especially individuals who are at substantial risk of contracting the disease (CDC, 2014b). According to the CDC (2014b), PrEP has been shown to reduce the risk of HIV infection by $92 \%$, when used consistently. With the Caribbean being the second leading region of new HIV infection in the world, the implementation of PrEP in Trinidad and Tobago should be an obvious prevention method. However, currently PrEP is not available in Trinidad and Tobago, or in other Caribbean countries (Dowrich-Phillips, 2017). Policy makers in Trinidad and Tobago need be informed and aware of the benefits of PrEP, and work towards making it available to not only heterosexual Trinidadian women, but to the general public of Trinidad and Tobago. Awareness and willingness to provide PrEP services among Trinidadian health-care providers and policy makers are crucial and critical, and should be integrated and combined with other HIV prevention methods.

\section{Research}

A research gap exists in Trinidad and Tobago regarding safer sexual behaviors. Contributing factors include myths and misconceptions about HIV transmission, religious beliefs, and attitudes about condom use. This study focused on adult Trinidadian women; 
therefore, further research should be conducted to assess the knowledge and attitudes of other sub-groups of Trinidadians. In the event that Trinidadian men and adolescents also have myths and misconceptions about HIV transmission, then education and interventions to prevent the transmission of HIV infection can be established and disseminated to the general public. Further research studies should be conducted to determine the details regarding why Trinidadian women still have misconceptions about HIV transmission nearly four decades after the first case of HIV/AIDS was discovered.

This study revealed a statistical difference between race/ethnic backgrounds and HIV knowledge among Trinidadian women. However, the details contributing to the difference was not identified in this study. Therefore, further research should be done to determine what factors (if any) contributed to these findings, or whether these findings were coincidental due to convenience sampling method used to recruit participants for this specific study. There is a gap in knowledge about race/ethnic difference in Trinidad and Tobago, as well as the Caribbean as a whole.

Further research should be conducted to explore religious beliefs and attitudes about condom use. This study revealed that the more religious beliefs impact daily lives, the more negative the attitudes about using condoms during sexual activities. Further research and collaborative efforts need to be explored to determine and create interventions that can be beneficial for religious leaders and Trinidadian women, without compromising the sanctity of religious beliefs.

Future research studies should seek to examine the influence of cultural norms by integrating a theoretical model of culture, and the impact culture has on HIV knowledge, condom attitudes, and sexual risk behaviors among Trinidadian women. Empirical 
cultural data gathered in future studies have the potential for developing interventions that are specifically designed to reduce HIV/AIDS among Trinidadian women.

\section{Summary of Chapter 5}

There is currently no cure for HIV/AIDS; therefore, it is imperative that safer sexual behaviors are practiced. The purpose of this study was to evaluate HIV knowledge, attitudes, and sexual risk behaviors of Trinidadian women. Several insights were obtained from this study, with regards to HIV knowledge, attitudes about condom use, and safer sexual behaviors among adult Trinidadian women. The Theory of Planned Behavior (Ajzen 1991) guided the research study among Trinidadian women and the major factors associated with the study. This study's findings provide a baseline to guide

future studies, and develop culturally aware, gender-relevant interventions that could decrease the rate of HIV transmission among Trinidadian women. 


\section{References}

Adefuye, A. S., Abiona, T. C., Balogun, J. A., \& Lukobo-Durrell, M. (2009). HIV sexual risk behaviors and perception of risk among college students: Implications for planning interventions. BMC Public Health, 9:281. Doi: 10.1186/1471-2458-9281

AIDS.gov. (2015). Symptoms of HIV. Retrieved from https://www.aids.gov/hiv-aidsbasics/hiv-aids-101/signs-and-symptoms/

Ajzen, I. (1991). The theory of planned behavior. Organization Behavior and Human Decision Processes, 50(2), 179-211.

Ajzen, I. (2011). Theory of planned behavior: Bibliography. Retrieved from http://people.umass.edu/aizen/tpbrefstxt.html

Amaro, H. (1995). Love, sex, and power. Considering women's realities in HIV prevention. The American Psychologist, 50(6), 437-447

Arrey, A. E., Bilsen, J., Lacor, P., \& Deschepper, R. (2016). Spirituality/Religiosity: A cultural and psychological resource among sub-Saharan African migrant women and HIV/AIDS in Belgium. PLoS One, 11(17), e0159488. Doi: 10.1371/journal.pone.0159488

Asante, K. O. \& Doku, P. N. (2010). Cultural adaption of condom use self-efficacy scale (CUSES) in Ghana. BMC Public Health, 10:227

Asare, M. (2015). Using the theory of planned behavior to determine the condom use behavior among college students. American Journal of Health Studies, 30(1), 4350 .

Aslan, M. M. \& Cutler, D. M. (2013). Girl's education and HIV: Evidence from Uganda. Journal of Health Economics, 32(5), 863-872. http://dx.doi.org/10.1016/j.jhealeco.2013.06.002

Avants, S, K, Warburton, L. A., Hawkins, K. A., \& Marigolin, A. (2000). Continuation of high-risk behavior by HIV-positive drug users: Treatment implications. Journal of Substance Abuse Treatment, 19, 15-22

Averting HIV and AIDS (2012). Caribbean HIV and AIDS statistics. Retrieved from http://www.avert.org/caribbean-hiv-aids-statistics.htm

Averting HIV and AIDS. (2017). HIV stigma and discrimination. Retrieved from https://www.avert.org/professionals/hiv-social-issues/stigmadiscrimination\#footnote1_9106f07 
Babbie, Earl R. The Practice of Social Research. 12th ed. Belmont, CA: Wadsworth Cengage, 2010; Muijs, Daniel. Doing Quantitative Research in Education with SPSS. 2nd edition. London: SAGE Publications, 2010.

Baird, D. S., Yearwood, E. L., \& Perrino, C. S. (2007). Small Island, big problem: HIV/AIDS and youth in Trinidad and Tobago. Journal of Child and Adolescent Psychiatric Nursing, 20(4), 243-251.

Baldeo, R. (2012, October 8). Alcohol consumption and teens. The Trinidad Guardian.

Banaj, M. R. \& Heiphetz, L. (2010). Attitudes. S. T. Fiske, D. T. Gilbert, \& G. Lindzey $\left(5^{\text {th }} \mathrm{Ed}\right)$. The handbook of social psychology. Hoboken, NJ: Wiley

Bartholomew, C., Raju, C. C., \& Jankey, N. (1983). The acquired immune deficiency syndrome in Trinidad: A report of two cases. West Indian Medial Journal, 32(3), $177-180$

Basen-Engquist, K. (1992). Psychosocial predictors of 'safer sex' behaviors in youth adults. AIDS Education and Prevention, 4(2), 120-134

Bell, D. C., Atkinson, J. S., Mosier, V., Riley, M., \& Brown, V. L. (2007). The HIV transmission gradient: Relationship patterns of protection. AIDS Behavior, 11(6), 789-811

Bertens, M. G. P. C., Eiling, E. M., van den Borne, B. \& Schaalma, H. P. (2009). Uma tori! Evaluation of an STI/HIV-prevention intervention for Afro-Caribbean women in the Netherlands. Patient Education and Counseling, 75(1), 77-83. Doi:10.1016/j.pec.2008.09.002

Besson, G. A. (2011). The Caribbean History Archives. Retrieved from http://caribbeanhistoryarchives.blogspot.com/2011/08/african-slavery.html

Boer, H., \& Mashamba, M. T. (2005). Psychosocial correlates of HIV protection motivation among black adolescents in Venda, South Africa. AIDS Education Prevention, 17(6), 590-602

Bombereau, G. \& Allen, C. F. (2008). Social and cultural factors driving the HIV epidemic in the Caribbean. St. Augustine, Trinidad and Tobago: Caribbean Health Research Council

Brewer, N. T., Weinstein, N. D., \& Cuite, C. L. (2004). Risk perceptions and their relation to risk behavior. Annals of Behavioral Medicine, 27(2), 125-130

Brown, J. L., Gause, N. K., \& Northern, N. (2016). The association between alcohol and sexual risk behaviors among college students: A review. Current Addiction Report, 3(4), 349-355. Doi: 10.1007/s40429-016-0125-8 
Burke, H. M., Fleming, P. J., \& Guest, G. (2014). Assessment of the psychometric properties of HIV knowledge items across five countries. AIDS Education and Prevention, 26(6), 577-587

Campbell, J. C., Baty, M. L., Ghandour, R. M., Stockman, J. K., Fransicso, L., \& Wagman, J. (2008). The intersection of intimate partner violence against women and HIV/AIDS: A review. International Journal of Injury Control and Safety Promotion, 15(4), 221-231. Doi: 10.1080/17457300802423224

Carey, M. P., Morrison-Beedy, D., \& Johnson, B. T. (1997). Development and evaluation of a reliable, valid, and practical self-administered questionnaire. AIDS and Behavior, 1(1), 61-74

Carey, M. P., \& Lewis, B. P. (1999). Motivational strategies can augment HIV-risk reduction programs. AIDS and Behavior, 3(4), 269-276

Carey, M. P., \& Schroder, K. E. E. (2002). Development and psychometric evaluation of the brief HIV knowledge questionnaire. AIDS Education and Prevention, 14(2), $172-182$

Caribbean Medical News (2014). Trinidad concerns about high HIV/AIDS rate. Retrieved from http://caribbeanmedicalnews.com/2014/01/trinidad-concernsabout-high-hivaids-rate/

Centers for Disease Control and Prevention. (2012). HIV among women. Retrieved from http://www.cdc.gov/hiv/topics/women/index

Centers for Disease Control and Prevention. (2013). Condom effectiveness. Retrieved from https://www.cdc.gov/condomeffectiveness/brief.html

Centers for Disease Control and Prevention. (2014a). HIV among women. Retrieved from http://www.cdc.gov/hiv/topics/women/index

Centers for Disease Control and Prevention. (2014b). Pre-exposure prophylaxis. Retrieved from http://www.cdc.gov/hiv/prevention/research/prep

Centers for Disease Control and Prevention (2015). HIV/AIDS. Retrieved from http://www.cdc.gov/hiv/statistics/basics/

Centers for Disease Control and Prevention (2016). HIV and substance use in the United States. Retrieved from https://www.cdc.gov/hiv/risk/substanceuse.html

Centers for Disease Control and Prevention (2017). HIV/AIDS. Retrieved from http://www.cdc.gov/hiv/statistics/basics/ 
Central Statistical Office (2016). Trinidad and Tobago 2000 housing and population census. Retrieved from http://cso.gov.tt/census/2000-census-data/

Chanakira, E., O'Cathain, A., Goyder, E. C., \& Freeman, J. V. (2014). Factors perceived to influence risky sexual behaviors among university students in the United Kingdom: A qualitative telephone interview study. BMC Public Health, 14:1055. Doi: $10.1186 / 1471-2458-14-105$

Chapin, J. (2000). Third person perception and optimistic bias among urban minority atrisk youth. Communication Research, 27(1), 51-81

Chen, X-K, Wen, S. w., Fleming, N., Demissie, K., Rhoads, G. G., \& Walker, M. (2007). Teenage pregnancy and adverse birth outcomes: A large population based retrospective cohort study. International Journal of Epidemiology, 36(2), 368-373

Clum, G., Chung, S-E, \& Ellen, J. M. (2009). Mediators of HIV-related stigma and risk behavior in HIV infected young women. AIDS Care, 21(11), 1455-1462.

Doi: 10.1080/09540120902883069

Coe, R. (2002). The effect size, stupid. What effect size is and why it is important: Annual Conference of the British Educational Research Association. University of Exeter, England.

Cohen, J. (1988). Statistical power analysis for the behavioral science $\left(2^{\text {nd }}\right.$ Ed). Hillsdale, NJ: Lawrence Erlbaum

Cook, C. (2011). "Nice girls don't": Women and the condom conundrum. Journal of Clinical Nursing, 21(3), 535-543

Cook, D. A. \& Beckman, T. J. (2006). Current concepts of validity and reliability if psychometric instruments: Theory and application. American Journal of Medicine, 119(2), 166.e7-16

Cook, R. L., Comer, D. M., Wiesenfeld, H. C., Tarter, R., Lave, J. R. \& Clark, D. B. (2006). Alcohol and drug use and related disorders: An under-recognized health issue among adolescents and young adults attending sexually transmitted disease clinics. Sexually Transmitted Diseases, 33(9), 565-570

Cooperman, N. A., \& Simoni, J. M. (2005). Suicidal ideation and attempted suicide among women living with HIV/AIDS. Journal of Behavioral Medicine, 28(2), $149-156$.

Corbett, A. M., Dickson-Gomez, J., Hilario, H., \& Weeks, M. R. (2009). A little thing called love: Condom use among high-risk primary heterosexual couples.

Perspectives on Sexual and Reproductive Health, 41(4), 218-224. Doi: $10.1363 / 4121809$ 
Corneli, A., Wang, M., Agot, K., Ahmed, K., Lombaard, J., \& Van Damme, L. (2014). Perceptions of HIV risk and adherence to a daily, investigational pill for HIV prevention in FEM-PrEP. Journal of Acquired Immune Deficiency Syndromes, 67(5), 555-563

Couture, M., Soto, J., Akom, E., Joseph, G., \& Zunzunegui, M. (2010). Determinants of intention to use condoms among clients of female sex workers in Haiti. AIDS Care: Psychological and Socio-medical Aspects of AIDS/HIV, 22(2), 253-262.

Crowell, T. A., Keshinro, B., Baral, S. D., Schwartz, S. R., Staahlan, S., Nowak, R. G.,...Ake, J. A. (2017). Stigma, access to healthcare, and HIV risk among men who sell sex to men in Nigeria. Journal of International AIDS Society, 20(1), 21489

Deveaux, L., Lunn, S., Bain, R.M., Gomez, P., Kelly, T, Brathwaite, N.,...Stanton, B. (2011). Focus on youth in the Caribbean: Beyond the numbers. Journal of the International Association of Physicians in AIDS Care, 10(5), 316-325. Doi: $10.77 / 1545109710397367$

Dias, S. F., Matos, M. G., \& Goncalves, A. C. (2005). Preventing HIV transmission in adolescents: An analysis of the Portuguese data from the health behavior schoolages children study and focus groups. European Journal of Public Health, 15(3), 300-304

Doi: https://doi.org/10.1093/eurpub/cki085

Dilorio, C., Parsons, M., Lehr, S., Adame, D., \& Carlone, N. (1992). Measurement of safe sex behavior in adolescents and young adults. Nursing Research, 41(4), 203208.

DiIorio, C., Dudley, W. N., Lehr, S., \& Soet, J. E. (2000). Correlates of safer sex communication among college students. Journal of Advanced Nursing, 2000, 32(3), 658-665

DiIorio, C., Dudley, W., N., Soet, J. E., \& McCarty, F. (2004). Sexual possibility situations and sexual behaviors among young adolescents: The moderating role of protective factors. Journal of Adolescent Health, 35(6), 528-548.

Dixon-Mueller, R. (2009). Starting young: Sexual initiation and HIV prevention in early adolescents. AIDS and Behavior, 13(1), 100-109

Dornyei, Z. (2007). Research Methods in Applied Linguistics. New York: Oxford University Press

Dowrich-Phillips, L., (2017). New drug to prevent HIV being pushed in region. Loop. Retrieved from http://www.looptt.com/content/new-drug-prevent-hiv-beingpushed-region 
Draughon, J. E., Lucea, M. B., Campbell, J. C., Paterno, M. T., Bertrand, D. R., Sharps, P. W.,...Stockman, J. K. (2015). Impact of intimate partner forced sex on HIV risk factors in physically abused African American and African Caribbean women. Journal of Immigrant and Minority Health, 17(5), 1313-1321

East, L., Jackson, D., O’Brian, L., \& Peters, K. (2011). Condom negotiation: experiences of sexually active young women. Journal of Advanced Nursing, 67(1), 77-85

Eisenberg, M. (2001). Differences in sexual risk behaviors between college students with same sex and opposite sex experience: Results from a national survey. Archives of Sexual Behavior, 30(6), 575-589. Doi: 10.1023/A:1011958816438

Ellickson, P. L., Mccaffrey, D. F., \& Klein, D. J. (2009). Long-term effects of drug prevention on risky sexual behaviors among young adults. Journal of Adolescent Health, 45(2), 111-117. Doi: 10.1016/j.jadohealth.2008.12.022.

Encyclopedia.Com. (2016). East Indians in Trinidad. Retrieved from http://www.encyclopedia.com/humanities/encyclopedias-almanacs-transcriptsand-maps/east-indians-trinidad

Etikan, I., Musa, S. A., \& Alkassim, R. S. (2016). Comparison of convenience sampling and purposive sampling. American Journal of Theoretical and Applied Statistics, 5(1), 1-4. Doi:10.11648/j.ajtas.20160501.11

Faul, F., Erdfelder, E., Lang, A. G., \& Buchner, A. (2007). G*Power 3: A flexible statistical power analysis program for the social, behavioral, and biomedical sciences. Behavior Research methods, 39(2), 175-191

Fenton, K. A., Johnson, A. M., McManus, S., \& Erens, B. (2001). Measuring sexual behavior: methodological challenges in survey research. Sexually transmitted infections, 77(2), 84-92

Ferguson, Y.O., Quinn, S.C., Eng, E., \& Sandelowski, M. (2006). The gender ratio imbalance and its relationship to risk of HIV/AIDS among African American women at historically black colleges and universities. AIDS Care, 18(4), 323-331.

Fisher, J. D. \& Fisher, W. A. (2000). Theoretical approaches to individual-level change in HIV risk-behavior. CHIP Documents. 4. http://digitalcommons.uconn.edu/chip_docs/4

Fitzpatrick, L., McCray, E. \& Smith, D. K. (2004). The global HIV/AIDS epidemic and related mental health issues: The crisis for African and Black Americans, Journal of Black Psychology, 30(1), 78-105 
Fladseth, K., Gafos, M., Newell, M. L., \& McGarth, N. (2015). Correction: The impact of gender norms on condom use among HIV-positive adults in KwaZulu-Natal, South Africa. PLoS One, 10(6):e0129637. Doi: 10.1371/journal.pone.0129637

Florida Department of Health (FDOH). (2012). HIV incidence surveillance in Florida. Retrieved from http://www.doh.state.fl.us

Foreman, F.E. (2003). African American college women: Constructing a hierarchy of sexual arrangements. AIDS Care, 15(4), 493-504

Garofalo, R., Gayles, T., Bottone, P. D., Ryan, D., Kuhns, L. M., \& Mustanski, B. (2015). Racial/ethnic difference in HIV-related knowledge among young men who have sex with men and their association with condom errors. Health Education Journal, 74(5), 518-530. Doi: 10.1177/0017896914549485.

Gellespie-Johnson, M. (2008). HIV/AIDS prevention practices among recent-immigrant Jamaican women. Ethnicity \& Disease, 18(2), 175-178

Genrich, G. L. \& Brathwaite, B. A. (2005). Response of religious groups to HIV/AIDS as a sexually transmitted infection in Trinidad. BioMed Central (BMC) Public Health 5:121 Doi: 10.1186/1491-2458-5-121

Gerver, S. M., Easterbrook, P.j., Anderson, M., Solarin, I., Elam, G., Fenton, K. A., Garrett, G., \& Mercer, C. H. (2011). Sexual risk behaviors and sexual health outcomes among heterosexual black Caribbean: Comparing sexually transmitted infection clinic attendees and national probability survey respondents.

International Journal of STD \& AIDS, 22(2), 85-90. Doi: 10.1258/ijsa.2010.010301

Giles, M., Liddell, C., \& Bydawell, M. (2005). Condom use in African adolescents: The role of individual and group factors. AIDS Care, 17(6), 729-739

Glanz, K., Rimer, B. K., \& Viswanath, K. (Eds). (2008). Health behavior and health education: Theory, research, and practice $\left(4^{\text {th }} \mathrm{Ed}\right)$. San Francisco, CA: JosseyBass.

Global Coalition on Women and AIDS. (2017). Education. Retrieved from https://gcwa.unaids.org/tags/education

Golub, S. A., Starks, T. J., Payton, G., \& Parsons, J. T. (2012). The critical role of intimacy in the sexual risk behaviors of gay and bisexual men. AIDS Behaviors, 16(3), 626-632.

Doi: 10.1007/s10461-011-9972-4 
Gottlieb, M. S., Schanker, H. M., Fan, P. T., Saxon, A., Weisman, J. D., \& Pozalski, I. (1981). Pneumocystis pneumonia Los Angeles. Morbidity and Mortality Weekly Report, 30 250-253

Gredig, D., Nideroest, S. \& Parpan-Blaser, S. (2006). HIV protection through condom use: Testing the theory of planned behaviors in a community sample of heterosexual men in a high-income country. Psychology Health, 21: 541-555

Hajiabdolbaghi, M., Razani, N., Karami, N., Kheirandish, P., Mohraz, M., Rasoolinejad, M., ... McFarland, W. (2006). Insights from a survey of sexual behavior among a group of at-risk women in Tehran, Iran. AIDS Education Prevention, 19(6), 519530

Harris, C., Small, C. B., Klein, R. S., Friedland, G. H., Moll, B., Emeson, E. E., Spigland, I., \& Steigland, N. H. (1983). Immunodeficiency in female sexual partners of men with the acquired immunodeficiency syndrome. New England Journal of Medicine, 308(20), 1181-1184. Doi: 10.1056/NEJM198305193082001

Harvey, S. M., \& Henderson, J. T. (2006). Correlates of condom use intentions and behavior among a community-based sample of Latin men in Los Angeles. Journal of Urban Health, 83(4), 558-574

He, F., Hensel, D. J., Harezlak, J., \& Fortenberry, J. D. (2016). Condom use as a function of number of coital events in new relationships. Sexually Transmitted Infections, 43(2), 67-70. Doi: 10.1097/OLQ0000000000000390

Helweg-Larsen, M., \& Collins, B. E. (1994). The UCLA multidimensional condom attitude scale: Documenting the complex determinants of condom use in college students. Health Psychology, 13(3), 224-237

Higgins, J. A., Hoffman, S. \& Dworkin, S. L. (2010). Rethinking gender, heterosexual men, and women's vulnerability to HIV/AIDS. American Journal of Public Health, 100(3), 435-445. Doi: 10.2105/AJPH.2009.159723

Hollub, V. A., Reece, M., Herbenick, D., Hensel, D. J., \& Middlestadt, S. E. (2011). College students and condom attitude: Validation of the multi-factor attitude toward condoms scale (MFACS). Journal of American College Health, 59, 708714. Doi: 10.1080/07448481.2010.546462

Holschneider, S. O. M., \& Alexander, C. S. (2003). Social and psychological influences on HIV preventive behaviors of youth in Haiti. Journal of Adolescent Health, 33(1), 31-40. Doi: 10.1016/S1054-139X(02)00418-4

Hoffman, S., Beckford Jarrett, S. T., Kelvin, E. A., Wallace, S. A., Augenbraun, M., Hogben, M., ...Wilson, T. e. (2008). HIV and sexually transmitted infection risk behaviors and beliefs among Black West Indian immigrants and US-born Blacks. 
American Journal of Public Health, 98, 2042-2050. Doi:

10.2105/ajph.2006.106443

Hotton, A. L., French, A. L., Hosek, S. G., Kendrick, S. R., Lemos, D., Brothers, J.,... Mehta, S. D. (2015). Relationship dynamics and sexual risk reduction strategies among heterosexual young adults: A qualitative study of sexually transmitted infection clinic attendees at an urban Chicago Health Center. AIDS Patient Care and STDs, 29(12), 668-674. Doi: 10.1089/apc.2015.0146

IBM. (2012). IBM SPSS Statistics. Retrieved from https://www.ibm.com/usen/marketplace/spss-statistics?

International Association of Providers in AIDS Care [IAPAC]. 2014. Condoms. Retrieved from http://aidsinfonet.org/fact_sheets/view/153

Isler, M. R., Eng, E., Maman, S., Adimora, A., \& Weiner, B. (2014). Public health and church-based constructions of HIV prevention: Black Baptist perspective. Health Education Research, 29(3), 470-484. Doi: 10.1093/her/cyu006

James, W. (2012). The rights of common law spouse. Trinidad and Tobago Guardian Online. Retrieved from http://www.guardian.co.tt/news/2012-07-23/rightscommon-law-spouse

Janahi, E. M., Mustafa, S., Alsari, S., Al-Mannai, M, \& Farhat, G. N. (2016). Public knowledge, perceptions, and attitudes towards HIV/AIDS in Bahrain: A crosssectional study. The Journal of Infection in Developing Countries, 10(9), 10031011. Doi: $10.3855 /$ jidc. 7665

Jarama, S. L., Belgrave, F. Z., Bradford, J., Young, M. \& Honnald, J. A. (2007). Family, culture, and gender role aspects in the context of HIV risk among African American women of unidentified HIV status: An exploratory qualitative study. AIDS Care, 19(3), 307-317

Jewkes, R. K., Dunkle, K., Nduna, M., \& Shai, N. (2010). Intimate partner violence, relationship power inequality, and incidence of HIV infection in young women in South Africa: A cohort study. Lancet, 376(9734), 41-48. Doi: 10.1016/S01406736(10)60548-X

Jing, G., Lau, J. T. F., Xi, C. Chuliang, L., Jun, L., Hongyao, W., Renfan, L., Zhangquan, L. \& Zhenglin, L. (2009). Using the theory of planned behavior to investigate condom use behavior among female injection drug users who are also sex workers in China. AIDS Care, 21(8), 967-975. Doi: 10.1080/09540120802657548.

Joanes, D. N., \& Gill, C. A. (1998). Comparing measures of sample skewness and kurtosis. The Statistician, 47(1), 183-189 
Jones, S. G. (2005). The Caribbean/West Indies cultural competency program for Florida nurses: Implications for HIV/AIDS prevention and treatment. The Journal of Multicultural Nursing \& Health, 11(1)

Jones, V., Modeste, N., Marshak, H. H. \& Fox, C. (2013). The effects of HIV/AIDS education on adolescents in Trinidad and Tobago. International Scholarly Research Notices, volume (2013), 8 pages. http://dx.doi.org/10.5402/2013/691054

Jukes, M., Simmons, S., \& Bundy, D. (2008). Education and vulnerability: The role of schools in protecting young women and girls from HIV in Southern Africa. AIDS, 22(4), 541-556. Doi: 10.1097/01.aids.0000341776.71253.04

Kadam, P. \& Bhalerao, S. (2010). Sample size calculation. International Journal of Ayurveda Research, 1(1), 55-57. Doi: 10.4103/0974-7788.59946

Kalichman, S. C., Simbayi, L. C., \& Cain, d. (2010). HIV transmission risk behaviors among HIV seropositive sexually transmitted infection clinic patients in Cape Town, South Africa. The European Journal of Public Health, 20(2), 202-206. Doi: $10.1093 /$ eurpub/ckp127

Kapadia, F., Latka, M. H., Wu, Y., Strathdee, S. A., Mackesy-Amiti, M. E., HJudson, S. M., Thiede, H., \& Garfein, R. S. (2011). Longitudinal determinants of consistent condom use by partner type among young injection drug users: The role of personal and partner characteristics. AIDS Behavior, 15(7), 1309-1318. Doi: $10.1007 / \mathrm{s} 10461-009-9569-3$

King, K. M., Nguyen, H. V., Kosterman, R., Baily, J. A., \& Hawkins, J. D. (2012). Cooccurrence of sexual risk behaviors and substance use across emerging adulthood: Evidence for state-and trial-level associations. Addiction, 107(7), 1288-1296. Doi: $10.1111 / \mathrm{j} .1360-0443.2012 .03792 . x$

Kitzinger, C. (2005). Heteronormativity in action: Reproducing the heterosexual nuclear family in after-hours medical calls. Social Problems, 52(4), 477-498

Kontomandis, E. N., Michalopoulos, S., Gkasdaris, G., \& Fasoulakis, Z. (2017). The social stigma of HIV-AIDS: Society's role. HIV/AIDS, 9, 111-118. Doi: $10.2147 /$ HIV.S129992

Kopelman, L. M. (2002). If HIV/AIDS is punishment, who is bad? The Journal of Medicine and Philosophy, 27(2), 231-243

Kremer, H., Ironson, G., \& Porr, M. (2009). Spiritual and mind-body beliefs as barriers and motivators to HIV-treatment decision making and medication adherence: A qualitative study. AIDS Patient Care and STDs, 23(2), 127-134. Doi: 10.1089/apc.2008.0131. 
Lalani, S. (2006). Evaluation of HIV/AIDS knowledge among eight grade students in Kenya. Women Can International, USA.

Lam, A. G., \& Barnhart, J. E. (2006). It takes two: The role of partner ethnicity and age characteristics on condom negotiations of heterosexual Chinese and Filipina American college women. AIDS Education and Prevention, 18(1), 68-80

Lee, R. S., Kochman, A., \& Sikkema, K. J. (2002). Internalized stigma among people with HIV-AIDS. AIDS and Behaviors, 6(4), 309-319

Leedy, P. \& Ormrod, J. (2001). Practical Research: Planning and design $\left(7^{\text {th }} \mathrm{Ed}\right)$. Upper Saddle River, NJ: Merrill Prentice Hall. Thousand Oak: SAGE Publications

Letamo, G. \& Mokgatlhe, L. L. (2013). Predictors of risky sexual behavior among young people in the era of HIV/AIDS: Evidence from the 2008 Botswana AIDS impact survey III. African Journal of Reproductive Health, 17(3), 169-181

Lewis, D., Hutton, H. E., Agee, T. A., McCaul, M. E., \& Chander, G. (2015). Alcohol use and unintended sexual consequences among women attending an urban STI clinic. Women's Health Issues, 25(5), 450-457

Lou, J., Chen, S., Yu, H., Lin, Y., \& Li, R. (2010). Sexual cognitive predictors of sexual communication in junior college adolescents: Medical student perspectives. Journal of Nursing Research, 18(4), 290-297. Doi: 10.1097/JNR.0b013e3181fbe178

Lui, P. S., Sarangapany, J., Begley, K., Coote, K, \& Kishore, K. (2014). Medical and nursing students perceived knowledge, attitudes, and practices concerning human immunodeficiency virus. INRB Public Health, vol. 2014, Article ID 975875. Doi: $10.1155 / 2014 / 975875$

Malcolm, S., Huang, S., Cordova, D., Freitas, D., Arzon, M., Jimenez, G. L., Pantin, H., $\&$ Prado, G. (2013). Predicting condom use attitudes, norms, and control beliefs in Hispanic problem behavior youth: The effects of family functioning and parent-adolescent communication about sex on condom use. Health Education Behavior 40(4), 384-391

Maman S., Campbell J., Sweat M.D., Gielen A.C. (2000). The intersections of HIV and violence: Directions for future research and interventions. Social Science and Medicine, 50: 459-78

Mangla, S. (2016, April 22). Dougla (Dogla): The mixed ancestry. Newsgram. Retrieved from https://www.newsgram.com/dougla-dogla-the-mixed-ancestory

McNeil, J. I. (2003). A model for cultural competency in the HIV management of African American patients. Journal of the National Medical Association, 95(2), 3-7 
Merriam-Webster Dictionary. (2017). Heterosexuality. Retrieved from https://www.merriam-webster.com/dictionary/heterosexual

Merson, M. H., O'Malley, J., Serwadda, D. \& Apisuk, C. (2008). HIV prevention 1: The history and challenges of HIV prevention. The Lacet, 372, 475-488.

Meyer, J. P., Springer, S. A., \& Altice, F. L. (2011). Substance abuse, violence, and HIV in women: A review of the syndemic. Journalf Women's Health, 20(7), 991-1006

Mirzaei, M., Ahmadi, K., Saadat, S. H., \& Ramezani, M. A. (2016). Instruments of high risk sexual behavior assessment: A systematic review. Journal of the Academy of Medical, Sciences of Bosnia and Herzegovina, 28(1), 46-50.

Doi: $10.5455 / \mathrm{msm} .2016 .28 .46-50$

Monahan, K. C., Oesterle, S., Rhew, I, \& Hawkins, J. D. (2014). The relation between risk and protective factors for problem behaviors and depressive symptoms, antisocial behavior, and alcohol abuse in adolescence. Journal of Community Psychology, 42(5), 621-638. Doi: 10.1002/jcop.21642

Morrison-Beedy, D. (2003). HIV risk behaviors and testing rates in adolescent girls: Evidence to guide clinical practice. Pediatric Nursing, 31(6), 508-512

Morrison-Beedy, D., Barey, M. P. \& Aronowitz, T. (2003). Psychosocial correlates of HIV risk behaviors in adolescent girls. Journal of Obstetrics, Gynecology \& Neonatal Nursing, 32(1), 94-101

Morrison-Beedy, D., Carey, M. P., Feng, C., \& Tu, X. M. (2008). Predicting sexual risk behaviors among adolescent and young women using a prospective diary method. Research in Nursing and Health, 31(4), 329-340. Doi: 1002/nur.20263

Munoz-Silva, A., Sanchez-Garcia, M., Nunez, C. \& Martins, A. (2007). Gender differences in condom use prediction with theory of reasoned action and planned behavior: the role of self-efficacy and control. AIDS Care, 19(9), 1177-1181

Musiimenta, A. (2012). Contextual mediators influencing the effectiveness of behavioral change interventions: A case of HIV/AIDS prevention behaviors. Online Journal of Public Health Informatics, 4(2)

Mwamenda, T. S. (2014). Education level and HIV/AIDS knowledge in Kenya. Journal of AIDS and HIV Research, 6(2), 28-32. Doi: 10.5897/JAHR2013.0279

Nanda, S. \& Pramanik, A. (2010). Media exposure, gender stereotype, and contextual stigma perceptions about HIV and AIDS: Evidence from Gujarat, India. Journal of the Health Management, 12(4), 461-481. Doi: 10.1177/097206341001200404 
National Census Report Trinidad and Tobago (NCRTnT). 2009. Retrieved from https://www.caricomstats.org/Files/Publications/NCR\%20Reports/Trinidad\%20an d\%20Tobago.pdf

National HIV and AIDS Strategic Plan 2013-2018 [NSP]. (2013). Retrieved from http://files.unaids.org/ru/dataanalysis/knowyourresponse/countryprogressreports/2 014countries/file,94766,ru.pdf

National Institute of Allergy and Infectious Diseases (NIAID). (2014). HIV/AIDS research program. Retrieved from http://www.niaid.nih.gov/topics/hivaids/Pages/Default.aspx

National Institute of Drug Abuse [NIDA]. (2017). How does drug abuse affect the HIV epidemic? Retrieved from https://www.drugabuse.gov/publications/researchreports/hivaids/how-does-drug-abuse-affect-hiv-epidemic

Noar, S. M., Zimmerman, R. S., Palmgreen, P., Lustria, M., \& Horosewski, M. L. (2006). Integrating personality and psychosocial theoretical approaches to understanding safe sexual behavior: Implications for message design. Health Communication,19(2), 165-174. Doi: 10.1207/s15327027hc1902_8

Odimegwu, C. \& Somefun, O. D. (2017). Ethnicity, gender and risky sexual behavior among Nigeria youth: An alternative explanation. Reproductive Health, 14:16. Doi: 10.1186/s12978-017-0284-7

O'Leary, A. (2000). Women at risk for HIV from a primary partner: Balancing risk and intimacy. Annuls Review of Sex Research, 11: 191-234

Oliveira-Campos, M., Giatti, L., Malta, D., \& Barreto, S. M. (2013). Contextual factors associated with sexual behavior among Brazilian adolescents. Annals of Epidemiology, 23(10). 629-635. Doi: 10.1016/j.annepidem.2013.03.009

Okeke, C. E., Onwasigwe, C.N, \& Ibegbu, M. D. (2012). The effect of age on knowledge of HIV/AIDS and risk related behaviorsamong army personnel. African Health Science, 12(3), 291-296.

Oskouie, F., Kashefi, F., Rafii, F., \& Gouya, M. M. (2017). Qualitative study of HIV related stigma and discrimination: What women say in Iran. Electron Physician Journal, 9(7), 4718-4724. Doi: 10.19082/4718

Ouzouni, C., \& Nakakis, K. (2012). HIV/AIDS knowledge, attitudes and behaviours of students nurses. Health Science Journal, 6(1), 129-150

Padilla, M. B., Guilamo-Ramos, V., Bouris, A., \& Reyes, A. M. (2010). HIV/AIDS and Tourism in the Caribbean: An ecological systems perspective. American Journal of Public Health, 100(1), 70-77. Doi:10.2105/AJPH.2009.161968 
Pallant, J. (2016). SPSS survival manual: A step by step guide to data analysis using SPSS. Maidenhead: Open University Press/McGraw-Hill

Parks, K. A., Collins, R. L., \& Darrick, J. L. (2012). The influence of marijuana and alcohol use on condom use behavior: Findings from a sample of young adult female bar drinkers. Psychology of Addictive Behaviors, 26(4), 888-894. Doi: $10.1037 / \mathrm{a} 0028166$

Pellowski, J. A., Kalichman, S. C., Matthews, K. A., \& Adler, N. (2013). A pandemic of the poor: Social disadvantage and the U.S. HIV epidemic. American Psychologist, 68(4), 197-209. Doi: 10.1037/a0032694

Pinder-Butler, S. Frankson, M. A., Hanna-Mahase, C., \& Roberts, R. (2013). HIV/AIDS knowledge and sexual behavior among junior high school students in New Providence, Bahamas. West Indian Medical Journal, 62(4), 318-322

Polit, D. F., \& Beck, C. T. (2012). Nursing research: Generating and assessing evidence for nursing practice. $\left(9^{\text {th }}\right.$ ed.). Philadelphia, PA: Lippincott Williams \& Wilkins.

Pulerwitz, J., Amoro, H., DeJong, W., Gortmaker, S. L. \& Rudd, R. (2002). Relationship power, condom use and HIV risk among women in the USA. AIDS Care, 14(6), 789-800

Purnell, L. (2000). A description of the Purnell model for cultural competence. Journal of Transcultural Nursing, 11(1), 40-46. Doi: 10.1177/104365960001100107

Purnell, L. (2013). Transcultural health care, a culturally competent approach. (4 ${ }^{\text {th }}$ ed.). Philadelphia, PA: F. A. Davis Company

Rael, C. T. \& Hampanda, K. (2016). Understanding internalized HIV/AIDS-related stigmas in the Dominican Republic: A short report. AIDS Care, 28(3), 319-324. Doi: 10.1080/09540121.2015.1095277

Rahman, M. M., Kabir, M., \& Shahidullah, M. (2009). Adolescent knowledge and awareness about AIDS/HIV and factors affecting them in Bangladesh. Journal of Ayub Medicl College, Abbottabad, 21(3), 3-6

Rairikar, S. V., \& Bhandari, S. R. (2016). Knowledge and attitude of paramedical staff and hospital support staff towards HIV infection. Journal of Contemporary Medicine and Dentistry, 4(1), 36-40

Ramezani, T. F., \& Malek-Afzali, H. (2008). Knowledge, attitude and practices concerning HIV/AIDS among Iranian at-risk sub-populations. East Mediterranean Health Journal, 14(1), 142-156 
Randolph, M. E., Pinkerton, S. D. Bogart, L. M., Cecil, H., \& Abramson, P. R. (2007). Sexual pleasure and condom use. Archives of Sexual Behavior, 26(6), 844-848. Doi: 10.1007/S10508-007-9213-0

Reid, S. D. (2005). Substance abuse in the Caribbean. Images of Psychiatry-The Caribbean. Kingston, Jamaica: World Psychiatry Association: 2005, 197-231

Reid S. D., Malow, R. M. \& Rosenberg R. (2012). Alcohol, drugs, sexual behavior, and HIV in Trinidad and Tobago-The way forward. Journal of the International Association of Physicians in AIDS Care, 11(1), 66-82. Doi: $10.1177 / 1545109711416245$

Reynolds, E. K., Magidson, J. F., Bornovalova, M. A., Gwadz, M., Ewart, C. K., Daughters, S. B., \& Lejuez, C. W. (2010). Application of the social action theory to understand factors associated with risky sexual behavior among individuals in residential substance abuse treatment. Psychology of Addictive Behaviors, 24(2), 311-321. Doi: 10.1037/a0018929

Rich, A., Mullen, B., Sainsbury, K., \& Kuczmierczyk, A. R. (2014). The role of gender and sexual experience in predicting adolescent condom use intentions using the theory for planned behavior. The European Journal of Contraception and Reproductive Health Care, 19(4), 295-306.

Doi.org/10.3109/13625187.2014.917624

Rose, J. P. (2008). Are direct or indirect measures of comparative risk better predictors of concern and behavioral intentions? Psychology \& Health, 25(2), 149-165. Doi.org/10.1080/08870440802340164

Rotimi, O. O. \& Oluwafemi, O. O. (2008). Knowledge and attitudes of students in a Caribbean medical school towards HIV/AIDS. African Journal of Biomedical Research, 11; 137-143

Sacco, W. P., Levine, B., Reed, D. L., \& Thompson, K. (1991). Attitudes about condom use as an AIDS-relevant behavior: Their factor structure and relation to condom use. Psychological Assessment, 3(2), 265-272.

Sacco, W. P., Rickman, R. L., Thompson, K., Levine, B., \& Reed, D. L. (1993). Gender differences in AIDS-related condom attitudes and condom use. AIDS Education and Prevention, 5(4), 311-326

Saint-Jean, G., Devieux, J., Malow, R. Tammara, H. \& Carney, K. (2011). Substance abuse, acculturation, and HIV risk among Caribbean-born immigrants in the United States. Journal of the International Association of Physicians in AIDS Care, 10(5), 326-332. Doi: 10.1177/1545109711401749 
Salkind, N. J. (2008). Statistics for people who think they hate statistics. Chicago: Sage Publications, Inc.

Sano, Y., Antabe, R., Atuoye, K. N., Hussey, L. F., Bayne, J., Galaa, S. Z., Mkandawire, P., \& Luginaah, I. (2016). Persistent misconceptions about HIV transmission among males and females in Malawi. BMC International Health \& Human Rights, 16: 16

Sayegh, M. A., Fortenberry, J. D., Shew, M., \& Orr, D. P. (2006). The developmental association of relationship quality, hormonal contraceptives choice, and condom non-use among adolescent women. Journal of Adolescent Health, 39(3), 388-395

Scott-Sheldon, L. J., Carey, M. P., Vanable, P. A., Senn, T. E., Coury-Doniger, P., \& Urban, M. A. (2009). Alcohol consumption, drug use, and condom use among STD clinic patients. Journal of Studies on Alcohol and Drugs, 70(5), 762-770

Schneider, B. E., \& Stoller, N.E. (1995). Introduction: Feminist Strategies of Empowerment. In B. E. Schneider, \& Stoller, N.E. (Ed.), Women Resisting AIDS. Feminist Strategies of Empowerment. (pp. 1-20). Philadelphia, PA: Temple University Press

Schneider, M., Cherish, M., Neuman, M., \& Parry, C. (2012). Alcohol consumption and HIV/AIDS: The neglected interface. Addiction, 107(8), 1369-1371. Doi.org/10.1111/j.1360-0443.2012.03824.x

Senn, T. E., Scott-Sheldon, L. A., \& Carey, M. P. (2014). Relationship-specific condom attitudes predict condom use among STD clinic patients with both primary and non-primary partners. AIDS Behavior, 18(8), 1420-1427. Doi: 10.1007/s10461014-0726-y.

Sheeran, P., Abraham, C., \& Orbell, S. (1999). Psychosocial correlates of heterosexual condom use: A meta-analysis. Psychological Bulletin, 125(1), 90-132

Shlay, J. C., McClung, M., W., Patnaik, J. L., \& Douglas, J. M. (2004). Comparison of sexually transmitted disease prevalence by reported level of condom use among patients attending an urban sexually transmitted disease clinic. Sexually Transmitted Disease, 31(3), 154-160

Song, R., Hall, H. I., Harrison, K. M., Sharpe, T. T. Lin, L. S., \& Dean, H. D. (2011). Identifying the impact of social determinants of health on disease rates using correlation analysis of area-based summary information. Public Health Reports, $126(3), 70-80$

Steinberg, L. (2004). Risk taking in adolescence: What changes, and why? Annals of New York Academy of Science, 1021:51-58 
Stephenson, R., Finneran, C., Goldenberg, T., Coury-Doniger, P., Senn, T. E., Urban, M., Schwartz, A., \& Sullivan, P. (2015). Willingness to use couples HIV testing and discussion on sexual agreements among heterosexuals. Springerplus, 8(4), 169

Stockman, J. K., Lucea, M. B., Draughon, J. E., Sabri, B., Anderson, J. C., Bertrans, D.,...Campbell, J. C. (2013a). Intimate partner violence and HIV risk factors among African American and African Caribbean women in clinic-based setting. AIDS Care, 25(4), 472-480. Doi: 10.1080/09540121.2012.722602

Stockman, J. K., Lucea, M. B., \& Campbell, J. C. (2013b). Forced sexual initiation, sexual intimate partner violence and HIV risk in women: A global review of the literature. AIDS Behavior, 17(3), 832-847

Stulhofer, A., Graham, C., Bozicevic, I., Kufrin, K., \& Ajdukovic, D. (2007). HIV/AIDSrelated knowledge, attitudes and sexual behaviors as predictors of condom use among young adults in Croatia. International Perspectives on Sexual and Reproductive Health, 33(2), 58-65

Sullivan, M. (2008). CRS Report for Congress. HIV AIDS in the Caribbean and Latin America. Retrieved from http://fpc.state.gov/documents/organization/32921.pdf

Sullivan, G. M. (2011). A primer on the validity of assessment instruments. Journal of Graduate Medical Education, 3(2). 119-120

Sullivan, G, M. \& Feinn, R. (2012). Using effect size - or why the p value is not enough. Journal of Graduate Medical Education, 4(3), 279-282

Sutherland, M. E. (2014). The Caribbean's, HIV/AIDS epidemic: Theory, research and interventions. Journal of HIV/AIDS and Infectious Diseases, 2: 1-8

Talwar, P., \& Rahman, M. F. b A. (2015). Assessment of HIV knowledge among university students using the HIV-KQ-18 scale: A cross-sectional study. South East Asia Journal of Public Health, 5(1), 33-38. Doi:

http://dx.doi.org/10.3329/seajph.v5i1.24849

Tanny, M. R., Naar-King, S., \& MacDonner, K. (2012). Depression and stigma in high risk youth living with HIV (YLH): A multisite study. Journal of Pediatric Healthcare, 26(4), 300-305. Doi: 10.1016/j.pedhc.2011.02.014

Teitelman, A. E., Ratcliff, S. J., Morales-Alerman, M. M., \& Sullivan, C. M. (2008). Sexual relationship power, intimate partner violence, and condom use among minority urban girls. Journal of Interpersonal Violence, 23(12), 1694-1712. Doi: $10.1177 / 0886260508314331$ 
Teva, I., Bermudez, M. P., \& Buela-Casal, G. (2010). Sexual sensation seeking, social stress and coping styles as predictors of HIV/STD risk behavior in adolescents. Youth \& Society, 42 (2), 255-277. Doi: 10.1177//0044118X09353572

The Global Coalition of Women and AIDS [GCWA]. (2017). Empower. Retrieved from https://womenandaids.unaids.org/empower

Trinidad and Tobago International Religious Freedom Report (2003). Released by the Bureau of Democracy, Human Rights and Labor. Retrieved from https://www.state.gov/j/drl/rls/irf/2003/24523.htm

Trinidad and Tobago Office of the Prime Minister [TTOPM]. (2011). Global AIDS response progress Trinidad and Tobago country progress report: January 201December 2011. UNAIDS Publication

Trochim, W. (2006). Research methods: the concise knowledge base. Cincinnati, OH: Atomic Dog

UN Joint United Nations Programme on HIV/AIDS (UNAIDS). (2011). HIV/AIDS in the Caribbean-UNAIDS 2010 report. Retrieved from http://testifyingtotruth.wordpress.com/2011/10/13/hiv-in-the-caribbean-unaids2010-report?

UN Joint United Nations Programme on HIV/AIDS (UNAIDS). (2012). Global Report: UNAIDS report on the global AIDS epidemic. Retrieved from http://www.unaids.org/en/media/unaids/contentassets/documents/epidemiology/2 012/gr2012/20121120_UNAIDS_Global_Report_2012_en.pdf.

UN Joint United Nations Programme on HIV/AIDS (UNAIDS). (2015). On the fast-tract to end AIDS by 2030: Focus on location and population. Retrieved from http://www.unaids.org/sites/default/files/media_asset/WAD2015_report_en_part0 1.pdf

United Nations Educational, Scientific and Cultural Organization (UNESCO). (2018). Trinidad and Tobago Education and Literacy. Retrieved from http://uis.unesco.org/country/TT

van Veen, M. G., Schaalma, H., van Leeuwen, A. P., Prins, M., de Zwart, O., van de Laar, M. J., \& Hospers, H. J. (2011). Concurrent partnerships and sexual risk taking among African and Caribbean migrant populations in the Netherlands. International Journal of STI and AIDS, 22(5), 245-250. doi:10.1258/ijsa.2009.008511

Vanable, P. A., Carey, M. P., Blair, D. C., \& Littlewood, R. A. (2006). Impact of HIVrelated stigma on health behaviors and psychological adjustment among HIV- 
positive men and women. AIDS Behavior, 10(5), 473-484. doi: 10.1007/s10461006-9099-1

Varas-Diaz, N., Neilands, T. B., Rivera, S. M., \& Betancourt, E. (2010). Religion and HIV/AIDS stigma: Implications for health professionals in Puerto Rico. Global Public Health, 5(3), 295-312

Voisin, D. R., Baptiste, D. R., Martinez, D. D. C., \& Henderson, G. (2006). Exporting a US HIV/AIDS program to a Caribbean island-nation. International Social Work, 49(1), 75-86

Voisin, D. R., \& Dillon-Remy, M. (2001). Psychocultural factors associated with HIV infection among Trinidad and Tobago adolescents. Journal of HIV/AIDS Prevention and Education, 4(2-3), 65-82.

Volpe, E. M., Nelson, L. E., Kraus, R. A. \& Morrison-Beedy, D. (2007). Adaptation and refinement of the HIV knowledge questionnaire for use with adolescent girls. Journal of the Association of Nurses in AIDS Care, 18(5), 57-63

Wagenaar, B. H., Sullivan, P. S., \& Stephenson, R. (2012). HIV knowledge and associated factors among internet-using men who have sex with men (MSM) in South Africa and the United States. PLoS One, 7(3):e32915.

Watts, C., \& Seeley, J. (2014). Addressing gender inequality and intimate partner violence as critical barriers to an effective HIV response in sub-Saharan Africa. Journal of the International AIDS Society, 17:19849

Wight, D., Plummer, M. \& Ross, D. (2012). The need to promote behavior change at the cultural level: One factor explaining the limited impact of the AEMA kwa Vijana adolescent sexual health intervention in rural Tanzania. A process evaluation. BMC Public Health, 12: 788. Doi: 10.1186/1471-2458-12-788

Williams, C. (2007). Research methods. Journal of Business \& Economic Research, 5(3). $65-72$

Williams, C. C., Newman A. P., Sakamoto I., Massaquoi A. N. (2009). HIV Prevention Risks for Black Women in Canada. Social Science and Medicine, 68(1), 12-20. doi.10.1016/j.socscimed.2008.09.043

Wise, D., Goggin, K. J. Gerkovich, M. M., Metcalf, A., Kennedy, S. L. (2013). Predicting intentions to use condoms using gender, sexual experiences, and the theory of planned behavior. American Journal of Health Education, 37(4), 210218. Doi.org/10.1080/19325037.2006.10598905

Wood, E. B. (2010). HIV-related sexual risk behaviours among late-adolescent Jamaican girls with older male partners. West Indian Medical Journal, 59(4), 403-408 
World Health Organization (WHO). (2011). Global status report on alcohol and health. Retrieved from

http://www.who.int/substance_abuse/publications/global_alcohol_report/msbgsru profiles.pdf

World Health Organization (WHO). (2015). Gender inequalities and HIV. Retrieved from http://www.who.int/gender/hiv_aids/en/

World Health Organization (WHO). (2017). HIV/AIDS. Retrieved from http://www.who.int/mediacentre/factsheets/fs360/en/

Yaya, S., Bishwajit, G., Danhoundo, G., Shah, V., \& Ekholuenetale, M. (2016). Trends and determinants of HIV/AIDS knowledge among women in Bangladesh. BMC Public Health, 16: 812. Doi: 10.1186/s12889-016-3512-0 
APPENDICES 
APPENDIX A

LETTERS OF ACCESS AND SUPPORT 


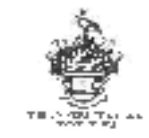

Gulf biew Medical Certre

715-716 Mc Conn'e St.

Gulf น'ievi \$al Fernando.

Tel.: 652--71(1)/1:xx: 652-0533

\section{DR. MICHAEL S. RAMPAUL}

BSc Hons. MEBS. FRCS. DIP. URDL.L ond. MAB

\section{Specialiei Urolugisl}

\author{
Mađaizạl Associabes Certal Hosaital \\ Mantrase Main Road \\ Chaguanas. \\ Tel.: 23.7-rik98
}

5t. Nugustine Privale Hust.llal 2-4 Aust n 5 t.

st áupustline

licl 6637274

MAลY 5 2017

TO WHHOM IT MAYY CONCERN

Re LETTER OF SUPPORT FOR RFSFAREH STUDY OF ROSEMARIE GRACZKOUYSXI

I have keamt fram Rosemarie thal she wishes to undertake a research project on "HIW knowledge, attitudes and sexua! risk behaviaurs amonf women In Trinidad". In the Caribbean, HIV irfąction Is a slgnificant health problem in that young women camprise the at rlsk Rucup must aifected.

I feel that this research is relevant and timely and findlngs can bcnefit all parties involved. I wholeheortedly erdorse thls project and look farward to a successful exerclse.

As a Urologist I am aware that stxual practices Impact personal and nabional health and I believe that d scientific aporooch to local health issues can assist us all in praviding better healith care fo' our communities.

Sincerely,

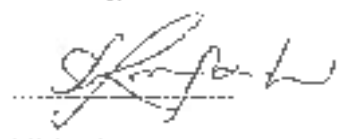

Michael 5. Rampaul, MARS fRt's 
M.S. FOODCITY SUPERMARKET LTD

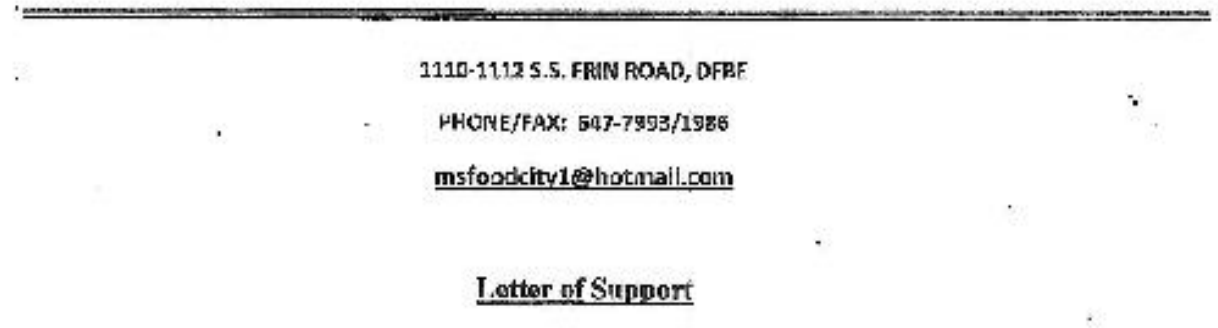

From: Nishla S.R. Mismilu]

$05: 105 / 2017$

To: Whom it maly concern

R.E.: Research Dissertation

Mv name is Nishlat S.R. Moonilul and I am the atare manager at a laroc sumermarkot located in - Debe, Trinidad.

Rosemarie Graczkowski and I lave diseussed the nature of her rewerrch study, and I belicwe that she сап successfully recruit participants that ale nppropriate for ber study at ryy busiatas: estroblislument.

It is my nistaune tu support the resentch dissertation study of Ms. Graczkowiki, who is currently

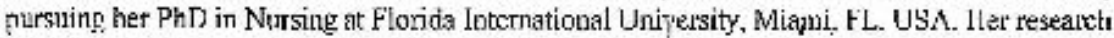
topic "HV Knowledge, Atütudes, and Sexual Risk Behmirns amony Women from Trinidan" is an impartanl and timely issue in 'Trinidad.

I would like to affirm that Rosemarie Ciraczkoursiki has pennission to rocruit paticipatrs firom nıy pluce ur' buxinuss.

Sinutrely,

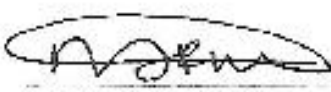

Nisea $\triangle . k$. Moonual

1-R68-290-1288

Store linuger

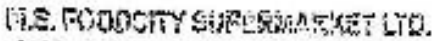

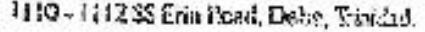

Tehphors: 647 7959 


\section{APPENDIX B \\ PERMISSION TO USE INSTRUMENTS}

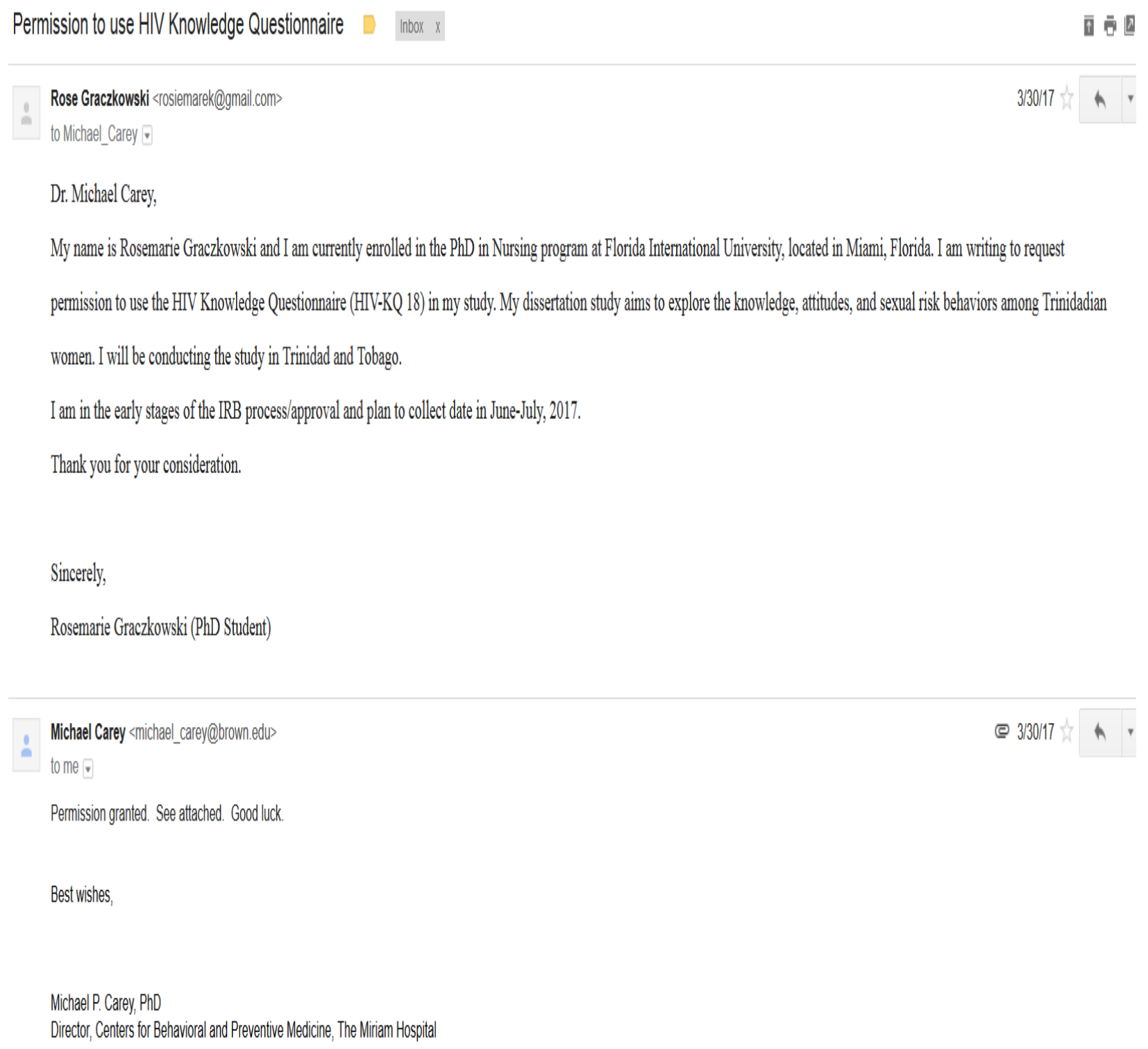




\section{Permission to use Condom Attitude Scale (CAS) Inbox}

(2) Rose Graczkowski<rosiemarek@gmail.com>

to sacco -

Good Morning Dr. Sacco,

My name is Rosemarie Graczkowski and I am currently enrolled in the $\mathrm{PhD}$ in Nursing program at Florida International University, located in Miami, Florida. I am writing to request permission to use the Condom Attitude Scale (CAS) in my study. My dissertation study aims to explore the knowledge, attitudes, and sexual risk behaviors among Trinidadian women, with an emphesis on condom use. I will be conducting the study in Trinidad and Tobago.

I am in the early stages of the IRB process/approval and plan to collect date in June-July, 2017.

Thank you for your consideration.

Sincerely,

Rosemarie Graczkowski (PhD Student)

Sacco, Bill <sacco@usf.edu>

3/30/17

to me $\nabla$

Dear Rosemary: Please feel free to use the CAS for your research.

Sincerely,

William P. Sacco, Ph.D.

Sent from Mail for Windows 10

From· Rnse Grac7knwcki 


\section{APPENDIX C \\ FLORIDA INTERNATIONAL UNIVERSITY IRB APPROVAL}

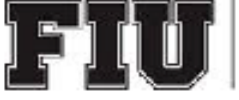

ORIDA

INTERNATIONAL

UNIVERSITY

\section{MEMORANDUM}

To:

CC:

From:

Date:

Protocol Title:

Dr. Sandra Gracia-Jones

File

Maria Melendez-Vargas, MIBA, IRB Coordinator

June 16, 2017

"HIV Knowledge, Attitudes, and Sexual Risk Behaviors among Women

from Trinidad"
Office of Research Integrity Research Compliance, MARC 414

The Social and Behavioral Institutional Review Board of Florida International University has approved your study for the use of human subjects via the Expedited Review process. Your study was found to be in compliance with this institution's Federal Wide Assurance (00000060).

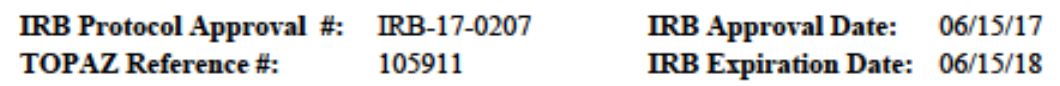

As a requirement of $I R B$ Approval you are required to:

1) Submit an IRB Amendment Form for all proposed additions or changes in the procedures involving human subjects. All additions and changes must be reviewed and approved by the IRB prior to implementation.

2) Promptly submit an IRB Event Report Form for every serious or unusual or unanticipated adverse event, problems with the rights or welfare of the human subjects, and/or deviations from the approved protocol.

3) Utilize copies of the date stamped consent document(s) for obtaining consent from subjects (unless waived by the IRB). Signed consent documents must be retained for at least three years after the completion of the study.

4) Receive annual review and re-approval of your study prior to your IRB expiration date. Submit the IRB Renewal Form at least 30 days in advance of the study's expiration date.

5) Submit an IRB Project Completion Report Form when the study is finished or discontinued.

Special Conditions: N/A.

For further information, you may visit the $\mathbb{I R B}$ website at http://research.fiu.edu/irb.

MMV/em 


\section{APPENDIX D \\ COVER LETTER TO OBTAIN VERBAL CONSENT}

\begin{tabular}{|l|l|}
\hline FIU IRB Approval: & $06 / 15 / 2017$ \\
\hline FlU IRB Expiration: & $06 / 15 / 2018$ \\
\hline FIU IRB Number: & IRB-17-0207 \\
\hline
\end{tabular}

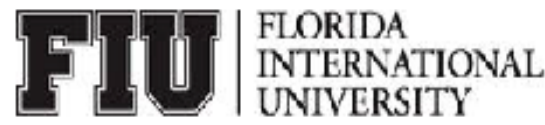

ADULT VERBAL CONSENT TO PARTICIPATE IN A RESEARCH STUDY

HIV Knowledge, Attitudes, and Sexual Risk Behaviors among Women from Trinidad

Hello, my name is Rosemarie Graczkowski. The purpose of this study is to examine the knowledge, attitudes, and risky sexual behaviors that put women at risk for contracting HIV infection. If you decide to be in this study, you will be one of one (1) of 100 people in this research study. Participation in this study will take approximately 15-20 minutes of your time. If you agree to be in the study, I will ask you to do the following things:

1. Please do not include any personal identifiers (i.e. name, phone number, address, email address) on the questionnaire.

2. Please read each question thoroughly, and answer each question completely and honestly.

3. The questionnaire consist of questions that examine HIV knowledge, attitudes about condom use, sexual nisk behaviors, and drug use.

4. Upon completion, please place the completed questionnaire in the provided envelope, seal the envelope, and drop in the provided box.

It is possible that you may find a few questions embarrassing but you don't have to answer any questions you don't want to. Your participation will beneficial to society by helping us understand, identify, and provide pertinent information about the transmission of HIV infection in Trinidad and Tobago. Information gathered can potentially be used by healthcare providers, and policy makers to promote HIV prevention strategies.

There is no cost or payment to you for participating in this study. Participants who complete the questionnaire will receive a lip gloss and a costume jewelry bracelet. If you have questions while taking part, please stop me and ask.

You will remain anonymous, and the information you provide will be confidential. In any sort of report I might publish, I will not include any information that will make it possible to identify you as a subject. Research records will be stored securely and only I will have access to the records.

If you have questions for me, you may contact me: Rosemarie Graczkowski at Irrac004@fiu.edu

If you would like to talk with someone about your rights of being a subject in this research study or about ethical issues with this research study, you may contact the FIU Office of Research Integity by phone at 305-348-2494 or by email at on @ fiu.edu.

Your participation in this research is voluntary, and you will not be penalized or lose benefits if you refuse to participate or decide to stop. Do you consent to participate in this project? If your answer is yes, please say "Yes" and open the packet and complete the questionnaire. 


\section{APPENDIX E DEMOGRAPHIC QUESTIONNAIRE}

Please read the following questions and choose or list the answer that best describes you.

For

each question, fill in the blank or fill in the bubble. There are no right or wrong responses to these answers or statements.

1. What is your current age? years-old

2. What is your current relationship status?

$\bigcirc$ Single

$\bigcirc$ In a relationship but not legally married (common-law)

O Married

Separated

$\bigcirc$ Divorced

$\bigcirc$ Widowed

3. If you are in a relationship, is it monogamous (only one sexual partner)?

$\bigcirc$ Yes

$\bigcirc$ No

$\bigcirc$ Not in a relationship

4. How long are you in your current relationship (if applicable)?

5. How old were you when you had your first sexual experience?

6. What is the total number of sexual partners you had in your lifetime?

7. Have you been tested for HIV?
$\bigcirc$ Yes
$\bigcirc$ No

8. Have you been tested for any sexually transmitted disease?
$\bigcirc$ Yes
O No

9. What is your sexual orientation? 
$\bigcirc$ Heterosexual (sexual relations with only men)

Homosexual (sexual relations with only women)

$\bigcirc$ Bisexual (sexual relations with both men and women)

$\bigcirc$ Prefer not to answer

10. What is your highest level of education?

$\bigcirc$ Less than high school

Completed high school

Technical (Trade) school

$\bigcirc$ Associates of Science (2-year college)

$\bigcirc$ Bachelors of Science Degree (4-year college)

$\bigcirc$ Graduate Degree (Masters or Doctoral)

11. Are you currently employed?
$\bigcirc$ Yes
$\bigcirc$ No

12. What is your yearly level of income? (Answer in Trinidad dollars)

Less than $\$ 25,000$

○ $\$ 25,001$ to $\$ 50,000$

○ $\$ 50,001$ to $\$ 75,000$

○ $\$ 75,001$ to $\$ 100,000$

O $\$ 100,001$ to $\$ 125,000$

○ $\$ 125,001$ to $\$ 150,000$

O More than $\$ 150,001$

Prefer not to answer

13. What is your race?

$\bigcirc$ East Indian

$\bigcirc$ African

$\bigcirc$ Caucasian (White)

$\bigcirc$ Chinese

$\bigcirc$ Hispanic

$\bigcirc$ Mixed race

Other: Please specify 
14. What is your religion?

O Roman Catholic

$\bigcirc$ Hindu

○uslim

$\bigcirc$ Baptist

Methodist

$\bigcirc$ Presbyterian

O Jehovah's Witness

$\bigcirc$ Other Christian: Please specify

$\bigcirc$ Other Non-Christian: Please Specify

15. Would you consider yourself religious?

$\bigcirc$ Very religious

$\bigcirc$ Somewhat religious

$\bigcirc$ Not religious

16. How often do you attend religious services?

Two or more times per week (specify

$\bigcirc$ Once per week

$\bigcirc$ Two times per month

Once per month

$\bigcirc$ Only on special occasions

O Not at all

17. If you do something bad, do you think God will punish you?

○ Yes

$\bigcirc$ No

18. How strongly do your religious beliefs influence your daily life?
$\bigcirc$ Very much
Somewhat
$\bigcirc$ Not at all

19. Do you use any type of drugs?
$\bigcirc$ Yes
$\bigcirc$ No 
O Sometimes

20. If you do use drugs: what type do you use? Please specify

21. If you do use drugs: How often do you use? Please specify

22. Do you drink alcoholic beverages?
$\bigcirc$ Yes
O No

23. If you drink alcohol: what type is it (select all that applies)

$\bigcirc$ Beer

$\bigcirc$ Wine

$\bigcirc$ Rum

V Vodka

Scotch whisky

$\bigcirc$ Cocktail

Other (please specify)

24. If you drink alcohol: how much and how often do you drink? (choose one answer)

More than 3 alcoholic drinks per day

1-2 alcoholic drinks per day

More than 3 alcoholic drinks per week

○ 1-2 alcoholic drinks per week

$\bigcirc$ Only on special occasions (family meeting, weddings, farewells)

25. Do you smoke cigarettes?
$\bigcirc$ Yes
O No

26. Does smoking cigarettes make you want to drink more alcohol?
$\bigcirc$ Yes
No
Not applicable (does not smoke cigarettes) 


\section{APPENDIX F HIV KNOWLEDGE QUESTIONNAIRE}

For each statement, please choose the answer that best represents your point of view.

There is no right or wrong answer. By completing the questionnaires, you are consenting to be a part of this study. Choices are:

$$
\begin{aligned}
& \text { True }=\mathrm{T} \\
& \text { False }=\mathrm{F} \\
& \text { I don't know = DK }
\end{aligned}
$$

\begin{tabular}{|c|c|c|c|}
\hline $\begin{array}{l}\text { Circle the answer that best describes your knowledge } \\
\text { about HIV infection }\end{array}$ & True & False & $\begin{array}{c}\text { I } \\
\text { don't } \\
\text { know }\end{array}$ \\
\hline 1. Coughing and sneezing DOES NOT spread HIV & $\mathrm{T}$ & $\mathrm{F}$ & DK \\
\hline $\begin{array}{l}\text { 2. A person can get HIV by sharing a glass of water with someone } \\
\text { who has HIV }\end{array}$ & $\mathrm{T}$ & $\mathrm{F}$ & DK \\
\hline $\begin{array}{l}\text { 3. Pulling out the penis before a man climaxes/cums keeps a } \\
\text { woman from getting HIV during sex }\end{array}$ & $\mathrm{T}$ & $\mathrm{F}$ & DK \\
\hline 4. A woman can get HIV if she has anal sex with a man & $\mathrm{T}$ & $\mathrm{F}$ & DK \\
\hline $\begin{array}{l}\text { 5. Showering, or washing one's genitals/private parts, after sex } \\
\text { keeps a person from getting HIV }\end{array}$ & $\mathrm{T}$ & $\mathrm{F}$ & DK \\
\hline $\begin{array}{l}\text { 6. All pregnant women infected with HIV will have babies born } \\
\text { with AIDS }\end{array}$ & $\mathrm{T}$ & $\mathrm{F}$ & DK \\
\hline $\begin{array}{l}\text { 7. People who have been infected with HIV quickly show serious } \\
\text { signs of being infected }\end{array}$ & $\mathrm{T}$ & $\mathrm{F}$ & DK \\
\hline 8. There are a vaccines that can stop adults from getting HIV & $\mathrm{T}$ & $\mathrm{F}$ & DK \\
\hline $\begin{array}{l}\text { 9. People are likely to get HIV by deep kissing, putting their } \\
\text { tongue on their partner's mouth, if their partner has HIV }\end{array}$ & $\mathrm{T}$ & $\mathrm{F}$ & DK \\
\hline 10. A woman cannot get HIV if she has sex during her period & $\mathrm{T}$ & $\mathrm{F}$ & DK \\
\hline $\begin{array}{l}\text { 11. There is a female condom that can help decrease a woman's } \\
\text { chance of getting HIV }\end{array}$ & $\mathrm{T}$ & $\mathrm{F}$ & DK \\
\hline $\begin{array}{l}\text { 12. A natural skin condom works better against HIV than does a } \\
\text { latex condom }\end{array}$ & $\mathrm{T}$ & $\mathrm{F}$ & DK \\
\hline 13. A person will NOT get HIV if she or he is taking antibiotics & $\mathrm{T}$ & $\mathrm{F}$ & DK \\
\hline $\begin{array}{l}\text { 14. Having sex with more than one partner can increase a person's } \\
\text { chance of being infected with HIV }\end{array}$ & $\mathrm{T}$ & $\mathrm{F}$ & DK \\
\hline
\end{tabular}




\begin{tabular}{|l|c|c|c|}
\hline $\begin{array}{l}\text { 15. Taking a test for HIV one week after having sex will tell a } \\
\text { person if she or he has HIV }\end{array}$ & T & F \\
\hline $\begin{array}{l}\text { 16. A person can get HIV by sitting in a hot tub or a swimming } \\
\text { pool with a person who has HIV }\end{array}$ & T & F & DK \\
\hline $\begin{array}{l}\text { 17. A person can get HIV from oral sex } \\
\begin{array}{l}\text { 18. Using Vaseline or baby oil with condoms lowers the chance of } \\
\text { getting HIV }\end{array}\end{array}$ T & F & DK \\
\hline
\end{tabular}




\section{APPENDIX G \\ THE CONDOM ATTITUDE SCALE}

Directions: We are interested in how you feel about using condoms, and your perceived risk of

getting HIV or AIDS if you do not use condoms during sex.

For each statement, please choose the answer that best represents your point of view.

There is no

right or wrong answer. Choices are:

$0=$ strongly disagree

$1=$ somewhat disagree

$2=$ neither agree or disagree

$3=$ somewhat agree

$4=$ strongly agree

\begin{tabular}{|l|c|c|c|c|c|}
\hline $\begin{array}{l}\text { Please circle the answer that } \\
\text { best describes your point of } \\
\text { view about condom use during } \\
\text { sex }\end{array}$ & $\begin{array}{c}\text { Strongly } \\
\text { disagree }\end{array}$ & $\begin{array}{c}\text { Somewhat } \\
\text { disagree }\end{array}$ & $\begin{array}{c}\text { Neither } \\
\text { agree or } \\
\text { disagree }\end{array}$ & $\begin{array}{c}\text { Somewhat } \\
\text { agree }\end{array}$ & $\begin{array}{c}\text { Strongly } \\
\text { agree }\end{array}$ \\
\hline $\begin{array}{l}\text { 1. A condom is not necessary } \\
\text { when you know enough about } \\
\text { the person to trust his word } \\
\text { about his past }\end{array}$ & 0 & 1 & 2 & 3 & 4 \\
\hline $\begin{array}{l}\text { 2. A condom is not necessary } \\
\text { when you are with the same } \\
\text { person for a long time }\end{array}$ & 0 & 1 & 2 & 3 & 4 \\
\hline $\begin{array}{l}\text { 3. condom is not necessary } \\
\text { when you are pretty sure the } \\
\text { other person doesn't have a } \\
\text { sexually transmitted disease }\end{array}$ & 0 & 1 & 2 & 3 & 4 \\
\hline $\begin{array}{l}\text { 4. condom is not necessary } \\
\text { when you and your partner are } \\
\text { monogamous }\end{array}$ & 0 & 1 & 2 & 3 & 4 \\
\hline 5. A condom is not necessary \\
when you plan to marry the \\
person
\end{tabular}




\begin{tabular}{|c|c|c|c|c|c|}
\hline $\begin{array}{l}\text { 6. I am not inhibited (self- } \\
\text { conscious) about buying } \\
\text { condoms }\end{array}$ & 0 & 1 & 2 & 3 & 4 \\
\hline $\begin{array}{l}\text { 7. I would be embarrassed to buy } \\
\text { condoms }\end{array}$ & 0 & 1 & 2 & 3 & 4 \\
\hline $\begin{array}{l}\text { 8. I wouldn't keep condoms at } \\
\text { home because someone (e. g. } \\
\text { my parents, siblings, friends) } \\
\text { might find out I was having sex }\end{array}$ & 0 & 1 & 2 & 3 & 4 \\
\hline $\begin{array}{l}\text { 9. I'm too old-fashioned to buy or } \\
\text { carry a condom }\end{array}$ & 0 & 1 & 2 & 3 & 4 \\
\hline $\begin{array}{l}\text { 10. If I'm not careful, I could catch } \\
\text { AIDS }\end{array}$ & 0 & 1 & 2 & 3 & 4 \\
\hline $\begin{array}{l}\text { 11. If I engage in sexual } \\
\text { intercourse without using a } \\
\text { condom, I could definitely } \\
\text { catch a sexually transmitted } \\
\text { disease }\end{array}$ & 0 & 1 & 2 & 3 & 4 \\
\hline $\begin{array}{l}\text { 12. If I engage in sexual } \\
\text { intercourse without using a } \\
\text { condom, I could definitely } \\
\text { catch AIDS }\end{array}$ & 0 & 1 & 2 & 3 & 4 \\
\hline $\begin{array}{l}\text { 13. If I'm not careful, I could } \\
\text { definitely catch a sexually } \\
\text { transmitted disease }\end{array}$ & 0 & 1 & 2 & 3 & 4 \\
\hline $\begin{array}{l}\text { 14. I worry that I could catch a } \\
\text { sexually transmitted disease }\end{array}$ & 0 & 1 & 2 & 3 & 4 \\
\hline $\begin{array}{l}\text { 15. I am concerned about catching } \\
\text { AIDS or some other sexually } \\
\text { transmitted disease }\end{array}$ & 0 & 1 & 2 & 3 & 4 \\
\hline
\end{tabular}




\section{APPENDIX H \\ SAFE SEX BEHAVIOR QUESTIONNAIRE}

Directions: We are interested in your sexual behaviors and practices.

For each statement, please choose the answer that best represents your point of view.

There is no

right or wrong answer. Choices are:

$1=$ Never

$2=$ Sometimes

$3=$ Most of the Time

$4=$ Always

\begin{tabular}{|c|c|c|c|c|}
\hline $\begin{array}{l}\text { Please circle the answer that best } \\
\text { describes your point of view about } \\
\text { your sex behaviors and practices }\end{array}$ & Never & Sometimes & $\begin{array}{l}\text { Most of } \\
\text { the Time }\end{array}$ & Always \\
\hline $\begin{array}{l}\text { 1. I insist on condom use when I have } \\
\text { sexual intercourse }\end{array}$ & 1 & 2 & 3 & 4 \\
\hline $\begin{array}{l}\text { 2. I use cocaine or other drugs prior to or } \\
\text { during sexual intercourse }\end{array}$ & 1 & 2 & 3 & 4 \\
\hline $\begin{array}{l}\text { 3. I stop foreplay long enough to put on a } \\
\text { condom (or for my partner to put on a } \\
\text { condom) }\end{array}$ & 1 & 2 & 3 & 4 \\
\hline $\begin{array}{l}\text { 4. I ask potential sexual partners about } \\
\text { their sexual history }\end{array}$ & 1 & 2 & 3 & 4 \\
\hline $\begin{array}{l}\text { 5. I avoid direct contact with my sexual } \\
\text { partner's semen (cum) }\end{array}$ & 1 & 2 & 3 & 4 \\
\hline $\begin{array}{l}\text { 6. I ask my potential sexual partners about } \\
\text { a history of bisexual/homosexual } \\
\text { practices }\end{array}$ & 1 & 2 & 3 & 4 \\
\hline $\begin{array}{l}\text { 7. I engage in sexual intercourse on a first } \\
\text { date }\end{array}$ & 1 & 2 & 3 & 4 \\
\hline $\begin{array}{l}\text { 8. I abstain from sexual intercourse when I } \\
\text { do not know my partner's sexual history }\end{array}$ & 1 & 2 & 3 & 4 \\
\hline $\begin{array}{l}\text { 9. I avoid sexual intercourse when I have } \\
\text { sores or irritation in my genital (private) } \\
\text { area }\end{array}$ & 1 & 2 & 3 & 4 \\
\hline $\begin{array}{l}\text { 10. If I know an encounter may lead to } \\
\text { sexual intercourse, I carry a condom } \\
\text { with me }\end{array}$ & 1 & 2 & 3 & 4 \\
\hline
\end{tabular}




\begin{tabular}{|l|c|c|c|c|}
\hline $\begin{array}{l}\text { 11. I insist on examining my sexual partner } \\
\text { for sores, cuts, or abrasion in the genital } \\
\text { (private) area }\end{array}$ & 1 & 2 & 3 & 4 \\
\hline $\begin{array}{l}\text { 12. If I disagree with information that my } \\
\text { partner presents on safer sex practices, I } \\
\text { state my point of view }\end{array}$ & 1 & 2 & 3 & 4 \\
\hline $\begin{array}{l}\text { 13. I engage in oral sex without using } \\
\text { protective barriers such as a condom or } \\
\text { rubber dam }\end{array}$ & 1 & 2 & 3 & 4 \\
\hline $\begin{array}{l}\text { 14. If swept away in the passion of the } \\
\text { moment, I have sexual intercourse } \\
\text { without using a condom }\end{array}$ & 1 & 2 & 3 & 4 \\
\hline $\begin{array}{l}\text { 15. I engage in anal intercourse } \\
\text { 16. I ask my potential sexual partners about } \\
\text { a history of IV drug use }\end{array}$ & 1 & 2 & 3 & 4 \\
\hline $\begin{array}{l}\text { 17. If I know an encounter may lead to } \\
\text { sexual intercourse, I have a mental plan } \\
\text { to practice safer sex }\end{array}$ & 1 & 2 & 3 & 4 \\
\hline $\begin{array}{l}\text { 18. If my partner insists on sexual } \\
\text { intercourse without a condom, I refuse to } \\
\text { have sexual intercourse }\end{array}$ & 1 & 2 & 3 & 3 \\
\hline $\begin{array}{l}\text { 19. I avoid direct contact with my partner's } \\
\text { blood }\end{array}$ & 1 & 2 & 3 & 4 \\
\hline $\begin{array}{l}\text { 20. It is difficult for me to discuss sexual } \\
\text { issues with my sexual partners }\end{array}$ & 1 & 2 & 3 & 4 \\
\hline $\begin{array}{l}\text { 21. I initiate the topic of safer sex with my } \\
\text { potential sexual partner }\end{array}$ & 1 & 2 & 3 \\
\hline $\begin{array}{l}\text { 22. I have sexual intercourse with someone } \\
\text { who I know is a bisexual or gay person }\end{array}$ & 1 & 2 & 3 \\
\hline $\begin{array}{l}\text { 23. I engage in anal intercourse without } \\
\text { using a condom }\end{array}$ & 1 & 2 & 4 \\
\hline $\begin{array}{l}\text { 24. I drink alcoholic beverages prior to or } \\
\text { during sexual intercourse }\end{array}$ & & 2 & 3 \\
\hline
\end{tabular}


VITA

ROSEMARIE GRACZKOWSKI

\section{EDUCATION:}

Florida International University, Miami, FL, 33181

Doctor of Philosophy in Nursing Program: PhD, Spring 2018

Florida Atlantic University, Boca Raton, FL, 33431

Master of Science in Nursing Education: MSN-Ed, 2010

Nova Southeastern University, Davie, FL, 33314

Bachelor of Science in Nursing: BSN, 2008

\section{GRANT/FUNDING/SCHOLARSHIP:}

Jonas Nurse Scholars Program 2016-2018. Category: PhD Nurse Leader. Funded $(\$ 20,000)$

Recipient of the 2016 Sigma Theta Tau International "Rising Star of Research and Scholarship Poster Program" held in Cape Town, South Africa. Selected by

Florida International University, Miami, FL. 33199

Scholarship (\$200) from Association of Nurses in AIDS Care (ANAC) Fort Lauderdale Local Chapter to attend the National ANAC Annual conference 2014 Assessment of Primary Prevention for Trauma/Surgical Amputation in Haiti: Funded $(\$ 125,000)$. NIH Center for Minority Health. October 2010. Role:

Research Assistant

\section{PRESENTATIONS:}

Graczkowski, R. Invited Student Poster Session: HIV and STD Knowledge of Female Minority College Students. 27th International Nursing Research Congress, Sigma Theta Tau International (STTI), Cape Town, South Africa, July 21-25, 2016

Jones, S. G., Graczkowski, R., \& Messmer, P., Poster: Minority Female College Students ${ }^{\text {ee }}$ HIV and STD Knowledge. 29th Annual Conference, Southern Nursing Research Society, Tampa, FL., February 26-28, 2015 
Kulwicki, A., Randolph, M., Elbaum, L., Brunt, D., \& Graczkowski, R. Oral Presentation: Post Traumatic Stress Disorder (PTSD) in Post-Earthquake Haitian Adults with Traumatic Amputations. 2nd Annual Conference on Nursing Graczkowski, R., Jones, S. G., \& Messmer, P., Student Poster Session: HIV and STD Knowledge of Female Minority College Students. 27th Annual Conference, Association of Nurses in AIDS Care, Miami, FL., November 6-8, 2014

Graczkowski, R., Jones, S. G., \& Graham, A. Student Poster Session: Pilot Evaluation: SENORITAS for Latin College Students, 39th Annual Conference, national Association of Hispanic Nurses, Miami, FL., July 15-18, 2014 